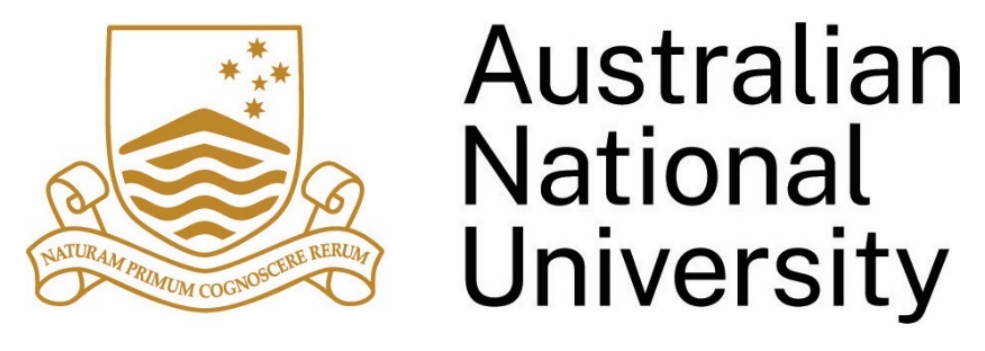

\title{
Pathways to empowerment and justice The Invisible Hurdles Stage II Research and Evaluation Final Report
}

\author{
Hume Riverina Community Legal Service \\ Albury Wodonga Aboriginal Health Service \\ North East Support \& Action for Youth \\ Wodonga Flexible Learning Centre
}

June 2021

Pamela Taylor-Barnett, Hon. Lecturer, The Australian National University

Dr Liz Curran, Hon. Associate Professor, The Australian National University

ISBN 978-0-646-99562-5

The authors acknowledge the traditional owners of the lands, including the Dhudhuroa, Wavereoo, Wiradjuri and Yorta Yorta people. We pay our respects to their elders, past, present and emerging. We acknowledge that the research for this report and the project to which it relates was undertaken on stolen land where sovereignty was never ceded. 


\section{Contents}

Contents

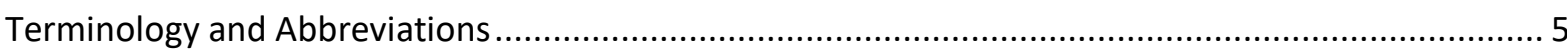

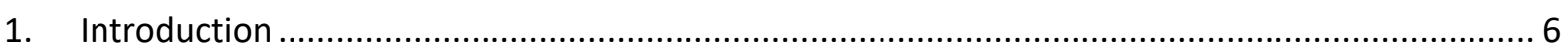

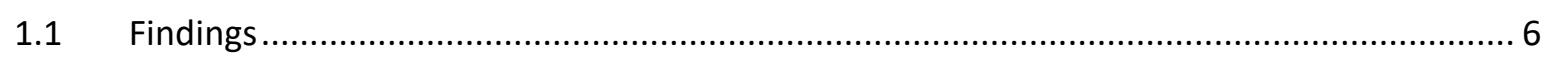

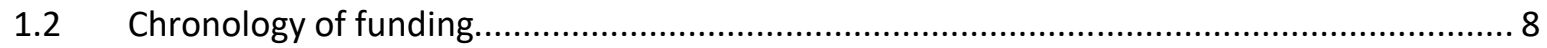

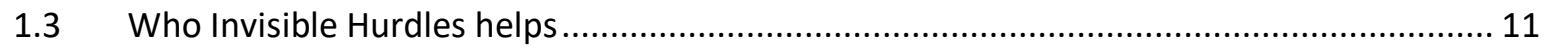

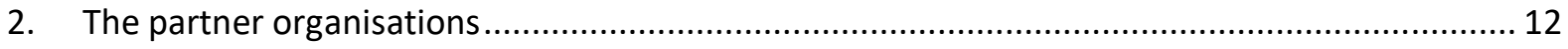

$2.1 \quad$ Hume Riverina Community Legal Service (HRCLS) ....................................................... 12

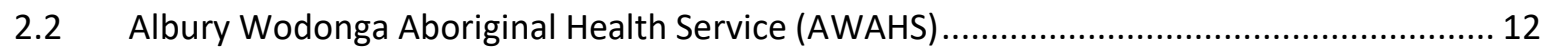

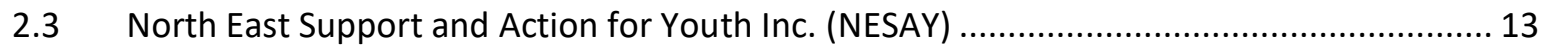

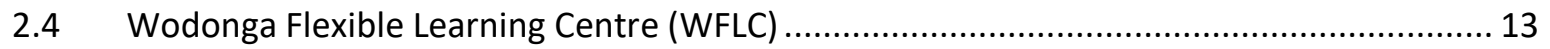

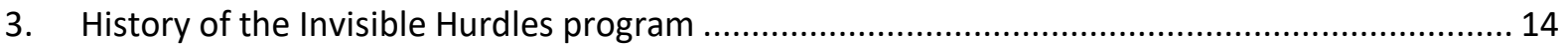

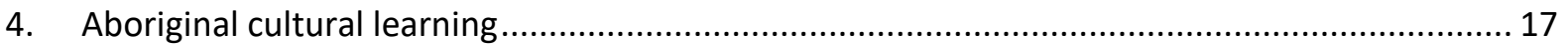

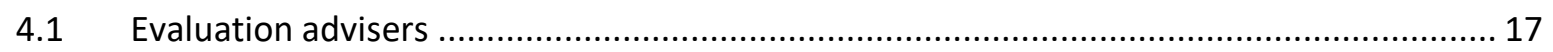

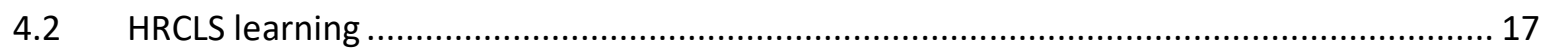

4.3 Recent history for Albury-Wodonga Aboriginal communities.......................................... 18

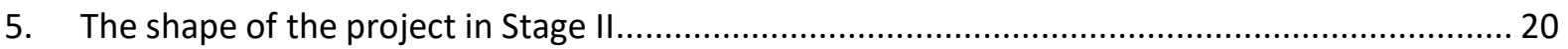

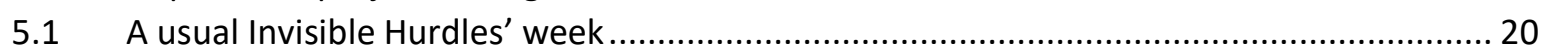

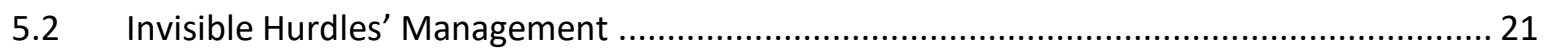

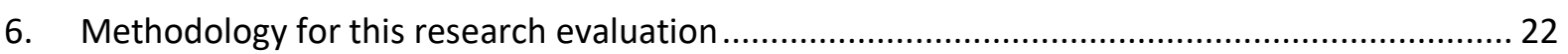

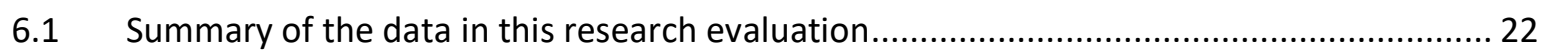

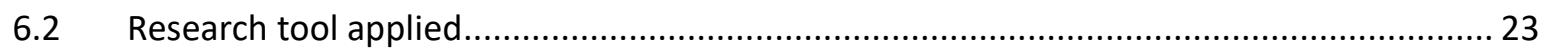

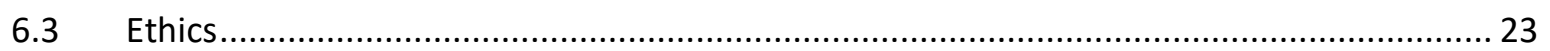

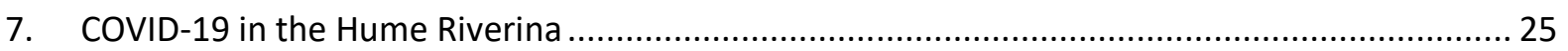

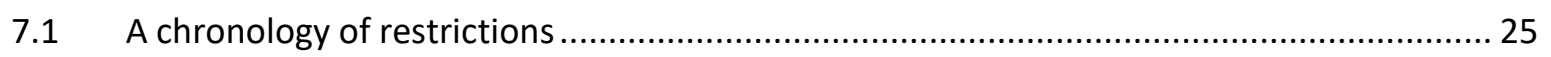

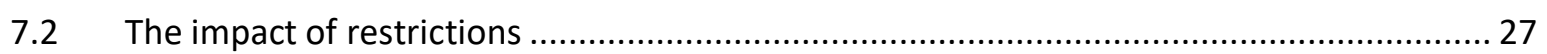

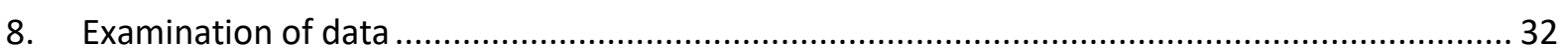

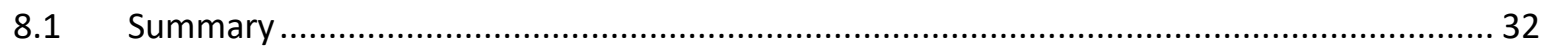

8.1.1 Summary analysis of referrals, advices, and secondary consultations data ................ 33

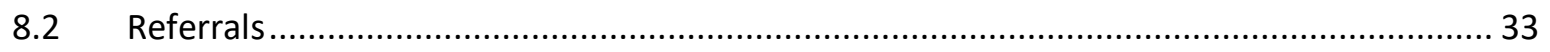

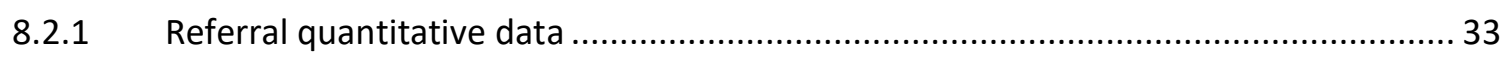

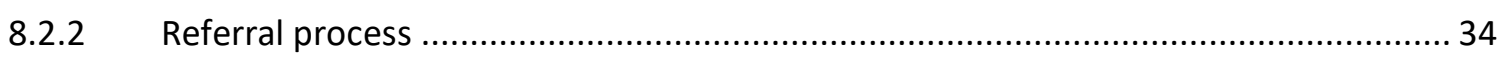

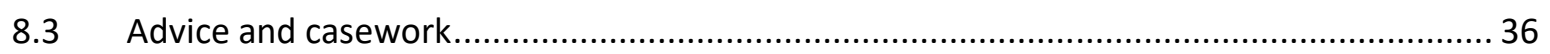

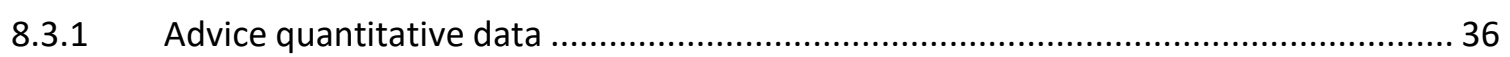

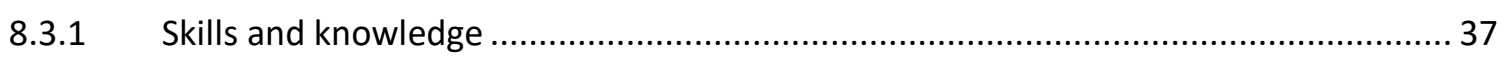

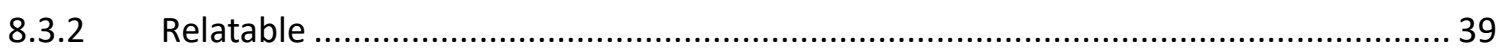

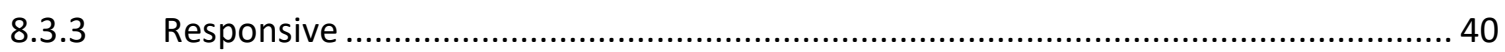




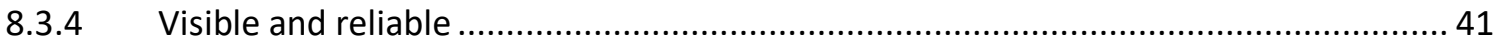

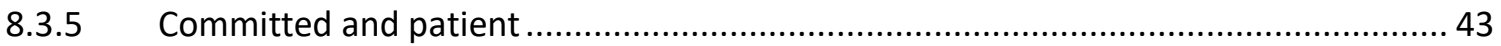

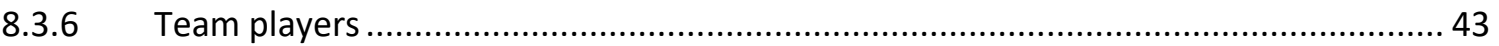

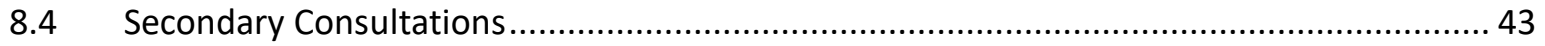

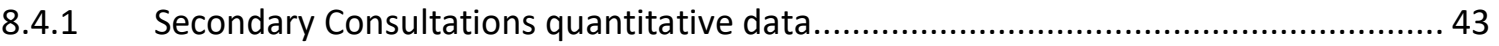

8.4.2 Secondary Consultations interview data ................................................................... 45

8.5 Service delivery broken down by partner .................................................................... 47

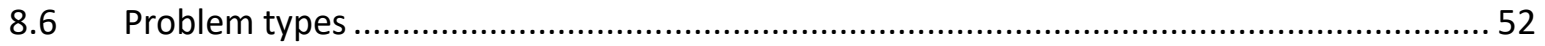

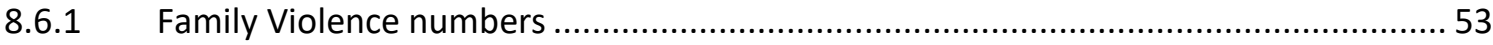

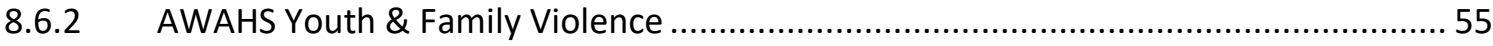

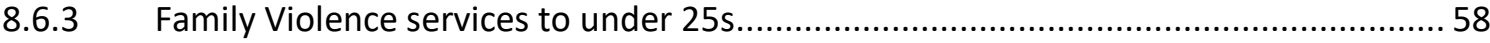

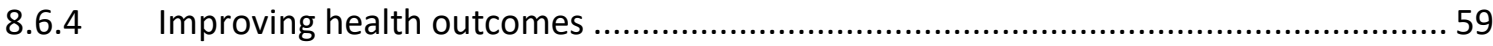

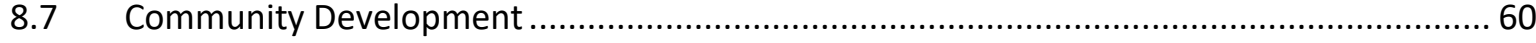

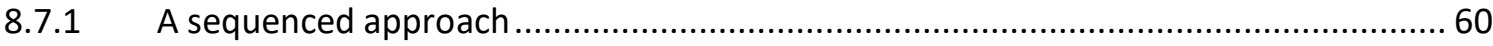

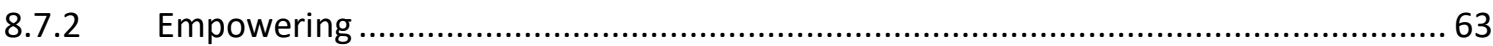

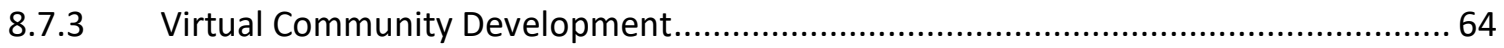

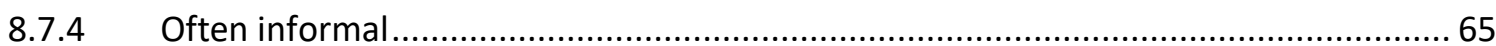

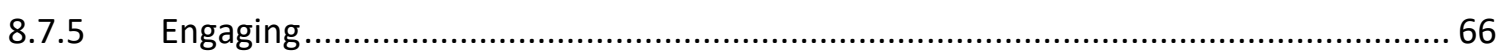

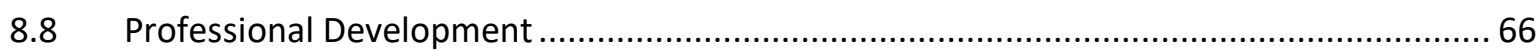

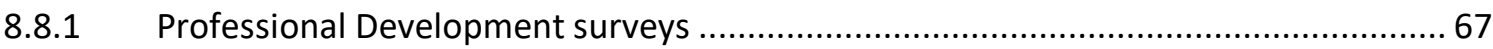

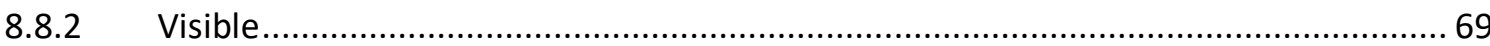

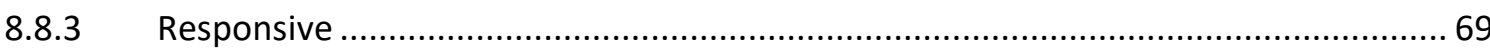

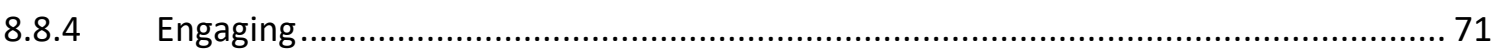

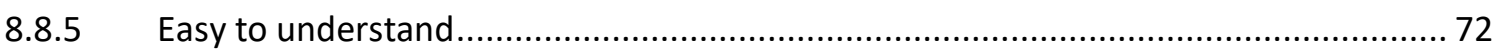

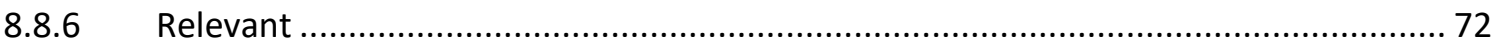

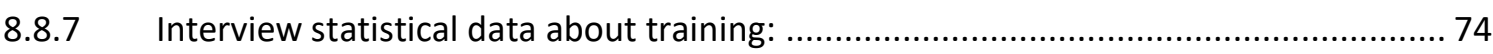

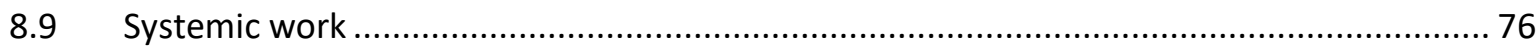

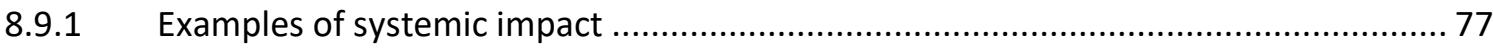

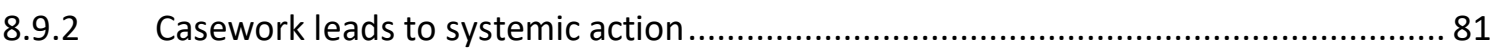

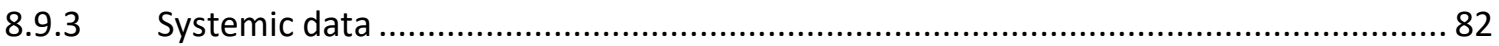

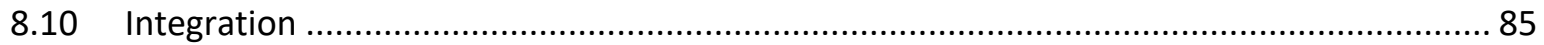

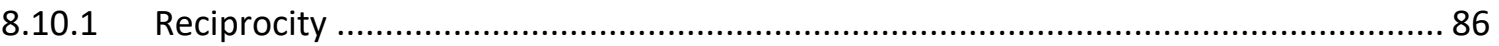

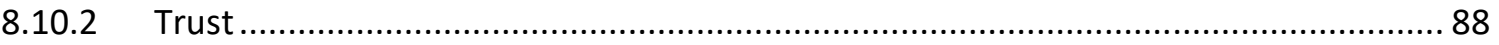

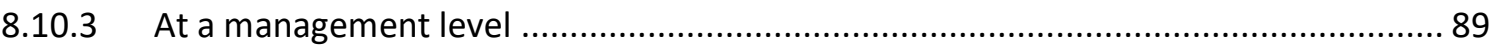

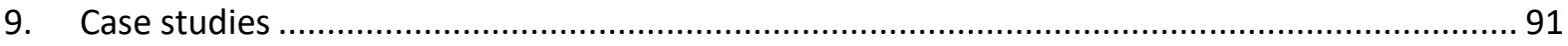

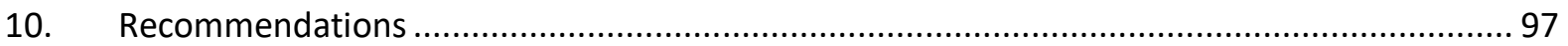




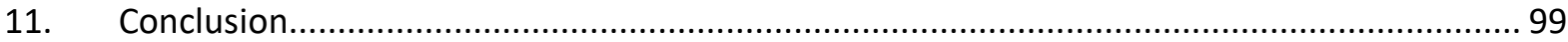

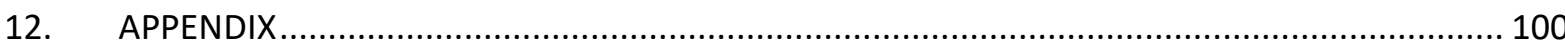

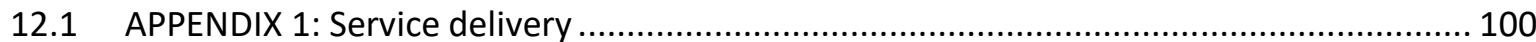

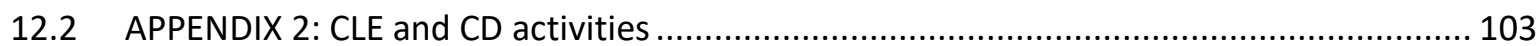

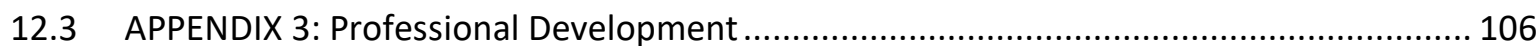

12.4 APPENDIX 4: Professional Development survey feedback .............................................. 111

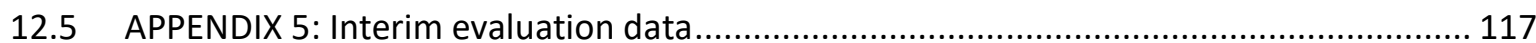




\section{Terminology and Abbreviations}

Aboriginal

ANU

AWAHS

DETV

HRCLS

$\mathrm{IH}$

LANSW

Lawyer 3

Lawyer 5

Lawyer 6

MAC

NESAY

SC

VDoJ

VLA

$\mathrm{VLSB}+\mathrm{C}$

WFLC

YP
The term used throughout this report to represent both Aboriginal and Torres Strait Islander people.

The Australian National University

Albury Wodonga Aboriginal Health Service

Department of Education and Training Victoria

Hume Riverina Community Legal Service

Invisible Hurdles

Legal Aid New South Wales

The term used throughout this report to represent the lawyer who regularly attends WFLC and NESAY.

The term used throughout this report to represent the lawyer who regularly attended AWAHS from August 2018 to July 2020.

The term used throughout this report to represent the lawyer who has attended AWAHS since August 2020. She is also the Legal Project Worker in all three projects.

Mungabareena Aboriginal Corporation

North East Support and Action for Youth

Secondary Consultations

Victorian Department of Justice and Community Services

Victoria Legal Aid

Victorian Legal Services Board and Commissioner

Wodonga Flexible Learning Centre

Young person 


\section{Introduction}

The Invisible Hurdles project is an integrated justice project of four partner organisations in the Hume Riverina region of Victoria and New South Wales, led by the Hume Riverina Community Legal Service (HRCLS).

HRCLS places a lawyer one day per week in each of the three other partner organisations. Each lawyer is then available to the organisations by phone for two further days, as they are working on casework from the HRCLS office. That is, the lawyers are accessible five days per week either by phone or in-person, for each of the partner agencies and their clients.

Additionally, a full-time project worker spreads her time across the three organisations delivering community legal education and community development activities, and working on systemic reform activities. Since August 2020, the project worker has simultaneously held the role of lawyer at one of the partners, the Albury Wodonga Aboriginal Health Service (AWAHS).

\subsection{Findings}

1. The project is efficient and effective in reaching young people who would not otherwise have been reached.

2. The aspects of the project are now connecting well. That is, secondary consultations are leading to referrals, which leads to casework, which leads to further secondary consultations and then to systemic action (see case study at 8.10.2). Community Development is leading to casework (see case study at 8.6.2) and Community Development is also leading to systemic work (see case studies at 8.9.1).

3. Management are committed to the Invisible Hurdles project and are well briefed on what happens in the project.

4. The Community Development delivery has been structured enough to be deliberate but flexible enough to allow for scaffolding (see examples at 8.7.2 where the confidence and skills of the young people grew).

5. The Community Development program at WFLC has increased democratic engagement of the young people who participated.

6. Secondary Consultations are easily available and routine.

7. The project has achieved integration in most aspects. The main aspects that are not fully integrated are in organisational connectedness and achieving seamless delivery of Community Development work at NESAY.

8. There is a high level of mutual trust and understanding between the individual agencies and the Invisible Hurdles' lawyers.

9. HRCLS is committed to continually improving its staff's understanding of and appreciation for Aboriginal history and culture and this commitment has directly related to service 
delivery to Aboriginal Invisible Hurdles' clients.

10. The Invisible Hurdles project needs to engage more deeply with young Aboriginal people so that they can better reach this group. This should be a focus now that restrictions are easing, and new connections can once again be made. This engagement is challenging work the efforts of the Invisible Hurdles project team has shown tenacity, further inroads need to be made given this group have difficulty accessing legal help and early intervention and as an endeavour to 'close the gap'.

11. Professional Development has exceeded goals set, has been accessible, engaging and relevant. However, it is an area for improvement and growth at AWAHS.

12. The referral process continues to be clear and operationalised well in all organisations. New successes have been made at AWAHS, with increased referrals reported from health professionals.

13. There is a high level of reflective practice skills of the lawyers involved in the program and changes in practice appear to be supported by management.

14. Overall the proxies (used in this evaluation as indicators to measure impact) have been met or on the trajectory of being met, namely: reach, capacity, engagement, empowerment, reciprocity and collaboration.

15. The lawyers in the Invisible Hurdles team worked closely together and delivered some outstanding Community Legal Education programs.

16. The lawyers in the Invisible Hurdles team co-ordinated systemic work giving voice to young people and became a 'go-to' source of legal help for many young people.

17. In Stage II, in contrast to the first year of the project in Stage I, there has been a continuity of staff with the two lawyers remaining in their lawyer roles. This has contributed to the seamless and continuous service delivery, and to the relationships being built with staff and clients.

18. The ongoing nature of the project, the relationships established and the awareness and visibility of the project and its staff and their availability to help is increasing. This is enabling this project to continue to gain traction and to reach more young people than previously would have been the case, without the Invisible Hurdles Project.

19. The HRCLS team's preparedness to find new ways of working around the lockdowns and the restrictions of each of the partners and staff that had been built up in the lead up to the pandemic meant that not only were the services able to be delivered consistently despite the difficulties, it was able to be sustained and, on occasion, even increased.

20. The data suggests that the project has been effective in making inroads in responding to family violence occurring in the lives of young people and their families. This is attributable to its longitudinal nature; its ability over time to build an understanding of family violence and its manifestations; and its ability to provide service pathways both to young people and 
their trusted intermediaries such as teachers, health professionals and other social services.

21. There was a marked improvement on the Interim (end 2019) data, $75 \%$ of non-legal professionals interviewed said they had collaborated on advocating for systemic reform, as compared with 33\% 14 months earlier. Participants also reported a marked increase in being asked for their views (62\% in February 2021, compared to $22 \%$ in December 2019). This is suggestive of a significant shift from Stage 1 where minimal, if any, collaborative policy reform was undertaken. Moving from working together for service delivery to working together on policy trends in this service delivery, for greater impact indicates a more sophisticated approach.

22. Over five years of funding from multiple sources, the Invisible Hurdles team has delivered what can, on the data collected, be assessed against the benchmarks as 'integrated' and holistic legal practice.

\subsection{Chronology of funding}

The project is funded by grants from the Victorian Legal Services Board and Commissioner (VLSB $+C$ ), the Victorian Department of Justice and Community Safety (VDoJ), Legal Aid New South Wales (LANSW) and Victoria Legal Aid (VLA). Funding (from VDoJ) commenced on 6 June 2018 and VLSB+C funding commenced on 1 January 2019. From 1 July 2017 to 31 July 2020, LANSW funded a Lawyer 0.6 at AWAHS. Funding has also been provided by Victoria Legal Aid (VLA) at various points during the project while waiting for funding to be allocated or where grant funding has not fully met the requirements of the project. VLA also funded the project for the period 6 June to 30 June 2020 which was an unfunded gap period. An extension due to COVID-19 from the VLSB+C meant that funding concluded on 1 April 2021 and the VDoJ funding has likewise been extended until 30 June 2021.

The project ran in pilot form from December 2015 to May 2018 with funding from the Victorian Legal Services Board and Commissioner. This pilot was evaluated by the authors of this report and a final report was published in 2018 and is publicly available. ${ }^{1} \mathrm{~A}$ second and linked project provides a lawyer at the Albury Wodonga Aboriginal Health Service (AWAHS) focussing on family law and family violence. Funding from Legal Aid NSW (Commonwealth family law/family violence funding) provided a lawyer at Albury Wodonga Aboriginal Health Service (AWAHS) for 2 days per week until July 2020, when the AWAHS lawyer retired. The same lawyer attends AWAHS for the Invisible Hurdles project as for that service. This funding is described in the below chronology at 1 July 2017, provided to the authors by the HRCLS.

\footnotetext{
1 'Overcoming the Invisible Hurdles to Justice for Young People: A Final Research and Evaluation Report of the Invisible Hurdles Project (Health Justice Partnership) November 2018. http://www.hrcls.org.au/wpcontent/uploads/2018/11/DESIGNED_Full-final-Report_October_20181102.pdf
} 


\begin{tabular}{|c|c|c|}
\hline DATE & \multicolumn{2}{|l|}{ EVENT } \\
\hline $\begin{array}{l}1 \text { October } \\
2015\end{array}$ & \multicolumn{2}{|c|}{$\begin{array}{l}\text { HRCLS receives Grant funding from VLSB+C for Invisible Hurdles (Stage 1) - } \\
\text { (1 October } 2015 \text { - } 30 \text { September 2017) - extended to } 31 \text { May } 2018 \text { due to delay in initial } \\
\text { recruiting and staff changes throughout the term of the project. }\end{array}$} \\
\hline $\begin{array}{l}7 \\
\text { December } \\
2015\end{array}$ & $\begin{array}{l}\text { Commencement of employment - Lawyer } 1 \\
\text { - Commenced with HRCLS on 7/12/2015. }\end{array}$ & \multirow{4}{*}{$\begin{array}{l}4 \text { day/week lawyer } \\
\text { working with all } \\
\text { partners } \\
\text { (Lawyer worked full- } \\
\text { time due to also } \\
\text { working one } \\
\text { day/week providing } \\
\text { family violence duty } \\
\text { lawyer services - } \\
\text { funded by another } \\
\text { funder) }\end{array}$} \\
\hline $\begin{array}{l}4 \text { April } \\
2016\end{array}$ & Finish date of Lawyer 1 & \\
\hline $\begin{array}{l}4 \text { July } \\
2016\end{array}$ & $\begin{array}{l}\text { Commencement of employment - Lawyer } 2 \\
\text { - Commenced with HRCLS on 4/7/2016 }\end{array}$ & \\
\hline $\begin{array}{l}4 \text { August } \\
2017\end{array}$ & Finish date of Lawyer 2 & \\
\hline $\begin{array}{l}1 \text { July } \\
2017\end{array}$ & $\begin{array}{l}\text { HRCLS receives funding from Legal Aid NSW for Family Law / } \\
\text { Family Violence (Cth) - } \\
\text { (1 July } 2017 \text { - } 30 \text { June } 2020 \text { with expected rollover for a further 3-5 } \\
\text { years) } \\
\text { Lawyer } 4 \text { was present at AWAHS on a } 0.6 \text { fraction up to } 11 \text { October }\end{array}$ & $\begin{array}{l}3 \text { day/week lawyer } \\
\text { to partner with } \\
\text { AWAHS }\end{array}$ \\
\hline $\begin{array}{l}14 \text { August } \\
2017\end{array}$ & $\begin{array}{l}\text { Commencement of employment - Lawyer } 3 \\
\text { - Commenced with HRCLS on 14/8/2017 }\end{array}$ & $\begin{array}{l}4 \text { day/week lawyer } \\
\text { to focus on WFLC \& } \\
\text { NESAY partnerships } \\
\text { (Lawyer worked full- } \\
\text { time due to also } \\
\text { working one } \\
\text { day/week providing } \\
\text { family violence duty } \\
\text { lawyer services - } \\
\text { funded by another } \\
\text { funder) }\end{array}$ \\
\hline $\begin{array}{l}2 \text { March } \\
2018\end{array}$ & \multicolumn{2}{|c|}{$\begin{array}{l}\text { Finish date of Lawyer } 3 \text { - maternity leave } \\
\text { - No replacement or backfill arranged as the project was due to end } 31 \text { May } 2018 \text { and } \\
\text { there had been no confirmation received regarding funding for Stage } 2 \\
\text { - HRCLS Lawyers on staff provided support to NESAY \& WFLC as best they could }\end{array}$} \\
\hline $\begin{array}{l}6 \text { June } \\
2018\end{array}$ & \multicolumn{2}{|l|}{$\begin{array}{l}\text { HRCLS receives funding from Department of Justice - } \\
\text { (6 June } 2018 \text { - } 5 \text { June 2020) }\end{array}$} \\
\hline
\end{tabular}




\begin{tabular}{|c|c|c|}
\hline $\begin{array}{l}6 \text { July } \\
2018\end{array}$ & \multicolumn{2}{|l|}{ Finish date of Lawyer 4 - retired } \\
\hline $\begin{array}{l}13 \text { August } \\
2018\end{array}$ & \multicolumn{2}{|c|}{$\begin{array}{l}\text { Commencement date of Lawyer } 5 \text { to replace Lawyer } 4 \text { and continue the partnership with } \\
\text { AWAHS }\end{array}$} \\
\hline $\begin{array}{l}20 \text { August } \\
2018\end{array}$ & Recommencement of Lawyer 3 - (employed through DoJR funding) & $\begin{array}{l}4 \text { day/week lawyer } \\
\text { worked across } 5 \\
\text { days to focus on } \\
\text { WFLC \& NESAY } \\
\text { partnerships }\end{array}$ \\
\hline $\begin{array}{l}1 \text { January } \\
2019\end{array}$ & $\begin{array}{l}\text { HRCLS receives grant funding from VLSB+C for Invisible Hurdles } \\
\text { (Stage 2) - } \\
\text { (1 January 2019 - } 1 \text { January 2021) }\end{array}$ & \multirow{2}{*}{$\begin{array}{l}\text { Adding } 5 \text { day/week } \\
\text { Legal Project Work } \\
\text { to work with all } \\
\text { partners on legal } \\
\text { education and } \\
\text { reform work }\end{array}$} \\
\hline $\begin{array}{l}15 \text { April } \\
2019\end{array}$ & $\begin{array}{l}\text { Legal Project Worker for IH (Stage } 2 \text { ) } \\
\text { Lawyer } 6 \text { commenced as Legal Project Worker-(employed } \\
\text { through LSB funding) }\end{array}$ & \\
\hline $\begin{array}{l}23 \text { March } \\
2020\end{array}$ & \multicolumn{2}{|c|}{ COVID-19 pandemic. Invisible Hurdles/ HRCLS staff commenced working from home. } \\
\hline $\begin{array}{l}13 \text { April } \\
2020\end{array}$ & $\begin{array}{l}\text { Legal Project Worker role changed- Lawyer } 6 \text { commenced as NSW } \\
\text { Outreach lawyer (13 April 2020-23 August 2020) }\end{array}$ & $\begin{array}{l}3 \text { days } p / w \text { at LPW } \\
\text { and } 2 \text { days } p / w \text { as } \\
\text { NSW Generalist } \\
\text { lawyer }=2 \text { days not } \\
\text { IH related }\end{array}$ \\
\hline $\begin{array}{l}31 \text { July } \\
2020\end{array}$ & \multicolumn{2}{|l|}{ Finish date of Lawyer 5 - retired } \\
\hline $\begin{array}{l}24 \text { August } \\
2020\end{array}$ & $\begin{array}{l}\text { Legal Project Worker role changed- Lawyer } 6 \text { ceased as NSW } \\
\text { Outreach lawyer and commenced as AWAHS Lawyer ( } 23 \text { August } \\
\text { 2020) }\end{array}$ & $\begin{array}{l}3 \text { days } \mathrm{p} / \mathrm{w} \text { as LPW } \\
\text { and } 2 \text { days } \mathrm{p} / \mathrm{w} \text { as } \\
\text { AWAHS lawyer }\end{array}$ \\
\hline & \multicolumn{2}{|l|}{ HRCLS receives rollover funding from Department of Justice } \\
\hline $\begin{array}{l}4 \text { January } \\
2021\end{array}$ & \multicolumn{2}{|c|}{$\begin{array}{l}\text { Transition/return to office- Invisible Hurdles/ HRCLS staff hybrid model of working from } \\
\text { home and working in HRCLS office }\end{array}$} \\
\hline $\begin{array}{l}1 \text { April } \\
2021\end{array}$ & \multicolumn{2}{|l|}{ Invisible Hurdles funding ceases (from VLSB+C) } \\
\hline $\begin{array}{l}30 \text { June } \\
2021\end{array}$ & \multicolumn{2}{|l|}{ Invisible Hurdles funding ceased (from VDoJ) } \\
\hline
\end{tabular}




\subsection{Who Invisible Hurdles helps}

The Invisible Hurdles project is focussed on providing legal advice, assistance and legal empowerment to young people aged 12 to 25 years' old who have experienced or are at risk of experiencing family violence. The partner agencies are ideally placed to connect young people with the HRCLS legal expertise through their pre-established relationships with young people experiencing disadvantage. Numerous hurdles get in the way of young people receiving legal assistance, particularly where they face disadvantage in other forms such as poverty, family violence, drug or alcohol issues and insecure housing. Research, including from the first iteration of the project shows that young people are reluctant to trust legal professionals and to seek help, relying instead on family and friends' advice or failing to address their legal problems at all. ${ }^{2}$

Legal problems cause anxiety and fear for young people and this itself can be disabling for them to act. Young people experiencing disadvantage have financial impediments to seeking legal assistance too, both in terms of transportation to legal centres and the ability to pay for a lawyer - they may not qualify for legal aid and may lack the skills and knowledge to seek out help from appropriate agencies. The project intends to overcome these hurdles by bringing legal help and information directly to where the young person visits; by building trust from an initial borrowed-trust introduction, from non-legal professionals such as social workers and teachers who the young person respects; by re-thinking the ways legal information needs to be passed on and utilising the concept of 'legal secondary consultations'; ; and by utilising a network of organisations to activate for change on issues that continually affect the young people they all service.

\footnotetext{
2 Ibid p.9.

${ }^{3}$ Curran L (2017) 'Lawyer Secondary Consultations: improving access to justice and human rights: reaching clients otherwise excluded through professional support in a multi-disciplinary practice' 8(1) Journal of Social Inclusion https://josi.journals.griffith.edu.au/index.php/inclusion/article/view/8
} 


\section{The partner organisations}

\subsection{Hume Riverina Community Legal Service (HRCLS)}

HRCLS has offices in Wodonga and Wangaratta, as well as various outreaches, servicing people in 17 municipalities across North East Victoria and the Southern Riverina of New South Wales - in 201819 , the HRCLS lawyers travelled $17012 \mathrm{~km} .{ }^{4}$ HRCLS relies upon funding from grants and Commonwealth and State Government sources. The service began in 1999, founded by local lawyers, and is one of the few cross-border community legal centres for Victoria/NSW and in fact, in Australia.

HRCLS offers a generalist advice and casework service, staffed by both permanent and volunteer lawyers and students. As well as the Invisible Hurdles program, HRCLS places a lawyer at the Centre Against Violence (CAV) in Wangaratta and Wodonga; runs an outreach service to the Women's Centre for Health and Wellbeing in Albury as well as other locations and partnerships. It also provides community legal education through sessions (delivered to 678 participants in 2018/19) and written information, for example, 'Bring your Bills days', Wills Clinics and Legal Health Checks and more. $^{5}$

\subsection{Albury Wodonga Aboriginal Health Service (AWAHS) ${ }^{6}$}

AWAHS is an Aboriginal Community Controlled organisation and is fully funded by the Department of Health (Cwth), Department of the Prime Minister and Cabinet and Department of Health (NSW). The organisation's vision is to 'Provide and improve health outcomes for our local Aboriginal community with a range of culturally appropriate, flexible, reliable, professional and viable health and wellbeing services, to strengthen, nurture, enhance and maintain the overall quality of life of our community members. ${ }^{7}$ It was founded in 2009 after research and lobbying since the 1990s from the Mungabareena, Wandoo and Woomera Aboriginal Corporations about the need to address the gaps in Aboriginal health.

The services provided by AWAHS span medical, nursing, social and emotional wellbeing, dental, optometry, psychology, dietician, diabetes education, podiatry, occupational therapy, speech pathology, social work, child and family health, chronic disease support, drug and alcohol support, health promotion, stolen generation support and transport. These services are provided free to Aboriginal people, who in this region come from 50 different language groups. From 2018-2019, 2680 community members were seen at AWAHS' main locations or outreaches across Albury, Wodonga, Wangaratta, Bright and Benalla. ${ }^{8}$ Our cultural advisers also noted that although local Aboriginal people come from 50 different language groups and many families, young Aboriginal people do not focus on these differences. There is some overlap between AWAHS services and that of the Mungabareena Aboriginal Corporation (MAC) but the two organisations have different

\footnotetext{
${ }^{4}$ Hume Riverina Community Legal Service (HRCLS), Annual Report 2018/19 https://www.hrcls.org.au/hrclspublications/

${ }^{5}$ Ibid.

${ }^{6}$ Albury Wodonga Aboriginal Health Service (AWAHS), https://www.awahs.com.au/

${ }^{7}$ AWAHS Vision Statement, https://www.awahs.com.au/about/vision/

${ }^{8}$ AWAHS Annual Report 2019, CEO Report.
} 
directions and objectives. There is a Memorandum of Understanding between the two organisations which has routinely been revised.

\subsection{North East Support and Action for Youth Inc. (NESAY)}

Founded in 2012, NESAY is a leading agency supporting young people and their families in North East Victoria, servicing a vast region of seven municipalities. It has a community Board of Governance and is funded by State and Commonwealth departments, grants and other funding opportunities. Its mission is 'Supporting young people and their families in our community to achieve their goals and aspirations. $^{\text {9 }}$

The scope of NESAY's work is in early intervention and support for young people experiencing or at risk of homelessness, independent living skills, a learner driver program, a healthy eating and living program, support leaving care, a school focused youth service to help vulnerable or disengaged young people, school counselling, support for young people at risk of entering child protection, support transitioning from residential care and a fair feed meal program with local cafes. ${ }^{10}$

\subsection{Wodonga Flexible Learning Centre (WFLC)}

The Wodonga Flexible Learning Centre (WFLC) is a campus of the Wodonga Senior Secondary College. The alternative education centre was established in 2014 by the Victorian Education Department and subsequently expanded to three other regional locations. The Invisible Hurdles lawyer only services the WFLC.

The program aims, among other things, to 'reconnect young people with learning inside and outside the Centre by connecting them to their community, to assist the young person to develop a positive image of themselves, [and] to work with the young person to understand possible pathways to future learning and employment. ${ }^{11}$ The school services students aged 15-19, all of whom have individual reasons that prevent them from attending regular school. Up to 140 students are enrolled (with 94 being enrolled in 2020) and each is provided with personalised learning plans which set individual goals, program plans, timetables and attendance. The students include young parents, students with mental health issues, learning difficulties, home schoolers and students with social and behavioural issues. ${ }^{12}$

\footnotetext{
${ }^{9}$ North East Support and Action for Youth Inc. (NESAY), https://nesay.com.au/

${ }^{10}$ NESAY, Programs https://nesay.com.au/nesay-programs/

${ }^{11}$ WFLC, Program aims http://www.nefln.vic.edu.au/wodonga/program-aims/

${ }^{12}$ Wodonga Flexible Learning Centre (FLC), http://www.nefln.vic.edu.au/wodonga/program-aims/
} 


\section{History of the Invisible Hurdles program}

The Invisible Hurdles program was first funded by the Victorian Legal Services Board and Commissioner, from December 2015 to June 2018. From the program's inception, HRCLS contracted the Australian National University (ANU), with the authors as key personnel, to conduct an actionresearch evaluation of the program. An interim evaluation report was delivered in March 2017, as well as a final evaluation report in May 2018 with a public launch in November 2018.

The project placed a lawyer in each of the partner organisations for up to one day per week, with advice readily available on the other four weekdays by phone. This lawyer was tasked firstly with providing legal advice and casework assistance to young clients under 25 years old, usually referred to them by trusted non-legal professionals in the organisation. Secondly, the lawyer was to provide 'legal secondary consultations' to non-legal professionals, which is defined as where a lawyer provides legal information or advice to a staff member of the partner organisation which may, where relevant, be relayed back to the client by the staff member, discussed further below at 7.1.5. Thirdly, the lawyer was to initiate systemic law reform action on issues that affect the client groups. Finally, the model allowed for the lawyer to increase engagement of young people with legal help and information, either through community legal education activities or community development activities.

As an integrated justice project, the Invisible Hurdles aims through educational and health/social service/justice agencies to target vulnerable young people. It was a key feature of this multidisciplinary practice model that a lawyer is embedded as a part of the partner organisation, thus differentiating the model from an 'outreach'. That is, that the lawyer is on the team as a staff member (including attending staff meetings and joining in on events) at the partner agencies and interacts with their staff to build relationships and trust. Such rapport building enables legal secondary consultations to take place more easily as the lawyer is visible and approachable and as they are on site, accessible in a timely way for support and advice. This also enables joined- up services that reach people and engage effectively across service disciplines. This is what categorises a project as 'integrated'. Often this term is used loosely and does not necessarily exist. This evaluation therefore as a key feature sets out to, through applying data against pre-set benchmarks determined by research, to measure if integration in fact occurs and establish the circumstances that facilitate its occurrence if this is indicated. Another feature of this integrated model is that the partner organisations come to know one another, particularly from a management perspective so that they collaborate for better outcomes for young people. One example in the data of how this took place in the first stage was that AWAHS (main centre in Glenroy, NSW) partnered with NESAY (main centre in Wangaratta, Vic) to place an AWAHS outreach van at NESAY once a week.

Some initial challenges of Stage 1 included transitioning lawyering styles into best practice integrated justice practice methods, increasing the time spent at each organisation, building organisational trust, and the gradual uptake of secondary consultations. The HRCLS team and the partners were committed to overcoming these challenges though and the first iteration of the Invisible Hurdles program finished on a strong high note. The final evaluation report found that the model, an integrated justice practice, was effective in reaching the vulnerable young people who were the target group and in achieving breakthrough outcomes for these clients. ${ }^{13}$ Further, the

\footnotetext{
${ }^{13}$ Above, n 1, p. 11
} 
report found that the model enhanced decision-making and responsiveness in the organisation due to the secondary consultations. Key findings are replicated in the below box.

\section{Stage 1 Final Report, Key Findings ${ }^{14}$}

- The 'Invisible Hurdles' project, across all the measurement tools, was effective, efficient and had an impact reaching clients who would otherwise not have been reached.

- Engagement, capacity, empowerment and collaboration improved throughout the project for many young people and non-legal professionals as awareness grew about the possibilities that legal problem solving could present.

- Secondary consultations were delivered as a way of reaching young people, who this and other research reveal, often distrust authority or are frightened, with the project's approach minimising the young person feeling exposed and with them turning to a trusted teacher or health and allied health professional.

- The presence of 'justice' service providers, advising alongside other disciplines, was seen to enhance decision-making, not just of the young person and their worker but at times led to enhanced decision-making and a deeper understanding of legal options at agency and organisational level, increasing agency responsiveness.

- Secondary consultations enabled young people to get access to accurate, relevant timely legal information, through their trusted intermediary being able to quickly access a lawyer, and then support them or if the young person felt able to later be referred, having established trust from both the worker and the young person.

- Secondary Consultations also built capacity of non-legal professionals to be able to respond in a timely way, to improve decision-making, and reduce the professionals' sense of anxiety as they know the information through the lawyer is reliable.

- Word of mouth about the project, in that young people felt the lawyer was okay, took time to develop, but in the recent twelve months of the project there was evidence in the data that young people were starting to self-present because of the experiences of other young people.

- Young people experiencing family violence are unlikely to reveal it unless they feel safe, the lawyer is approachable, non-hierarchical, non-judgemental and speaks simply and are likely to disclose other issues first and test out a lawyer first before opening-up. Poor lawyer stereotypes can inhibit willingness to seek help and so the type of lawyer is critical to engagement.

- Young people will wait and observe how the lawyer interacts with others first, sometimes for up to six months, before feeling they can approach a lawyer or their worker about a legal issue.

- Many young people relied on family members or friends for legal opinions and often these sources were suspicious of lawyers and the legal system and so opportunities for early intervention and problem prevention or escalation were not utilised but with the lawyer on site, visible, available and approachable more young people were availing themselves of legal help either directly or through a trusted non- legal professional than would have been the case without the project.

Whilst the above noted that the model was highly effective, key recommendations in the report noted that there was room for development in the project. Specifically, in the areas of community

${ }^{14}$ Ibid, p. 6-7 
development, professional development between the partners and systemic reform action (Recommendations 1, 2 and 11). These recommendations are replicated in the box below.

\section{Stage 1, Final Report, Recommendations 1, 2 and $11^{15}$}

\section{Community development}

Lawyers and community educators have a role in giving the young people the power, information, skills and opportunities to engage in decision-making processes that affect them. There are opportunities being missed that could be taken up.

\section{Professional development and reciprocity}

There is capacity for professional development work to continue in both opportunistic ways (lunchroom, staff meetings) and formal planned ways. This should be reciprocal, that is not only from the HRCLS lawyer to the other partners, but also from and between all four partners.

\section{Systemic policy work}

Policy reform is critical to avert the revolving doors of problems that might be resolved with grass roots informed policy responses. All partners across the data expressed a wish for opportunities to further identify, explore and work together on policy work that might address problems that might be alleviated or changed for better outcomes for young people. The involvement of young people in policy work that affects them is important.

HRCLS applied for further funding in 2018 , this time to continue the integrated justice practice method from Stage 1 but to add an appropriately qualified project worker to the Invisible Hurdles team, who could lead the work on the three key areas above: community development, professional development and systemic policy work. On this basis, the VLSB+C, as well as the VDoJ agreed to fund what became known as 'Stage II' of the Invisible Hurdles project.

In April 2019, a 'legal project worker' was recruited for Stage II, following discussion by the advisory committee (comprised of managers from each of the partner agencies) and an interview by managers from HRCLS and NESAY. That project worker had recently been employed by the HRCLS on a short-term basis as an outreach lawyer. She appropriately maintained a practicing certificate, but client advice and casework were not intended to be the core of her role in the project worker position. In April 2020, she started to do two days per week of casework and in August 2020 Unrelated to IH but rather due to HRCLS staffing issues and complications of COVID), she took over the lawyer role at AWAHS, following the retirement of the lawyer in that role. This essentially merged her role as Legal Project Worker with Lawyer. In their interim evaluation report, delivered in February 2020, the authors had also said that it would be beneficial to the project, given her skills and attributes, for the Legal Project Worker to take up some casework. ${ }^{16}$ Doing so also meant that she commenced work as the AWAHS lawyer while working remotely, a significant challenge even though she was already known to many staff at the organisation.

\footnotetext{
${ }^{15} \mathrm{Ibid}$, p.8-10

${ }^{16}$ Recommendation 6, Interim Evaluation Report, Invisible Hurdles, February 2020, Unpublished.
} 


\section{Aboriginal cultural learning}

\subsection{Evaluation advisers}

The authors appreciate the guidance provided by Ms Judith Ahmat and Ms Catherine Coysh of Watnanda Consulting. Ms Ahmat is an Aboriginal elder who provided pro bono cultural advice in Stage I of the project on the research evaluation tools and instruments and reports, which accorded with ethics approval. Ms Coysh is a leader the Albury/Wodonga area. She is a board member at AWAHS, chairperson of the Wodonga Aboriginal Network, and founder of the Wodonga Youth Koori Network. In Stage II, Watnanda Consulting provided valuable cultural advice, ideas and guidance to the authors on the tools, method and the report in draft format. The authors are very grateful to Judith and Catherine for sharing what they know, teaching us and insightful responses to our questions.

\subsection{HRCLS learning}

The legal team at HRCLS have also actively sought out learnings from Aboriginal elders. Through the connections that the Legal Project Worker/Lawyer at AWAHS made, she developed a relationship with an elder held in high esteem by the local community and HRCLS, who was willing to visit their team and talk with them about his life on a mission near Griffith, NSW. The lawyers reported how humbled they were to have Uncle (de-identified Aboriginal elder) visit. They reported that they found his stories were difficult to hear, but important.

\footnotetext{
The transformative nature of taking time to hear Aboriginal voice

'We've done a range of different [cultural competency] things, which is great and it's great to have those conversations and workshops, some of those things (sic). But having someone like Uncle come and actually share was amazingly powerful.'
}

'You could hear a pin drop [when he was speaking]'.

'Everyone was extraordinarily uncomfortable, but it was amazing and shaped everyone's thinking.'

- Reflections from HRCLS staff on an Aboriginal elder's visit

One participant described that the elder was 'so chuffed that someone would ask him, that these lawyers wanted to hear from him.' Listening and truth-telling are a core action towards reconciliation. Actively asking for these stories to be told demonstrates a commitment to reconciliation and the authors have observed a genuine desire in the HRCLS staff to do more than pay lip service to reconciliation. The Uncle's visit and the trust required came about only because HRCLS had the opportunity to build the relationship with the Aboriginal community - that is, not just at an organisational level, but also with local Aboriginal people in Albury Wodonga. Much is often 
said about the need for actions in reconciliation. Legal services to Aboriginal communities must be funded long-term if the relationships and trust are going to be able to be built up enough for listening and truth-telling to occur. It took four years for this relationship to be strong enough for this visit to occur.

Further, legal projects must invest in non-legal advice/casework work. The Uncle came to know the Legal Project Worker because she spent hours talking and listening at the Men's Shed building on the relationship that had developed between Uncle and Lawyer 5 over a number of years. Had the project not had this room for relationship building, the opportunity of his visit to the HRCLS office, would never have occurred. Community law organisations and their funders must start to view 'legal help' differently from a traditional model of counting the number of cases and legal tasks, if it is to make further inroads into access to justice, break down perceptions about lawyers and move towards genuine reconciliation.

\section{Lawyers are shearers}

'A very powerful and important insight into the life of an Aboriginal man and the trauma he has faced during his life as a result of white laws and processes. Learnings of awareness in how we work with Aboriginal clients, in particular listening and fighting for them. It was very moving and incredibly uncomfortable at times as Uncle has had some seriously bad experiences with lawyers in the past and is not afraid to say so!

He referred to lawyers as 'Shearers' in the way they deal with clients i.e., quickly doing the work and moving on to the next sheep or client. That was hard to hear because particularly in a duty lawyer capacity that is what is done to ensure that all the clients have an opportunity to get legal advice. Thoughts for me about how lawyers can balance the requirement to work quickly with the need to connect with clients and to ensure their voice is heard- are these things incompatible?'

- HRCLS staff member on the elder's visit

\subsection{Recent history for Albury-Wodonga Aboriginal communities}

Below is an extract from a local Wiradjuri elder, Liz Heta, in her submission to the Australian Parliament's Joint Select Committee on Constitutional Recognition relating to Aboriginal and Torres Strait Islander Peoples. This extract is instructive because it describes the recent history of Aboriginal people living in the region. The authors of this report are from immigrant families and live on Wurundjeri land, and both have been friends and colleagues of Aboriginal people from various parts of Victoria. We acknowledge that solutions to current problems come from knowing and remembering the past, and so excerpts such as the below are important.

My name is Liz Heta I am a proud Wiradjuri person. My Aboriginal ancestry runs through my maternal blood line my mother is Nancy Rooke born on the sandhills of Narrandera, my nana Annie Scott (Glyde) born in Hay, my great grandmother Martha Glyde was born? unsure no record though through oral history was told Martha was born on the Grong Grong reserve (station) and taken at the age of 2 by reverent Watson who gave her the name Martha Watson and took her to Wellington.

I was at the Wodonga Hearing on the 24 September and listen to the questions directed at the people been interviewed. 


\section{My knowledge of Albury Wodonga}

Albury Wodonga - I moved here in 1981 my mother was already living in Albury and moved here around 1977. When I first came to the area Albury Land Council was established and was dominated by Barkindji people. Wiradjuri people living here were the minority. In the mid to late '70's Albury was well known as a resettlement area. Aboriginal people were enticed to Albury by government in lieu of jobs better conditions housing, education and health. Other the years of working with community and individuals I recognised that there was no family that had ongoing connection to the area or they did not identify anymore as Aboriginal loss of oral knowledge, Aboriginal people in Albury Wodonga were a mixed mob of over 50 nations living here, so we looked after community We always recognised Albury as Wiradjuri and the river was not a boundary as community moved to both sides and congregated both sides of the river.

I moved to Wodonga from Albury in 1986 were it was said no Aboriginal lived so a few of us living in Wodonga gathered and developed a LAECG then we developed Mungabareena Aboriginal Corporation a place for community to gather support and advocate.

There was a knowledge of North East Victoria of small pox and influenza causing great sickness for the tribes of North East. I had not met or heard of anyone saying they were ancestry linked to the area. In early 2000 I was working as a Aboriginal Liaison Officer and was involved in some work around the Hume dam, this is when I meet a man who was Dhudhuroa and lived near Wodonga but did not connect with the Aboriginal community, living in Wodonga. A Dhudhuroa and Waywuruu language retrieval project was done by a group in Wodonga, then it was spoken about the country been of Dhudhuroa, then when Registered Aboriginal Parties were been established in Victoria. Dhudhuroa people started to come forward (with no disrespect) as they were recognising themselves as another tribal group with ancestral links to Dhudhuroa, this confused a lot of community then people had their own thoughts re who country Wodonga sat on. While the tradition al owner groups were not communicating with each other or limited connection with the local Aboriginal communities... ${ }^{17}$

\footnotetext{
${ }^{17}$ Liz Heta, Submission to the Joint Select Committee on Constitutional Recognition relating to Aboriginal and Torres Strait Islander Peoples, Submission no. 469 (2018), p.1.

https://www.aph.gov.au/DocumentStore.ashx?id=1592a18d-d769-449a-8a9e-50ab44891e49\&subld=660955
} 


\section{The shape of the project in Stage II}

\subsection{A usual Invisible Hurdles' week}

AWAHS

NESAY - Lawyer 3 attends for approximately six hours on one day each week. She travels to and from Wodonga in the other two hours that day.

- Lawyer 6 attended NESAY on the same day. Occasionally, and at other times on different days depending on need and NESAY programs (e.g.: attendance at HEAL program) as the Legal Project Worker.

- All teams at NESAY are in the same building and Lawyer $3 \& 6$ sit in a private office. More recently, NESAY has restructured the way it sees clients, finding that many of the young people preferred the model of access provided during COVID, which has meant that the legal assistance that the lawyers provide is still mostly remote.

- Lawyers 3 and 6 are available by phone over the rest of the week, as needed.

WFLC - Lawyer 3 attends one day per week.

- Lawyer 6 also attends one day per week, with Lawyer 3, as the Legal Project Worker

- Most students are at the school from $10 \mathrm{am}$ to $2 \mathrm{pm}$ and the lawyers sit in the common room where the students take breaks.

- Lawyers 3 and 6 are available by phone over the rest of the week, if needed. 


\subsection{Invisible Hurdles' Management}

In Stage II, an 'Advisory Group' was meeting once every 4 to 6 months but during 2020 only managed to meet once due to the COVID-19 pandemic, as each organisation was heavily focussed on the internal stressors of the impact of restrictions that were introduced by the Victorian Government to manage the health and safety of the community. This included lockdowns, border closures and social distancing and limitation on work that led to on-line service delivery for periods of time in 2020 and 2021. The Advisory Group had also not met collectively in 2021 at the time of the evaluation interviews. Each organisation was still settling into the 'new normal' mode of operating, however. For instance, the date of the evaluation visit to Wangaratta was the first date that the NESAY workers had been back in the office.

Members of the committee include the AWAHS CEO, the NESAY CEO, a senior teacher or Principal of WFLC and the HRCLS Invisible Hurdles supervising lawyer or the HRCLS Manager. The authors understand that the Lawyers on the project sometimes attend part of the group meetings as well to provide data, reports and case studies etc. Ideally, future stages of Invisible Hurdles would seek to increase Aboriginal and young persons' representation on the committee or engage other means to feedback these voices to the committee. For example, in 2020, Lawyers 3 and 6 worked with the NESAY Youth Advisory Council on a submission. Such pre-established groups could feed back into the Invisible Hurdles Advisory Committee. 


\section{Methodology for this research evaluation}

\subsection{Summary of the data in this research evaluation}

The following data was considered:

1. The overall aggregated de-identified data routinely collected by the services as to be provided to the Evaluation team by HRCLS for the IH Project. These include:
i. number of clients seen;
ii. the nature and number of client matters;
iii. referrals to and from the services of the IH project (including the date, a brief description and the professional role e.g., nurse and agency);
iv. secondary consultations (including the number, nature of the query, date, a brief description and the professional role and agency);
v. an internal Legal Project Worker report, titled 'Activities, Events and Cups of Tea' by the Project Worker from 31 January - 31 October 2019;
vi. an internal Legal Project Worker report, titled 'Community Development work in a global pandemic' 1 December 2019 - 19 March 2021;
vii. written responses to three reflective questions, from both lawyers and three managers in the project in December 2020/January 2021.
viii. seven case studies

2. A focus group with young people from the WFLC (first week of December 2019)

3. Monthly Guided Professional Journals kept by the lawyers for each project throughout 2019, 2020 and 2021. The lawyer/s used some guiding questions as a framework and reflected on relationship building with and between the three services and young people; trust; barriers; breakthroughs; complexities of clients; and systemic issues (de-identified)

4. A 30-minute interview with 2-3 non-legal professionals from each of the partner agencies, conducted in the week of 2 December 2019 (for an interim evaluation) and on 25 and 26 February (in person), 2 March (by Zoom), and 27 April, 2021 (by Zoom). This gap between the February/March and April evaluations is almost two months. All WFLC interviews were conducted by Zoom on 27 April because the Department of Education and Training Victoria (DETV) paused Ethics approval for research projects due to COVID stressors, not permitting resumption of research activities in schools until April 2021.

5. A 30-minute interview with the current project lawyers conducted in the week of 2 December 2019 (interim evaluation) and on 26 February 2021.

6. A 30-minute interview with managers of the four partner agencies and the HRCLS Supervising Lawyer, conducted in the week of 2 December 2019 (interim evaluation) and on 25 and 26 February 2021. 


\begin{tabular}{|l|l|}
\hline \multicolumn{2}{|c|}{ Number of interviews conducted } \\
\hline December 2019 & February-April 2021 \\
\hline 9 Non-Legal Professionals & 8 Non-Legal Professionals \\
(3 from each partner) & (3 from NESAY, 3 from WFLC, 2 from AWAHS) \\
\hline 5 Managers & 5 Managers \\
(1 from each partner, 2 from HRCLS) & (1 from each partner, 2 from HRCLS) \\
\hline 3 Lawyers & 2 Lawyers \\
(2 Lawyers, 1 Project Worker) & (2 lawyers, 1 who is also the Project Worker) \\
\hline
\end{tabular}

The evaluators estimate that we have taken approximately 22 hours' worth of interviews, across the 2019 and 2021 interviews. We are grateful for the time of all the participants.

\subsection{Research tool applied}

The authors rely upon the HJP Evaluation - Collaboration Measurement of Progress Tool (ECMoPT) and an approach, set of questions and tools designed by Dr Liz Curran, one of the authors of this project. These seek to establish project effectiveness and impacts of the intervention/s. The ECMoPT is based on a VicHealth model (see Final Evaluation Report November 2018 for further details). The tool examines stages that an Integrated Justice Project may move through, towards genuine integration and the tools Dr Curran has designed include further indicators that indicate (or serve as proxies) that if demonstrated as present suggest integration has occurred.

The authors used the data to examine whether indicators of positive service delivery and impact were present. In this, the authors looked for signs of seven key benchmarks (proxies) in particular, that would indicate effectiveness and impact:

- Engagement

- Collaboration

- Capacity

- Empowerment

- Reach

- Reciprocity

\subsection{Ethics}

This research has approval from the ANU Human Research Ethics Committee (Protocol 2016/136). The Department of Education and Training Victoria have also approved this research (Application 2019_004219). The Board of AWAHS has previously approved this research (see Stage I) and the NESAY CEO has been apprised of and approved of all tools utilised and mentioned above and confirmed ethics approval from these agencies for Stage II just before a November field trip.

The researchers throughout Stage II of this project have been consulting with their two Aboriginal Advisers, Judith Ahmat and Catherine Coysh. In October 2019, immediately prior to the field trip in December 2019 (and during the ethics approval process in the same month by each agency and ANU) the authors provided the advisers, with all of the proposed tools. The advisors provided useful feedback not only on interacting with young people in general but also tweaking tools to better gauge and seek input from Aboriginal young people. This help was greatly appreciated and managed to hone the tools better to the participants. In addition, the advisors provided us with a list of the 
names of key independent stakeholders who could be involved in the service aspect of the project and in the community development and policy reform aspects which was passed on to HRCLS.

The authors endeavoured to seek ethics approval integrating the suggestions, of our Aboriginal advisers, into the field trip in December 2019. In view of time constraints, we were unable to implement these the additional suggestions and get the turnaround times for the ethics approval, which could not be expedited, if we adopted the new streams to target Aboriginal participants before the scheduled field trip in December 2019. These timeframes could not be adjusted due to the exigencies of the researchers and project timelines particularly with the interim report due on January 21, 2020, with the intervening Christmas period and students' summer vacation at WFLC.

The authors' view is that this feedback must be incorporated in the design of future research for this project. Although the authors intended to seek ethics approval to incorporate the suggested amendments for the second field trip, the difficulty of Covid 19 restrictions and the challenges of 2020 meant that developing the connections necessary to reach these alternate Aboriginal cohorts in the region was not feasible.

Unfortunately, we were unable to secure focus groups with either the young people at AWAHS or NESAY. Whereas the WFLC young people attend regularly, the NESAY and AWAHS clients attend more sporadically and have different relationships with the staff. This, coupled with their levels of disadvantage, including difficulty with transport and competing priorities mean that it continues to be difficult to draw together ad-hoc focus groups from these NESAY and AWAHS partners. 


\section{COVID-19 in the Hume Riverina}

This project must be contextualised in light of the COVID-19 pandemic. In Australia, governments applied strict restrictions and lock downs in order to suppress and eliminate virus transmission. Although there were very few outbreaks in regional areas, these areas were still subject to strict restrictions that included working from home requirements, and sometimes more severe lockdown rules. This meant that the lawyers were unable to engage with clients and workers in the traditional sense. ${ }^{18}$ Further, because this project is situated on the border of New South Wales and Victoria, there were severe border restrictions in place that prevented New South Wales people from travelling into Victoria for many months, and then vice versa for a period of time. The lawyers became a crucial source of interpretation of these ever-changing rules, but they also had to navigate how to connect with the vulnerable and disadvantaged clients whom they had always been able to arrange to meet, in person.

On top of the changes to work practices and movement restrictions, regional people experienced an influx of city-dwellers seeking to relocate to the country, with work from home rules enabling remote work. The evaluators were told of a young single mother trying to find a rental house and being faced with competing with hundreds of applicants from the city, with higher incomes and longer rental records to their name. The complexity of issues facing regional Victorians during the pandemic cannot be understated.

\subsection{A chronology of restrictions}

\begin{tabular}{|l|l|}
\hline 16 March & \multicolumn{2}{|c|}{ 2020 } \\
\hline 22 March & $\begin{array}{l}\text { The Victorian Government declared a State of Emergency for four weeks to } \\
\text { strengthen measures to 'flatten the curve' and give the Victorian health system its } \\
\text { best chance of managing COVID-19. }\end{array}$ \\
\hline 23 March & $\begin{array}{l}\text { The Victorian Premier announced he would inform the National Cabinet that Victoria } \\
\text { would implement a shutdown of all non-essential activities over 48 hours and that } \\
\text { school holidays would be brought forward, commencing 24 March. }\end{array}$ \\
\hline 25 March & $\begin{array}{l}\text { National lockdown commences including non-essential services and business } \\
\text { shutdown }\end{array}$ \\
\hline 30 March & $\begin{array}{l}\text { The Victorian Premier announced that Stage 2 restrictions would commence in } \\
\text { Victoria from midnight, which included temporary closure of non-essential } \\
\text { services. FIRST LOCKDOWN }\end{array}$ \\
\hline $\begin{array}{l}\text { The Victorian Premier announced that Stage 3 restrictions would } \\
\text { commence which included: } \\
\text { people only being allowed to leave their homes for four reasons: food } \\
\text { and supplies; medical care; exercise; and work or education and } \\
\text { gatherings of no more than two people unless they are members of } \\
\text { an immediate household and it is for work or education. }\end{array}$ \\
\hline
\end{tabular}

\footnotetext{
${ }^{18}$ Liz Curran (2021) 'From Fragmented to Holistic: Starting the evidence base the client centred practice through a navigator.' A report on the research evaluation of the Hammersmith Fulham Law Centre's, 'Women's Crisis Navigator Service Project' Pilot, Curran Consulting: Enhancing Justice and Human Rights (forthcoming on SSRN, June 2021). This report explores service implications on family violence victim survivors of COVID-19 restrictions.
} 


\begin{tabular}{|c|c|}
\hline 7 April & $\begin{array}{l}\text { The Victorian Government announced all Victorian government primary, secondary } \\
\text { and special schools would move to remote and flexible learning and teaching for Term } \\
2 \text {. }\end{array}$ \\
\hline 12 April & $\begin{array}{l}\text { The Victorian Premier announced that the State of Emergency for Victoria would be } \\
\text { extended by an additional four weeks, until midnight } 11 \text { May } 2020\end{array}$ \\
\hline 11 May & $\begin{array}{l}\text { The Victorian Premier announced some easing of restrictions. } \\
\text { State of Emergency for Victoria extended for another } 4 \text { weeks, }\end{array}$ \\
\hline 11 June & $\begin{array}{l}\text { The Victorian Government announced that learner permit and driver licence testing } \\
\text { would progressively resume, with more than } 200 \text { new staff hired to assist with } \\
\text { appointments postponed due to coronavirus restrictions. }\end{array}$ \\
\hline 20 June & $\begin{array}{l}\text { The Victorian Government re-tightened restrictions due to COVID clusters arising from } \\
\text { breach of hotel quarantine }\end{array}$ \\
\hline 21 June & $\begin{array}{l}\text { The Victorian Minister for Health announced that the State of Emergency for Victoria } \\
\text { would be extended by another four weeks until } 19 \text { July } 2020\end{array}$ \\
\hline 25 June & $\begin{array}{l}\text { Following an increase in cases, the Victorian Premier issued a statement on the } \\
\text { commencement of a Suburban Testing Blitz, }\end{array}$ \\
\hline 28 June & $\begin{array}{l}\text { The Victorian Premier announced mandatory testing for all returned travellers in hotel } \\
\text { quarantine. }\end{array}$ \\
\hline 30 June & $\begin{array}{l}\text { The Premier announced a return to tougher restrictions including a return to stage } 3 \\
\text { across } 10 \text { different Melbourne postcodes }\end{array}$ \\
\hline 4 July & $\begin{array}{l}\text { Two additional postcodes added to Melbourne lockdown, along with } 9 \text { public housing } \\
\text { towers }\end{array}$ \\
\hline 6 July & NSW state Governments announced border would be closed from the start of 8 July \\
\hline 7 July & $\begin{array}{l}\text { metropolitan Melbourne and the Shire of Mitchell re-entered lockdown from 12am on } \\
9 \text { July, for } 6 \text { weeks. SECOND LOCKDOWN }\end{array}$ \\
\hline 8 July & NSW/Victorian border closed at 12:01am \\
\hline 19 July & State of Emergency for Victoria extended for another 4 weeks to 16 August \\
\hline \multicolumn{2}{|c|}{$\begin{array}{l}\text { There were } 18 \text { Border Control Public Health Orders between July and October that had to be read and } \\
\text { understood in the context of the broader NSW Public Health Orders and the } 78 \text { Victorian } \\
\text { Directions/Orders that were made between March and November. } \\
\text { To give you an idea of the frequency of the changes, the first Border Control PHO came into effect on the } \\
8^{\text {th }} \text { July. The next one came in on the } 22^{\text {nd }} \text { July and then the } 24^{\text {th }} \text { July and then the } 25^{\text {th }} \text { July. And then in } \\
\text { August there were more changes }-7^{\text {th }} \text { August, } 10^{\text {th }} \text { August, } 13^{\text {th }} \text { August, } 17^{\text {th }} \text { August, } 18^{\text {th }} \text { August and so on } \\
\text { and so on. }\end{array}$} \\
\hline 2 August & $\begin{array}{l}\text { A state of disaster was declared and metropolitan Melbourne was moved to Stage } 4 \\
\text { restrictions, including the imposition of restrictions such as nightly curfew, mandatory } \\
\text { face coverings in public and closing of schools and businesses. } \\
\text { Regional Victoria moved to stage } 3 \text { restrictions. }\end{array}$ \\
\hline 6 September & $\begin{array}{l}\text { The "Roadmap for Reopening" was announced "COVID Normal" which would begin on } \\
13 \text { September. At the same time, it was announced that regional Victoria would move } \\
\text { to the "Second Step", which included a staged return of students to onsite learning as } \\
\text { well as the reopening of outdoor public pools and further increases to limits for } \\
\text { weddings, funerals and religious gatherings. }\end{array}$ \\
\hline 25 September & Regional Victoria could travel to other parts of state except Melbourne \\
\hline 27 September & restrictions there were loosened: the night-time curfew ended the next day \\
\hline 11 October & $\begin{array}{l}\text { Victoria's State of Emergency and State of Disaster were extended until } 11.59 \mathrm{pm} \text { on } 8 \\
\text { November }\end{array}$ \\
\hline 18 October & $\begin{array}{l}\text { Regional Victoria was moved to "Step Three", which included the reopening of most } \\
\text { businesses to the public, increased seating for hospitality, the allowance of visitors for } \\
\text { all residents and the resumption of some indoor sports. }\end{array}$ \\
\hline
\end{tabular}




\begin{tabular}{|c|c|}
\hline $\begin{array}{l}\text { With a length } \\
\text { wide, as of Oc }\end{array}$ & $\begin{array}{l}12 \text { days, Victoria's second lockdown was the longest continuous lockdown } \\
\text { ar } 2020\end{array}$ \\
\hline 26 October & The "second wave" ended \\
\hline 23 November & NSW/Victorian border reopened \\
\hline 19 December & Northern Beaches in NSW went into lockdown \\
\hline & 2021 \\
\hline 1 January & Victoria closed it border to NSW \\
\hline 30 January & Victoria opened the border to NSW \\
\hline 3 February & Victoria immediately reintroduced some rules \\
\hline 12 February & $\begin{array}{l}\text { five-day lockdown under Stage } 4 \text { restrictions would take effect beginning at } \\
\text { 11:59 p.m. THIRD LOCKDOWN }\end{array}$ \\
\hline 17 February & lockdown was lifted as anticipated at 11:59pm \\
\hline
\end{tabular}

There has since been a fourth lockdown, which is outside the evaluation period of data collected, announced by the Victorian State Acting Premier, James Merlino, which commenced at midnight on Thursday 27 May 2021 and was lifted with some ongoing restrictions (which for example, limit attendance at WFLC) for regional Victoria after seven days.

\subsection{The impact of restrictions}

This reflection from Lawyer 6 describes the practical effect of the above restrictions. Many of these things were accessible to people in Melbourne but not in Wodonga, for example, due to the border closures. Students were unable to cross for school in some cases, in others they couldn't visit unwell family. For many, the restrictions caused anxiety, stress and confusion.

\section{It meant you couldn't...}

'The impact of the two border closures on the local community was very significant; a 10 minute drive across the border turned into 90 minutes. A survey undertook by HRCLS a few years prior indicated that for the $47 \%$ of the survey participated crossed the border between Albury and Wodonga more than seven times a week and over $14 \%$ said they did so more than 16 times a week.

The result was that many of our clients were just too afraid to try to cross the border. Kids living in NSW were unable to get to school in Victoria because it was "too hard" for their parents or carers to take them across the border. At various times, it meant kids in Victoria (including those doing HSC) not being able to cross the border to go to school in NSW. It meant doctors and other health professionals and teachers not able to get to work or provide much needed services. It meant family members being told their gravely ill family member was not "terminal enough" for them to get a permit to visit them (they had to be facing death within the next 7 days - and yes, police were door knocking to check). It meant an intellectually disabled man being removed from a bus by police because he didn't have the "right" permit. It meant bushfire recovery workers not able to visit bushfire areas because they were outside the bubble. It meant people in Wodonga not being able to access Centrelink or Medicare offices (which are in Albury). It meant people on the Victorian side couldn't go fishing or boating in the Murray River (as the river is in technically NSW and you would need a permit to access).'

- Legal Project Worker's report 2021 page 7. 
These reflections describe restrictions imposed on the school by the Department of Education and Training and the difficulty of the foreign technology for vulnerable young people who usually do not even have access to a computer.

\section{Two teachers in every virtual room}

'You couldn't just have one teacher in the [virtual] room. Sometimes you couldn't get two teachers, so we had to rely on Tina, our admin staff, to be there in the background...

A lot of those conversations [of a private nature] had to happen on the phone because you can't have another person on the phone, and then it would be passed on through to [Lawyer 3] and [Lawyer 6] that way. So, there were all these hurdles that the kids had to jump through before they could even talk to us, because of COVID. Then there was the time that we were rostered to come in face to face.... I chose to come in face to face and I had nearly $100 \%$ attendance on the days that I came in, because this was another reason, they needed connection. And through all of this [Lawyer 6] and [Lawyer 3] continued to do their [work].'

- Staff 2021

\section{The technology was sprung on these kids}

'COVID has been difficult for everyone but vulnerable students who see school as their safe space and when that was not available, all the time, a lot of things happened to these people and in particular that safe space was no longer a trusted space because we weren't open all the time. So, it meant that [Lawyer 6] and [Lawyer 3] had to rely on phone consultations for some of the issues that arose. It meant that sometimes they had to do things via Zoom as well.

When you take into account the situations of our students, technology was not something that they had access to at their homes. It wasn't until the Government brought in the laptop scheme in about April/May last year, they also brought in dongles as well because a lot of these kids don't have internet. Also, the technology was sprung on these kids. Not many kids knew how to use Zoom or MS Teams so that was another thing that they had to adapt to. At first we were using Zoom and then we were told that the Education Department doesn't want us using Zoom. We switched to using Teams. We were told Zoom is not an option. Then we had to [web conference] students with another adult on the line too. So, there's that legal thing in the background. You couldn't just have one teacher and the students in the room.'

- Staff 2021

There were consequences too, for young people unable to attend school where they usually are supported by teachers, who are often parent figures for young people living in out-of-home care. These consequences were serious, including multiple pregnancies, STIs, relationships outside the age of consent, suicide attempts, domestic violence, and sexting. The data revealed that the stress of the border restrictions was extremely high for young people local to the area, leading them to act dangerously, for example, by hiding in the boot of a car, as described below. 
Below, we have included a series of quotes which tell the story about the region's COVID experience. The stories speak for themselves in describing the traumatic time.

\section{Pregnancy}

\section{Lockdown babies}

'I have two students in the same situation, both having lockdown babies and they're babies themselves. We're talking about a 16-year-old who's in the DHS system. DHS have let them down, they got pregnant on their watch. And now their babies have been removed from them too. It's all about that cycle. We want that cycle to be broken but unfortunately with COVID last year, we saw probably an increase [in teen pregnancy].'

- Staff 2021

\section{"The pregnancy factor"}

'The pregnancy factor happened three times with my students.

- Staff 2021

\section{The age of consent}

\section{It just gets bigger and bigger}

'One of these teen pregnancies, the father is 18 and the mother was 15 when she fell pregnant. This is happening on DHS's watch, and they knew about it.... We've gone over and over the age of consent [at school]. They've given so many examples of what's okay and what's not okay. But during lockdown, we couldn't control who was having sex with who.

And unfortunately, we do have a high incidence of STIs here in Wodonga too. So, then you've got to get the school nurse in too or they've got to go down to Gateway Health and have a test, so it gets bigger, and bigger, and bigger. So COVID really did do a few things last year, where some things did get out of control. But the [legal] advice was always given, and it was clearly given and advice was sought if it was needed.'

- Staff 2021

\section{Mental Health}

\section{Permits and police}

'We had a lot of suicide attempts where, touch wood and thank god they didn't go through with it. But there was a lot of mental health issues last year. I put it down to the isolation factor, the lockdown, here in Victoria we had the border closures as well. We had New South Wales locking out Victoria and then earlier in this year we had Victoria locking out New South Wales. There was a lot 
happening because these kids are border kids. Some of our kids live in Albury. Most of them live in Wodonga or in the outskirts. So not only were they dealing with the COVID stuff, but they were also being locked out of their own communities or having to go through a very big border closure.

[Lawyer 3 and [Lawyer 6] were really great with interpreting the law for teachers as well, when that happened.... Some of these kids were very confused about how they could go to Albury... Sometimes police were targeting kids and not all of our kids can get across the border in a car. So, some of them road their bikes or walked and there was a really big interaction. There's the bridge between Albury and Wodonga and there's a walking track and a bike track right next to the cars. So, if you were walking or riding, you had to go through a tent with two police officers. So that in itself is intimidating to our students. Just that feeling of 'what if'.

I even took an excursion over there and I didn't realise that one of my kids' permits had expired by one day. So, then we were hauled off onto the side of the street while I had to explain with a bus full of kids why. And then I got flustered too, I was like 'Oh I thought you told me it was up to date?' because I had 12 permits, I had to [think about] and they felt awful. They were fine but then I had to go and apply for another permit for this kid, on the spot.

It was stressful. So sometimes, their mental health wasn't probably as good.

We had kids hiding in boots to get across to Albury. Boots of cars. Because not everyone could access a permit. You had to either have a phone to show your permit or you had to have a printed copy and like I said, some of our kids don't always have a phone and don't have access to a printer unless they can come to school and print it off. So, there was a lot of uncertainty for these kids.

There were four reasons to leave home, so there was a lot of confusion and a lot of uncertainty. [Lawyer 3] and [Lawyer 6] would constantly remind us as staff, and we're all capable adults, but every staff meeting [Lawyer 3] and [Lawyer 6] would jump on and say 'Okay, so the rules have changed this week, blah, blah, blah, blah blah'.

It was a compromising situation for us as staff and so I can only imagine how the kids felt.'

- Staff 2021 


\section{Domestic Violence}

\section{Domestic violence and food parcels}

'Domestic violence - I didn't see as much physical, but I saw lots of emotional, psychological abuse. There was a lot of uncertainty about food security as well. That spiked a bit. We were doing lots and lots of food parcels for families. You know, the toilet paper crisis hit poor people as well so not just affluent people who could source it. There was a lot of uncertainty there.'

- Staff 2021

\section{Sexting}

\section{What's appropriate}

'I think the fact that [Lawyer 6] and [Lawyer 3] were able to just be there for people to chat to [was good] because sometimes we also look at things such as sexting and there was a lot of inappropriate sexting. So, they had to come in and basically give a talk on what's appropriate, which then led to what we've been discussing this year with consent. That's quite a topical issue. We've had one of the police officers from Wodonga police station come in as well and give some information and talks on consent. Just last week it was so topical, we talked about the milkshake video.' 


\section{Examination of data}

\subsection{Summary}

In Stage II, in contrast to the first year of the project in Stage I, there has been a continuity of staff with the two lawyers remaining in their lawyer roles. This has contributed to the seamless and continuous service delivery, and to the relationships being built with staff and clients.

This suggests that the ongoing nature of the project, the relationships established and the awareness and visibility of the project and its staff and their availability to help is increasing. This is enabling this project to continue to gain traction and to reach more young people than previously would have been the case, without the Invisible Hurdles Project.

As well, the lawyers in the Invisible Hurdles team have worked closely together to deliver some outstanding Community Legal Education programs, to co-ordinate systemic work that gives voice to young people and to become a 'go-to' source of legal help for many young people. They have shown persistence in solving the legal problems that the young people bring to them and are to be commended for their efforts during the 2020 restrictions, which showed how committed the team is to integrated justice practice.

The authors note, as indicated in the final report in 2019, that given the stigma, shame, embarrassment, the lack of empowerment and knowledge as well as concern about safety that surrounds victims of family violence, it is unlikely that the young people will present without encouragement, trust or a feeling of safety. This can take time.

We know from the demographic information on young people in this rural and regional areas, that there is a high likelihood that this young people experience family violence in some form. It is therefore unlikely that young people will present with a family violence problem without some encouragement and will only do so over time when trust and a 'safe space' exist.

Through integration, the young people are able to access services in their safe spaces and the lawyers are able to slot in alongside their regular caseworkers/teachers/health professionals, so that introductions are seamless and trust is transferrable. The partners have achieved great leaps in this respect.

\section{Having a safe space opens doors}

'They're getting support to be able to get this access from a safe space. If they have to go out and get it themselves, who knows what the other support is that they may or may not have. Having it at this space, definitely helps open up more doors for them.'

Staff 2021 


\subsubsection{Summary analysis of referrals, advices, and secondary consultations data}

This aggregated data around secondary consultations, referrals and advice provided, is indicative that the service has been able to sustain itself and keep reaching its clients and the service providers in the three agencies in a fairly consistent manner despite the interruptions during COVID-19 and the lockdowns. When examined in light of some of the staff qualitative data such as the professional journals and staff reports this data is explained by the pre-existing relationships that had already been established with the staff of the three agencies, and strong relationships between the management of the four partners.

\section{Relationships kept going}

'There's been so many lockdowns and border crossing issues, that just to keep the relationships going was in itself an achievement.'

- HRCLS staff, 2021

As the project had been ongoing for some time, relationships of trust and referral pathways were already in existence. The HRCLS team's preparedness to find new ways of working around the lockdowns and the restrictions of each of the partners and staff that had been built up in the lead up to the pandemic meant that not only were the services able to be delivered consistently despite the difficulties, it was able to be sustained and, on occasion, even increased.

\subsection{Referrals}

\subsubsection{Referral quantitative data}

\section{Total Across the three Partners (FC, NESAY \& AWAHS) $=\mathbf{5 3 4}$}

46 for Jan 2021 - Feb 2021

225 for Jan 2020 - Dec 2020

263 for Jan 2019 - Dec 2019

The referral numbers for the period of January- December 2019 were higher than for the period of January to December 2020 and quite high for the two-month period January to February 2021. The timeline around border closures and restrictions imposed considerable difficulty for service delivery alongside uncertainty. The need to find workarounds to reach and support clients and non-legal support staff of the three partner agencies, saw a slight dip in referrals in 2020. This decline is less than would ordinarily be expected given such service disruptions. The fact that the referral flow was still relatively high and consistent is suggestive of effective referral pathways and workarounds to manage the COVID-19 challenges. 


\section{Investment of time and resources has been worthwhile}

'The strength of the IH project has been seen particularly during COVID-19 with lockdowns, office closures and border closures. Despite having to offer services remotely, the relationships between our lawyers/project worker and the staff at each of the partner agencies has become so strong over the years that we were still getting client referrals throughout 2020 and did not appear to lose too much engagement with the partners and their communities. As a manager this reassures me that the investment of time and resources into this Project has been worthwhile. Credit should be given to the Lawyer and Project Worker who worked hard during this time to stay connected with the partners and the clients.'

- Manager 2021 reflection

\subsubsection{Referral process}

Interview data reveals that the referral process is clear, there is a high level of mutual trust and understanding and that non-legal professionals have confidence in the referral process. This is a slight increase from the end-2019 Interim evaluation data. It suggests improved collaboration among the organisations. This is a credit to the HRCLS team in keeping relationships strong during the COVID-19 restrictions. (2019 data available in Appendix 5).

\begin{tabular}{|c|c|c|c|}
\hline \multicolumn{4}{|c|}{$\begin{array}{l}\text { Non-legal professionals: Referral process } \\
\qquad \text { (2021) }\end{array}$} \\
\hline \multirow[t]{2}{*}{$\begin{array}{r}100 \% \\
90 \% \\
80 \% \\
70 \% \\
60 \% \\
50 \% \\
40 \% \\
30 \% \\
20 \% \\
10 \% \\
0 \%\end{array}$} & \multirow[b]{2}{*}{$\begin{array}{l}\text { Can confidently and } \\
\text { positively refer }\end{array}$} & & D \\
\hline & & $\begin{array}{l}\text { Referral process to and } \\
\text { from is clearly } \\
\text { understood }\end{array}$ & $\begin{array}{l}\text { High level of mutual } \\
\text { understanding and trust } \\
\text { between IH and you }\end{array}$ \\
\hline - Strongly Disagree & $0.00 \%$ & $0.00 \%$ & $0.00 \%$ \\
\hline Disagree & $0.00 \%$ & $0.00 \%$ & $0.00 \%$ \\
\hline Neutral & $0.00 \%$ & $0.00 \%$ & $0.00 \%$ \\
\hline$\square$ Agree & $0.00 \%$ & $12.50 \%$ & $0.00 \%$ \\
\hline Wtrongly Agree & $100.00 \%$ & $87.50 \%$ & $100.00 \%$ \\
\hline N/A & $0.00 \%$ & $0.00 \%$ & $0.00 \%$ \\
\hline
\end{tabular}




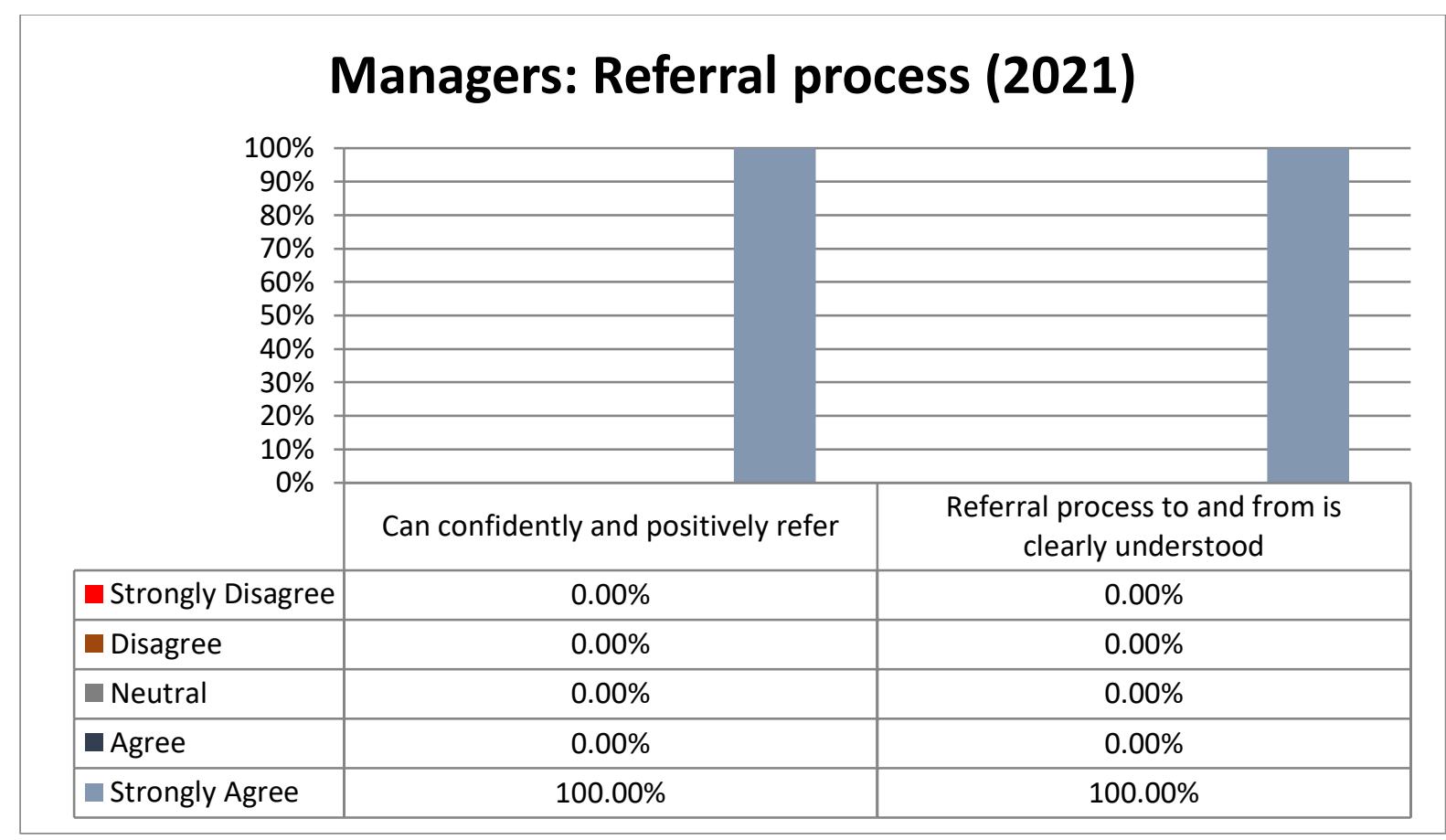

Interviewees at both the Interim and the Final evaluation visits repeatedly said that the referral process is easy. The reason that they report it is so easy, is clearly because it is informal. For example, it was noted that there are no time-consuming forms to fill out. Ordinarily, the process is simply a quick phone call or discussion with the lawyer, who then books the client in. At AWAHS, until lockdown, the process was that the front desk managed appointment times for the lawyer. This continued during lockdown as AWAHS was working remotely and appointments were made and provided by phone) but again this was profoundly simple. This may seem simple, but it is actually critical to the success of the project. The referral process must be uncomplicated and the HRCLS team have always acknowledged this by never seeking to impose formal structures on the referral process, which could frustrate access to legal help. The below case study illustrates the simplicity of the referral process and the benefits that flowed from such a simple interaction at the start.

\section{Teacher, project worker, lawyer, young person: working together}

A teacher came up to me and said this student had been banned from a local plaza. I met with this student who told me what happened. He had been disruptive in the plaza and annoying the security guards and shop owners. The security guards said if you keep doing this you are going to have to leave. He did it. Called the police, had a bad interaction with the police. A week later... he was banned for twelve months... I had a talk to him about what this meant. And he actually then realized that "I can't go there. I was about to go for a job interview at [the centre], ... I got banned. I can't go there. That's where my grandma and I have coffee. It's up the road from my house." He said I just didn't realize the impact. So, I called their manager and the manager said if he writes or comes in, writes a letter of apology or comes in and talks to me, I'll lift it. So, I went back and said to the young person this is the offer. And him and a teacher actually worked on the apology together. He wrote it from his words... He wrote it and the teacher went with him to the plaza and [the student] read it. 
But in between that, I was actually sick one day and I asked [the Project Worker] to check in with him to see how he was going. And [the Project Worker] and him had a chat and he was really nervous about giving that. And [the Project Worker] did a mock interview with him. And just took him through it as if she was the guy and talked him about appearance, eye contact, ran through the mock interview. And we caught up with him a week later after the interview and you should have just seen a smile on his face and even the teacher... She was just like "You empowered him to do it himself"... This is the Invisible Hurdles project. Then and there, working with the professional who brought the young person in. I could have written it for him. I could have gone to bat for him. But then I was like, no.

- Lawyer 2019

\section{Self-identifying requests for referral}

'There's a student who is under-aged and basically has told me about a sexual encounter that was not wanted and it was the age difference again. And she basically said 'I think I need to talk to the lawyer'. So they came to me and said 'I need [the lawyers'] number.'

Staff 2021

\subsection{Advice and casework}

\subsubsection{Advice quantitative data}

Total Across the three Partners (FC, NESAY \& AWAHS) $=339$

15 for Jan - Feb 2021

148 for Jan 2020 - Dec 2020

176 for Jan 2019 - Dec 2019

Although the number of advices offered in the period of January to December 2020 dipped, as noted above, it did not decline significantly in light of the COVID-19 pandemic and the need to recalibrate services and find new ways of working. The numbers of advices for a small service with a relatively small legal team working on this project are high, especially given the hard to reach client group of young people that this project is seeking to assist. This includes the multiple and complex problems that often cascade and intersect, that the service is assisting clients with. This is highlighted in the discussion of the nature of client problems that the young people across the three agencies present with. 


\subsubsection{Skills and knowledge}

The lawyers need to be across a very large array of laws. They need good general knowledge of the law and problem solving skills. The below quote demonstrates that the non-legal professionals in the project recognise this challenge and appreciate the lawyers' skillsets.

\section{Skilled: as big as the rights of the unborn child}

'Invisible Hurdles has been very important to me as a teacher, but extremely important to some of my vulnerable students. For example, it could be something as minor as a birth certificate that the lawyers have been able to assist or it could be something as big as the rights of the unborn child with a student who's about to have a baby, who is in the DHS system. So the fact that both Lawyer 3 and Lawyer 6 have been able to help and advise these students and me as their teacher, it's been absolutely wonderful.'

- Staff 2021

Numerous breakthroughs happened in this project. These ranged in size from wiping the debt of a young person not wearing a bike helmet to successfully receiving a birth certificate. Birth Certificates are a very common issue for the clients of the Invisible Hurdles program and with multiple stories about them appearing in and across the data.

One such instance of successfully acquiring a birth certificate for the young person meant that the young person could get a job. In other cases, it enabled them to receive Centrelink benefits for the first time, to apply for a bank account and to have photo ID.

\section{It enables her to break the cycle of poverty}

'[The lawyer's work] enables her to go to TAFE, to get a job, it enables her to break the cycle of poverty that she's currently living in and re-create a different pathway for herself. The mental health benefits and the physical health benefits potentially for her will be massive.'

- Staff 2021

A common problem that the lawyers assist with is debt that cannot be repaid. Debts cause stress and anxiety, and can inhibit a young person's ability to move forward. The Invisible Hurdles lawyers' abilities to address these worries and increase understanding makes an enormous difference in the lives of their clients.

\section{$\$ 11,000$ debt waived and a relationship of trust built}

Ellie was referred to the HRCLS by a worker from a local youth support agency. Ellie was receiving support from the youth agency in order to stabilise her living situation, reduce her risk of 
homelessness and improve her level of engagement with work and participating in the local community.

Ellie was referred to HRCLS as her case practitioner identified that she had a significant debt that was in her name and it was impacting on her ability to be financially secure and seeking gainful employment. Ellie also suffered from and brain injury and several mental health disorders.

Ellie's legal issue arose when her boyfriend, Greg, compelled Ellie into applying for a $\$ 8000$ loan with a bank. Once Ellie got the money, Greg took majority of the money from her used it for his own benefit. Not long after, Ellie lost her job and Greg started being both physically and emotional violence towards Ellie. They eventually broke up and Ellie returned home to live with her mother. Unfortunately, Ellie's mother suffers from alcoholism and perpetrated family violence against Ellie. Ellie was forced to flee her mother's home in order to avoid any further physical abuse, which resulted in her becoming transient and homeless.

By the time Ellie was referred to the HRCLS, the debt had arisen to over $\$ 11,000$.

HRCLS wrote to the bank and made several compelling arguments on the basis that the loan was unsuitable, a potential irresponsible lending claim, that she did not receive any benefit from the contract, that she was the victim of family violence and she had exceptional circumstances. The bank eventually agreed to waive the debt.

Throughout the time Ellie worked with HRCLS, the lawyer also offered to provide advice to Ellie on victim's compensation arising from the family violence she experienced. Ellie was not ready to discuss this with the HRCLS.

Several months after the HRCLS closed Ellie's file, Ellie contacted the HRCLS herself and was ready to talk about what family violence she experienced and discuss any potential legal options or solutions. Ellie had expressed that when this was raised with her initially, she was not ready to talk about it but that the offer by HRCLS to talk about it when she was ready was at the back of her mind and she felt she was in the right place to do it now. Ellie has chosen not to proceed with any potential action, but she appreciated being told what legal avenues were available to her.

- Case study provided to evaluators by Invisible Hurdles

\section{A $\$ 3000$ debt and she couldn't pay it}

'I've had one student that has a learning difficulty that owed like $\$ 3000$ for child-care placement for her child. The child got taken off her and yet the child was still going to the day care centre. And she hadn't filled out the paperwork and so she got this massive debt at the end of it. Of course, she couldn't pay it. That was [Lawyer 3] who sorted that one out.'

- Staff 2021 


\subsubsection{Relatable}

The evaluators found a common theme of the success of this project has been in the style of the lawyers. It is clear that a successful youth project needs the right lawyers. Hiring is as much about legal skill as it is about personality, if not more so. Readers are referred to the detail in the Final Evaluation Report from Stage 1.

\section{Down to earth: It's not all lawyers and suits on TV}

'There's so many stories about how its helped change their (young people) views of what a lawyer can do and that it can be a positive experience of the law. The way that [the lawyers] at the school, they're friendly and approachable, and [Lawyer 6] is funny. And it seems that young people haven't had that experience of a lawyer or even a legal system before. So, it means they're more confident to get legal support in the future. It's not all lawyers and suits on TV. It's like well there's actually a service that's down to earth and approachable and actually here to help make things better for you, rather than judge you.

One particular story from the Flexible Learning Centre where it's so transformational to a particular young person and their journey in not being caught up in the justice system but actually being able to contribute as a person. And they say that was because of the Invisible Hurdles Project, largely.'

- Staff, 2021

\section{A mirror to the profession?}

'I hear [young people say] "you're a different lawyer to what I know." Taking that step back, it's like 'Geez, lawyers must have bad rep. It's trying to turn that around and say well there are different lawyers... they may have their own limitations as well.' 


\subsubsection{Responsive}

All participants said that the lawyers were responsive to client need.
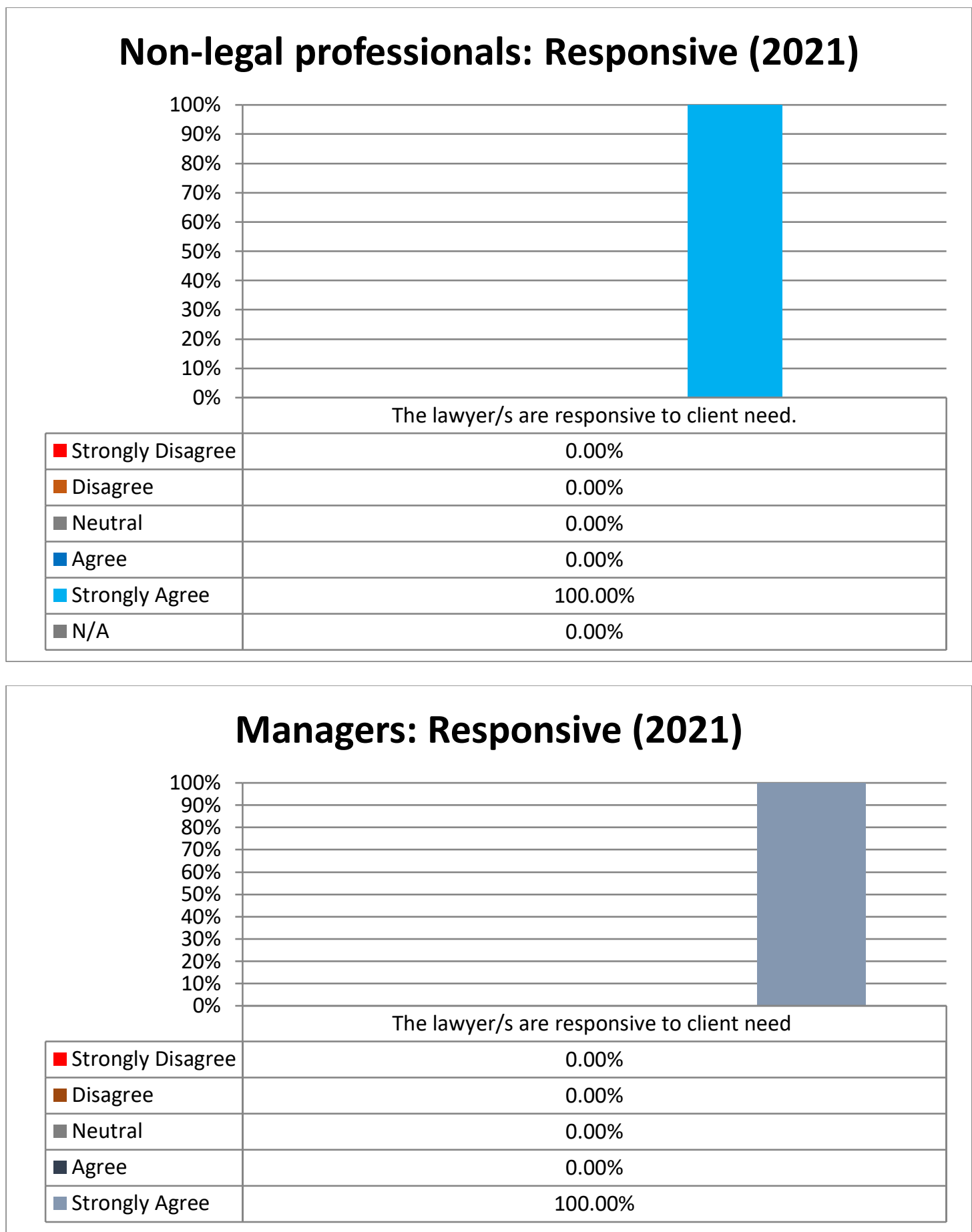

This responsiveness develops trust. The data suggests that many young people now felt confident enough to access the lawyers directly, for example by calling them or making a booking. Further, there is evidence that these young people who might not have previously consulted a lawyer, do so after they have seen the Invisible Hurdles lawyers. For example, the case below illustrates a young person who initially accessed Invisible Hurdles through the partner agency, no longer sees that agency and chose to access the service completely independently. 


\section{She saved my number!}

'I had one girl that I worked on a few matters for about a year and she called me out of the blue, she wanted to be an Uber Eats driver and she said 'Oh you helped me last time and I knew that you'd have the answer'... She saved my mobile number in her phone. She made the effort to keep my details.'

- Lawyer 2021

\subsubsection{Visible and reliable}

Although COVID-19 restrictions meant that the lawyers were unable to be physically present for much of the time, this remains a critical aspect of effective integrated justice practice. At WFLC this means that the lawyers are present in the general lunch room through much of the day if they are not working with or meeting with students. They might also, for example, be visiting a class. One of the lawyer's journal entries mentions, for example, that she attended a cooking class with the students which helps to build connections because they are not working on legal issues and are able to show personality and build rapport.

\section{Where a young person felt comfortable to talk to me and ask me questions}

I was just walking around the school moving from classroom to classroom (as I do most weeks) and student sitting on their own doing some work. I sat down and said 'hi' and the student just started talking to me about various things. Topics ranged from age of consent (having sex), how to get consent from potential sexual partner and ensure the age of sexual partner is correct, how Police prove physical assaults at the court, how to vote and the different platforms for all of the different political parties- we ended up doing the ABC website which determines 'your voting allegiance' based on a number of questions. This student said that he liked to be aware of and increase he knowledge in a range of different topics so that he can converse with different people. Was interesting to see what questions he posed and where his interests lay- felt like a breakthrough in where a YP felt comfortable to talk to me and wanted to ask questions and learn about things (increasing their capacity)

- Lawyer Guided Journal May 2019

Physical presence enhances access to justice. For Aboriginal people in particular, it is respectful to go to the place that they trust.

\section{A social connector}

'The service had to be provided here for the 'social connector'. Having the lawyer on site and use the facilities, already a barrier is broken down. [For clients they think] "You're there, in a place I feel comfortable enough to come." It shows that the organisation trusts that person. If we [clients] trust that organisation, then an element of trust is transferred... It provides equity for the community. Having someone attend here, people are more likely to want to come.' 
For young people generally, too, the service must be in the place where they regularly visit, as evidenced here:

\section{Without them coming regularly, she wouldn't have sought legal advice}

'I've had a young person mention that the mediation that one of the lawyers was able to organise with the father of her child was really beneficial, because she just didn't know how to go about it. And without them coming in regularly, she told me, she would never have sought legal advice.'

Staff 2021

This reliability was echoed by a leader of Invisible Hurdles at one of the agencies who observed that even though the organisation experienced changes in management some teaching staff, the Invisible Hurdles team were constant and reliable. This is one of the benefits of a partnership model, where the internal management issues do not fully affect the services of the integrating partner.

\section{Stability}

'There's probably been three years of instability [in leadership in the agency]... and I think that's why the Invisible Hurdles program has been so valuable on top of its value within itself... [Lawyer 3] and [Lawyer 6] have been consistent and reliable and they've built good relationships with the young people throughout their years here. We've even had [staff] come and go through this time.'

- Manager 2021

One barrier to attending AWAHS, and therefore to meeting the lawyer, is transport. AWAHS offers pro bono transport to all clients and patients who have an appointment on the day. The transport drivers are usually Aboriginal people themselves; which ensures the service is culturally safe. This was obviously affected by COVID and didn't happen when AWHAS and Lawyer 6 were working remotely. The AWAHS offices are not centrally located to Albury which means that if clients do not have private transport, they must rely on public transport to get there. The suggestion from an interview participant below is that to be more accessible, transport needs to be offered within the Invisible Hurdles program. Other AWAHS programs provide transportation to and from the centre and this could be explored more with the AWAHS management.

\section{Transport is a barrier}

'Yeah, I think transport is a big barrier for a lot of people. So if they can't get there then they're not going to come. Whereas if you're like 'well we can offer this or this, then they are more likely to say 'well I can get there'.'

- Staff 2021 


\subsubsection{Committed and patient}

It should also be acknowledged that providing seamless service delivery during the COVID-19 Pandemic was not easy for the lawyers. They have their own families and the pandemic restrictions affected the staff too. They were separated from their families on the other side of the border. The success of this project is underscored when considered in this light.

\section{Organised, committed, patient}

'And finally, on top of all this is your personal challenges, of working from home, to balancing family responsibilities with work commitments, dealing with technological issues and your own COVID-19 stress. All-in-all, we have survived 2020 and achieved some great leaps in the IH project'

- Lawyer, January 2021 reflections

\subsubsection{Team players}

The evaluators observed that another factor that drove the success was the teamwork that happened between the legal staff, as well as between organisations. In one of the author's recent research such collaboration was also found to generate passion and energy for the work. ${ }^{19}$ It is evident that there is a high level of trust and respect between staff.

\section{Another person to share the load}

'Having the project worker - another person to lean on, another person to share the load with, to make it fun, to make it engaging.'

- Lawyer 2021

\subsection{Secondary Consultations}

\subsubsection{Secondary Consultations quantitative data}

Total Across the three Partners (FC, NESAY \& AWAHS) $=\mathbf{2 7 3}$

32 for 1 Jan- Feb 2021 (21 AWAHS), 7 NESAY, 4 WFLC)

185 for 1 Jan - Dec 2020 (65 AWAHS, 87 NESAY, 34 WFLC)

56 for 1 Jan - Dec 2019 (across all 3 partners)

There appears to have been a substantial increase in secondary consultations as between 2019 and 2020. The interim report revealed 47 secondary consultations. This could be for two reasons; the first is the move to largely online service delivery due to the COVID-19 pandemic, or (as acknowledged in the qualitative data collected by the staff of the legal service), it could be as a result of their changing their practice in how they count secondary consultation as a result of interim ${ }^{19}$ Liz Curran 'Getting out of Debt: The Road to Recovery for Victim Survivors of Family Violence' ANU for
Consumer Action Law Centre (January 2020). Available at SSRN: https://ssrn.com/abstract=3512672 
report recommendations, in February 2020. The Stage 1 Final report revealed similar figures of 288 in the 12 months preceding the final evaluation visit. ${ }^{20}$

In the interim report for Stage 2, it was noted that the staff were not applying the correct definition of secondary consultations ${ }^{21}$ to their work or characterising their work correctly in line with that definition and accordingly were not collecting the data appropriately or consistently. In looking at the actual secondary consultation data collected it and the qualitative data around practice contained in the professional journals and the staff reports, it is evident that staff took on board the suggestions and were more consistent in 2020 and 2021 in both applying the definition of secondary consultations to their work. Also the staff were more consistent in recording the secondary consultation data than in Stage I and in 2019 prior to the publication of the interim report. This also has the consequence of aligning the lawyers' definition of secondary consultation with that of the non-legal professionals. In the Stage I Final Report it was noted the lawyers' narrow definition of secondary consultations had led to the underreporting of secondary consultations in Stage I.

The data on secondary consultations does not reflect a large number of secondary consultations that were delivered through online service delivery. This occurred during the various restrictions on lockdowns particularly the work done with NESAY, where the staff introduced innovative ways of delivering professional development for instance through the 'Cuppa Dates'. It is also important to acknowledge that secondary consultations at each of the partners may have been more limited, for example, not being able to quickly pull the lawyers aside with a question in the office. Border closures, restrictions, school closures and remote working all limited access to young people and staff far more than would otherwise be the case facility pre-COVID.

Despite this there did not appear to be a reduction in the number of secondary consultations in the period of the COVID-19 pandemic, however this needs to be regulated by the likely underreporting of secondary consultations in 2019, noted above. Nonetheless, this absence of a reduction in secondary consultations during the pandemic is counterbalanced by the fact that similarly, the referrals and advices do not appear to have been reduced during COVID-19, supporting the information we received in the qualitative interviews - that the Invisible Hurdles service remained as busy and as integral as ever, even during the extensive restrictions.

\section{Secondary consultations are easiest onsite:}

II feel that certainly in the case of AWAHS, having the role of LPW and lawyer merged and being done by the one person is the best arrangement for AWAHS staff. There is no confusion about who does what and what days they are there; I attend on a set day every week and have a consistent routine of staff meeting, visiting Men's Shed, appointments, lunch and appointments. The positive impact of this can be seen in the data on my secondary consultations for 2021 - there is a lot and they are mostly done on the day I am onsite, despite the fact that most staff if not all have my mobile number and email address.'

- Legal Project Worker Report, 2021, p.14

\footnotetext{
20 'Overcoming the Invisible Hurdles to Justice for Young People: A Final Research and Evaluation Report of the Invisible Hurdles Project (Health Justice Partnership) November 2018. http://www.hrcls.org.au/wpcontent/uploads/2018/11/DESIGNED_Full-final-Report_October_20181102.pdf p.62

${ }^{21}$ Liz Curran (2017) 'Lawyer Secondary Consultations: improving access to justice and human rights: reaching clients otherwise excluded through professional support in a multi-disciplinary practice' 8(1) Journal of Social Inclusion https://josi.journals.griffith.edu.au/index.php/inclusion/article/view/8
} 


\subsubsection{Secondary Consultations interview data}

$100 \%$ of non-legal professionals who responded agreed that the secondary consultations were of huge value. This contrasts with the end-2019 interviews, which showed 89\% agreeing (see Appendix 5 for 2019 data).

Secondary consultations upskill non-legal professionals with information so that they guide the young people they work with. Sometimes, the young person does not want to speak to the lawyer directly, as in the example below. At other times, the staff member might just need some general information about their own obligations or legal processes.

\section{It's about sharing information so they can be the conduit}

'Young person who had been part of a group who had assaulted a person on the weekend. The teacher wanted to know what they could do and how they could help. It was a matter of explaining to the teacher what the law is if they're bailed, what the services are to help the young person. I said I could speak to the young person or their parents but I don't know if they feel comfortable with that yet so it's about sharing information with the teacher so they can be the conduit as well.'

- Lawyer 2021

Further, the data suggests that the secondary consultations continue to translate to new referrals, particularly where there is a favourable outcome for a client after the first referral. The Invisible Hurdles team have built relationships through the project. It is also exciting to see that some of these referrals from secondary consultations are now coming from health providers such as midwives and doctors.

\section{Secondary consultations lead to referrals}

'We had a great outcome for a young Indigenous woman by working alongside the AWAHS midwife, support worker at Mungabareena Aboriginal Corporation the Obstetric social workers at Albury Wodonga Health. I used the opportunity to share knowledge with these workers about the mandatory reporting regime and the professional obligations of lawyers. This positive interaction particularly with the AWAHS midwife led to more referrals of young parents from AWAHS.' 


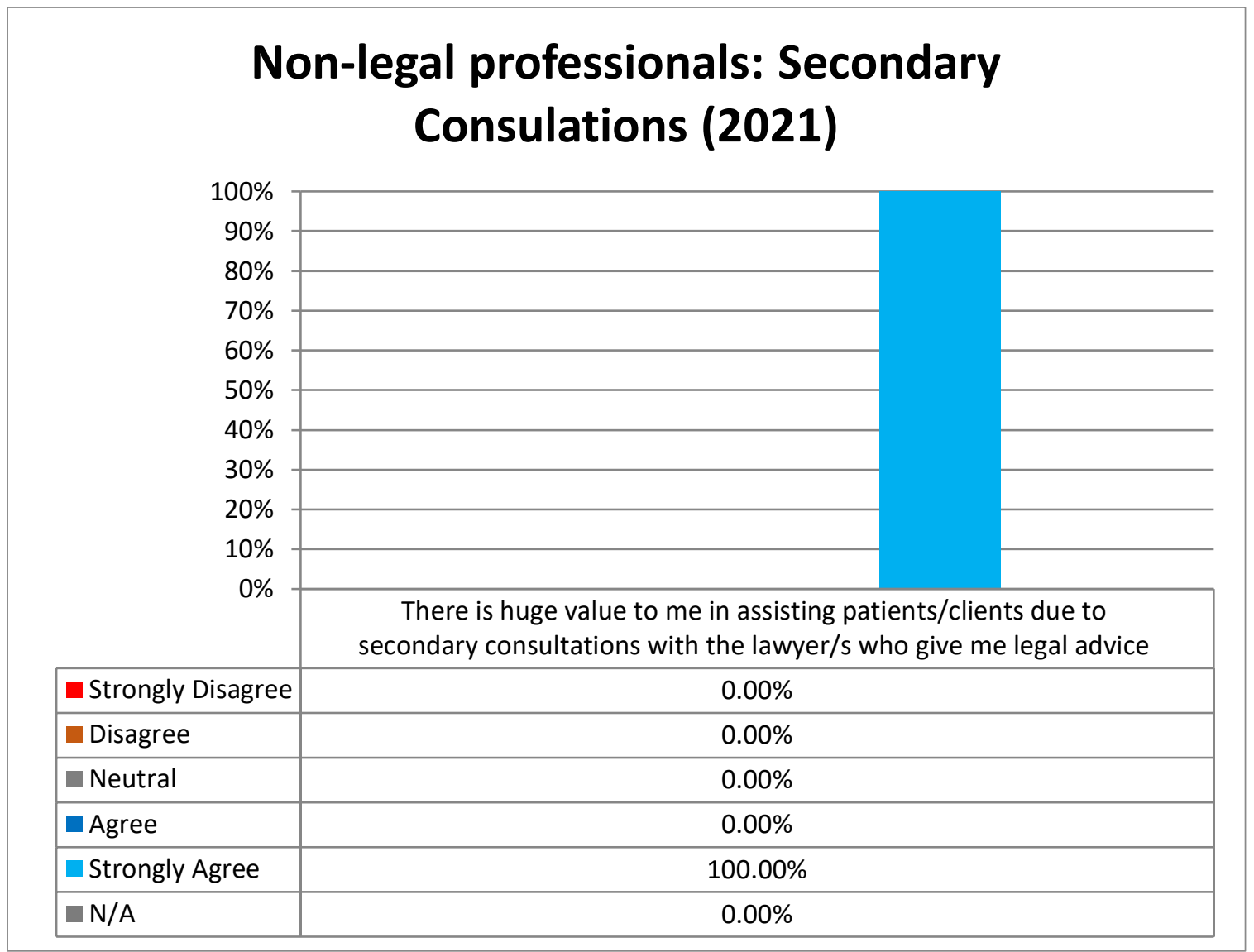


8.5 Service delivery broken down by partner

Referral Numbers

\begin{tabular}{|r|c|c|c|}
\hline & AWAHS & NESAY & FLC \\
\hline Jan-19 & 5 & 7 & 0 \\
\hline Feb-19 & 14 & 7 & 3 \\
\hline Mar-19 & 16 & 3 & 1 \\
\hline Apr-19 & 15 & 7 & 2 \\
\hline May-19 & 10 & 12 & 8 \\
\hline Jun-19 & 16 & 4 & 0 \\
\hline Jul-19 & 16 & 2 & 5 \\
\hline Aug-19 & 14 & 2 & 1 \\
\hline Sep-19 & 20 & 4 & 2 \\
\hline Oct-19 & 25 & 3 & 0 \\
\hline Nov-19 & 8 & 3 & 1 \\
\hline Dec-19 & 17 & 1 & 0 \\
\hline \multirow{2}{*}{} & $\mathbf{1 7 6}$ & $\mathbf{5 5}$ & $\mathbf{2 3}$ \\
\cline { 2 - 4 } & & & \\
\end{tabular}

\begin{tabular}{|r|c|c|c|}
\hline & AWAHS & NESAY & FLC \\
\hline Jan-20 & 19 & 7 & 0 \\
\hline Feb-20 & 12 & 6 & 5 \\
\hline Mar-19 & 15 & 7 & 2 \\
\hline Apr-20 & 8 & 2 & 1 \\
\hline May-20 & 16 & 8 & 1 \\
\hline Jun-20 & 4 & 4 & 2 \\
\hline Jul-20 & 9 & 6 & 3 \\
\hline Aug-20 & 10 & 5 & 0 \\
\hline Sep-20 & 12 & 5 & 2 \\
\hline Oct-20 & 12 & 7 & 2 \\
\hline Nov-20 & 15 & 1 & 3 \\
\hline Dec-20 & 8 & 5 & 2 \\
\hline & $\mathbf{1 4 0}$ & $\mathbf{6 3}$ & $\mathbf{2 3}$ \\
\cline { 2 - 4 }
\end{tabular}

\begin{tabular}{|c|c|c|c|} 
& AWAHS & NESAY & FLC \\
\hline Jan-21 & 14 & 6 & 0 \\
\hline Feb-21 & 17 & 6 & 3 \\
\hline & $\mathbf{3 1}$ & $\mathbf{1 2}$ & $\mathbf{3}$ \\
\hline
\end{tabular}


Advice

\begin{tabular}{|r|c|c|c|}
\hline & AWAHS & NESAY & FLC \\
\hline Jan-19 & 4 & 2 & - \\
\hline Feb-19 & 7 & 3 & 2 \\
\hline Mar-19 & 13 & 1 & 0 \\
\hline Apr-19 & 9 & 5 & 2 \\
\hline May-19 & 7 & 8 & 5 \\
\hline Jun-19 & 9 & 5 & 1 \\
\hline Jul-19 & 14 & 6 & 1 \\
\hline Aug-19 & 11 & 0 & 1 \\
\hline Sep-19 & 9 & 4 & 1 \\
\hline Oct-19 & 16 & 2 & 0 \\
\hline Nov-19 & 5 & 1 & 0 \\
\hline Dec-19 & 7 & 2 & 0 \\
\hline \multirow{2}{*}{} & 111 & 39 & 13 \\
\cline { 2 - 4 } & 7 & 5 & 1 \\
\cline { 2 - 4 } & 118 & $\mathbf{4 4}$ & $\mathbf{1 4}$ \\
\cline { 2 - 4 } & & &
\end{tabular}

\begin{tabular}{|r|c|c|c|}
\hline & AWAHS & NESAY & FLC \\
\hline Jan-20 & 8 & 5 & - \\
\hline Feb-20 & 9 & 7 & 4 \\
\hline Mar-19 & 12 & 5 & 1 \\
\hline Apr-20 & 7 & 0 & 0 \\
\hline May-20 & 10 & 4 & 1 \\
\hline Jun-20 & 3 & 5 & 0 \\
\hline Jul-20 & 10 & 2 & 1 \\
\hline Aug-20 & 6 & 1 & 2 \\
\hline Sep-20 & 10 & 3 & 1 \\
\hline Oct-20 & 3 & 5 & 2 \\
\hline Nov-20 & 11 & 1 & 2 \\
\hline Dec-20 & 2 & 4 & 1 \\
\hline \multirow{2}{*yy}{} & $\mathbf{9 1}$ & $\mathbf{4 2}$ & $\mathbf{1 5}$ \\
\cline { 2 - 4 } & & &
\end{tabular}

\begin{tabular}{|c|c|c|c|}
\hline & AWAHS & NESAY & FLC \\
\hline Jan-21 & 5 & 2 & - \\
\hline Feb-21 & 3 & 4 & 1 \\
\hline Mar-21 & $\mathbf{8}$ & $\mathbf{6}$ & $\mathbf{1}$ \\
\hline
\end{tabular}


Case work

\begin{tabular}{|r|c|c|c|}
\hline & AWAHS & NESAY & FLC \\
\hline Jan-19 & 0 & 2 & - \\
\hline Feb-19 & 5 & 8 & 1 \\
\hline Mar-19 & 1 & 5 & 0 \\
\hline Apr-19 & 9 & 1 & 0 \\
\hline May-19 & 2 & 9 & 1 \\
\hline Jun-19 & 3 & 1 & 0 \\
\hline Jul-19 & 4 & 3 & 1 \\
\hline Aug-19 & 6 & 1 & 0 \\
\hline Sep-19 & 0 & 1 & 0 \\
\hline Oct-19 & 0 & 1 & 0 \\
\hline Nov-19 & 3 & 0 & 0 \\
\hline Dec-19 & 1 & 4 & 0 \\
\hline \multirow{2}{*yy}{} & $\mathbf{3 4}$ & $\mathbf{3 6}$ & $\mathbf{3}$ \\
\cline { 2 - 4 } & 4 & 7 & 3 \\
\cline { 2 - 4 } & $\mathbf{3 8}$ & $\mathbf{4 3}$ & $\mathbf{6}$ \\
\cline { 2 - 4 }
\end{tabular}

\begin{tabular}{|r|c|c|c|}
\hline & AWAHS & NESAY & FLC \\
\hline Jan-20 & 1 & 6 & - \\
\hline Feb-20 & 1 & 0 & 2 \\
\hline Mar-19 & 7 & 4 & 0 \\
\hline Apr-20 & 4 & 2 & 0 \\
\hline May-20 & 0 & 0 & 3 \\
\hline Jun-20 & 0 & 4 & 0 \\
\hline Jul-20 & 3 & 0 & 0 \\
\hline Aug-20 & 4 & 0 & 0 \\
\hline Sep-20 & 2 & 1 & 0 \\
\hline Oct-20 & 0 & 3 & 2 \\
\hline Nov-20 & 3 & 5 & 2 \\
\hline Dec-20 & 3 & 5 & 2 \\
\hline \multirow{2}{*}{} & $\mathbf{2 8}$ & $\mathbf{3 0}$ & $\mathbf{1 1}$ \\
\cline { 2 - 4 }
\end{tabular}

\begin{tabular}{|c|c|c|c|}
\hline & AWAHS & NESAY & FLC \\
\hline Jan-21 & 2 & 0 & - \\
\hline Feb-21 & 2 & 4 & 0 \\
\hline \multirow{2}{*}{} & 4 & 4 & 0 \\
\cline { 2 - 4 } & &
\end{tabular}


$\underline{\text { Secondary Consultations }}$

\begin{tabular}{|r|c|c|c|}
\hline & AWAHS & NESAY & FLC \\
\hline Jan-19 & 3 & 1 & 0 \\
\hline Feb-19 & 3 & 0 & 3 \\
\hline Mar-19 & 0 & 2 & 0 \\
\hline Apr-19 & 3 & 2 & 0 \\
\hline May-19 & 1 & 5 & 0 \\
\hline Jun-19 & 0 & 4 & 1 \\
\hline Jul-19 & 0 & 1 & 0 \\
\hline Aug-19 & 2 & 1 & 0 \\
\hline Sep-19 & 2 & 5 & 0 \\
\hline Oct-19 & 1 & 5 & 2 \\
\hline Nov-19 & 0 & 2 & 0 \\
\hline Dec-19 & 0 & 7 & 0 \\
\hline \multirow{2}{*}{} & 15 & 35 & 6 \\
\cline { 2 - 4 }
\end{tabular}

\begin{tabular}{|r|c|c|c|}
\hline & AWAHS & NESAY & FLC \\
\hline Jan-20 & 6 & 10 & 0 \\
\hline Feb-20 & 6 & 8 & 2 \\
\hline Mar-19 & 2 & 9 & 2 \\
\hline Apr-20 & 3 & 3 & 2 \\
\hline May-20 & 4 & 4 & 3 \\
\hline Jun-20 & 1 & 9 & 3 \\
\hline Jul-20 & 1 & 5 & 4 \\
\hline Aug-20 & 8 & 8 & 3 \\
\hline Sep-20 & 8 & 10 & 2 \\
\hline Oct-20 & 7 & 7 & 5 \\
\hline Nov-20 & 9 & 8 & 5 \\
\hline Dec-20 & 9 & 6 & 3 \\
\hline \multirow{7}{*}{} & $\mathbf{6 4}$ & $\mathbf{8 7}$ & $\mathbf{3 4}$ \\
\cline { 2 - 4 } & & & \\
\cline { 2 - 4 } & AWAHS & NESAY & FLC \\
\cline { 2 - 4 } Jan-21 & $\mathbf{9}$ & $\mathbf{5}$ & - \\
\cline { 2 - 4 } Feb-21 & $\mathbf{1 2}$ & $\mathbf{2}$ & $\mathbf{4}$ \\
\cline { 2 - 4 } & $\mathbf{2 1}$ & $\mathbf{7}$ & $\mathbf{4}$ \\
\cline { 2 - 4 }
\end{tabular}


On first glance, it appears that AWAHS has provided much of the referrals and secondary consultations for the project. This however is not in fact necessarily the case and so the figures need to be read with some care, as they may relate to services in general rather than to the young people cohort that this service project is targeting. Although, these figures may reflect services provided not just young people but their families, it is important to still acknowledge that because of issues of trust in working with Aboriginal communities, often connections with young people are made through their family members. This explains why this mode of service delivery is in place in order to acknowledge cultural practice and sensitivities.

Similarly, it is noted that AWAHS does not have a youth specific worker and that one of the ways of reaching young people was to reach them through this family and kinship mechanism. In some of the qualitative data and reflections from staff it was evident that they had started to also connect with a separate Aboriginal agency that had a youth specific focus, and inroads in that relationship was starting to gain traction near the end of the project.

Having qualified data above of the breakdown of secondary consultations, referral numbers and advice provided by the project team, it is noted that despite COVID there was still sustained service delivery across all three partners. Although the figures for the WFLC were the lowest, given the client cohort of at-risk young people who may have limited access to familial supports, limited access to online facilities and safe environments at home in which to learn and share, it is not surprising and is explicable. The cohort itself is also small (94 students) (especially in comparison to the numbers accessing AWAHS and NESAY).

The nature of the program at the WFLC relies on the young people being in a safe space in the school environment and on-campus where they can make disclosures to their teachers and to the legal team who are visible. The fact that the schools were closed for such extended periods of time and the border restrictions explains the lower data overall for the WFLC. However, where perhaps the disclosures of client problems through referrals and case work were less likely to have been facilitated (due to the school campus closures and border restrictions), the community development work became a critical conduit.

\section{Most contact at WFLC was direct from young people in 2020:}

'In preparation for the first Lockdown, [Lawyer 3] and I distributed business cards with our work mobile numbers listed and updated our poster as below. These changes had to happen quickly and needed us to be flexible, adaptable and responsive. However, most contact from students has continued to occur via teachers rather than to us directly, or by the student when we are onsite. This indicates there is still work to be done in breaking down the barrier between us and the students to contact us via phone or text, but also shows the Project is otherwise effective in that the students approach us when we are onsite and/or via their teachers due to the high level of trust they have in them.'

- Legal Project Worker report 2021, p.40.

During restrictions, the qualitative data suggests that WFLC students who were at the school for longer, and more familiar with the lawyers, might have also been more likely to access their services. Familiarity with the lawyers keeps them front-of-mind. 


\section{The 'getting to know you' factor}

'Some of the older kids would come to me and ask 'Can you give me [Lawyer 6] or [Lawyer 3]'s number'. The older kids, yes, because some of them have been involved with the program for a long time. But then there's the newer kids, the younger kids who are newer to the program. They'll mention something and I'll say 'Hey, I can get [Lawyer 6] and [Lawyer 3] to help you out with that.' Older students who are used to the program know to ask.... At the front reception, we've got their contact details and some kids will know to go and grab that card. Otherwise, it will be me referring, of they grab them when they're in.'

- Staff 2021.

In contrast, NESAY has a different service model and client cohort that tends to work through professional staff who then reach young people who may often not be on-site at the service through their casework (and during the 2020 restrictions, never attended on-site). This meant that the professional development work and secondary consultation work was more convertible, although not easy, to the provision of online support by the Invisible Hurdles project team, albeit with some commendable creativity, discussed below.

Similarly, because AWAHS was in New South Wales, it was less susceptible to the sorts of lockdowns and closures that agencies based in Victoria were subject to during the pandemic (see COVID timeline). Its service model was nonetheless substantially affected, particularly as Aboriginal organisations and communities have been proactive and highly responsible with the pandemic response. ${ }^{22}$ The AWAHS lawyers were not able to be on-site for most of 2020. Perhaps the higher figures as between the three partner agencies in all the aggregated total data on secondary consultations, referrals and advice could be explained by the inroads that the Lawyer made into staff meetings, by having herself listed on the agenda.

Further, the relationship between the lawyers and the AWAHS staff has been well established as the lawyer attends twice a week. It may be that this relationship building work that took place early on, led to more referrals and secondary consultations.

\subsection{Problem types}

Also provided to the research evaluators with data on the problem types listed below by the project team as their aggregated service data, was very detailed matter data. This has not been summarised or replicated here in this final report although it has been considered by the evaluation team, as it does not add significantly to the information that is better represented by the problem types. Detailed data is provided in Appendix 1.

There is some consistency in the type of work that dominates the problem type across the three years under consideration in the areas of:

\footnotetext{
${ }^{22}$ Crooks, Casey and Ward, 'First Nations people leading the way in COVID-19 pandemic planning, response and management' (29 April 2020) Med J Aust. 2020; 213 (4) 151-152.e1.
} 
- Consumer complaints;

- Credit and debt owed;

- Government administrative issues relating to fines; and

- Child contacts or contact orders.

In the case of child contacts, these cases increased in 2020. There was also a number of cases in relation to victim compensation. Both of these were also impacted by FV to a high percentage. It is interesting to note that the cases involving fines increased dramatically in 2020 rising from 10 in 2019 to 18 in 2020. The authors speculate that some this may relate in some way to the fines that were administered during the COVID pandemic in 2020.

In the 'Matter Type Data (not replicated for the purposes of this report) there was a prevalence of family or domestic violence order advice, family or domestic violence advice as well as child contact or contact orders noted in the aggregated data across all three agencies which is consistent with the percentages noted above of young people seeking advice for family violence issues.

\subsubsection{Family Violence numbers}

This project has now been ongoing for at least five years. We know that is it is only through interaction on other legal matters and working alongside their non-legal professional supports that young people are more likely to present with family violence problems. The following statistics draw out some of the major areas of work that have been undertaken by the lawyers. We have drawn out specifically those that relate to family violence matters and areas which might be interrelated.

It is important to note that the family violence reported in the below figures directly relates to the problem type. Whereas, as the lawyer notes in the below observation, it is often a contributing factor to the legal issue. The family violence by age/service 2020 shows the CLASS data which is where the family violence indicator is ticked as connected to the problem type. The broader family violence impact is reflected in the manual data collected by the lawyers. E.g.: 43\% (29/68) of young people across the 3 partners under 25-year-old, had the family violence indicator ticked as directly connected to the problem type. The lawyers' data shows $70 \%$ impacted by family violence at NESAY \& Flexi in 2020. AWAHS data shows $45 \%$ (until July) and 58\% (from July onwards).

\section{Family Violence is an underlying factor to most of the legal problems}

'I believe that a majority of my client's would either be currently experiencing FV or have experienced it, but that for my purposes, when I report on this statistic, the FV has to directly relate to the problem type that I am giving advice on. I do not necessarily agree with this approach as in my experience the $\mathrm{FV}$ is an underlying factor to most of the legal problems, that is, it may not have directly caused the legal problem but it often is a contributing factor to the legal issue.'

- Lawyer, Guided Journal, November 2019 
Family violence or domestic violence

2020 (advice)

WFLC 1

NESAY 0

AWAHS 0

Family violence or domestic violence order

2020 (advice)

WFLC 1

NESAY 4

AWAHS 10

2021 (advice)

NESAY 2

Family violence or domestic violence casework (2020)

AWAHS 0 task 0 casework

WFLC 1 task 0 casework

NESAY 2 tasks 0 casework

Family violence or domestic violence casework (2021)

NESAY 2 tasks

Injuries sexual assault including rape

WFLC 1 (plus 1 task)

NESAY 1

AWAHS 0

Fines

Fines 2020 (advice)

WFLC 2

NESAY 7

AWAHS 5

Casework 2020

WFLC 3 tasks

NESAY 7 tasks 7 casework

AWAHS 2 tasks 
There seems to be a connection in the aggregated data between child contacts and VOCAT that suggests an increase a connection with family violence.

The region has high rates of family violence. In the Wodonga region alone, family violence incidents increased $11.6 \%$ in the year $2018-2019$ and almost $23 \%$ of affected family members were under the age of 24 years. ${ }^{23}$

One method of highlighting students who might have a legal issue, including family violence, is the legal first aid check that WFLC has introduced with all their students. Steps were also taken to introduce this at AWAHS ( \& NESAY) though while not implemented, it drew attention to some systemic issues relating to how FV was identified at AWHAS and the lack of comfort in doing so and knowing how and where to refer. These conversations are ongoing. The benefit of this form is that it allows teachers to get a gauge of potential risks and hazards in the young people's lives. For the most part though, the teachers report that legal problems aren't usually directly spoken about in a proactive way from the young people to their teachers. Rather, they usually come up in conversations that might lead a teacher to enquire further about the issue, or to suggest they see a lawyer. It should also be noted that the Invisible Hurdles Project as it is a project of the Human Riverina Community Legal Service is guided by risk management practices and standards. ${ }^{24}$

\section{Legal check-up}

'We also have the legal first aid check. That's really, really good because it will often highlight to us students we hadn't thought about, or who were not on our radar. Originally, we were going to do it with them when we do their individual education plans but then we realised it needs to be done just with us and with no parents or carers involved.... We say we should do them once a term... For some of them we get to know them so well, we don't have to do it once a term but definitely when they're brand new, we do that.'

- Manager 2021

\subsubsection{AWAHS Youth \& Family Violence}

Looking at more detailed data from AWAHS, it appears that 14 young people were seen by the lawyer during Stage II of the project up until $31^{\text {st }}$ of October 2019. In 2020 according to the report (FV by age by service) shows that in 2020, there were 19 young people who were given 21 advices, 6 tasks and 2 cases. Attempts to engage with young people young people (mentioned in the professional journals of staff) include Lore/Law Walkabout, attempts to engage with AW Koori Youth Network, attendance at Women's Circle - when discovered not many young people, reduced attendance, but good conversations around family violence (ochre ribbon day), Haircuts connecting

\footnotetext{
${ }^{23}$ Crime Statistics Agency, Crime by location - Wodonga, https://www.crimestatistics.vic.gov.au/explorecrime-by-location

${ }^{24}$ 'Risk Management and CLC Practice: A guide for Community Legal Centres in delivering legal and related services' Community Legal Centres Association ('The Risk Management Guide') and the Integrated Practice Toolkit: A Guide to Understanding Privilege and Mandatory Reporting in Integrated Practices (2018) Federation of Community Legal Services.
} 
community - children but not young people and the Koori Engagement Officer. Numbers have increased over project. Although, by helping the family they indirectly help the young person, the authors remain troubled by the fact that there are so few Aboriginal young people being seen by the project at AWAHS, given this project target audience. The Koori Engagement Officer Numbers have increased over project.

\begin{abstract}
Attempts to build trust through kinship
'[l]t took multiple weeks of me attending the Women's Circle before Aunty [name removed] approached me to discuss her legal problem (which was not family violence related). While this was ultimately a success story for the Project in that my discussions with Aunty [name removed] led to an appointment with Karen which resulted in a significant debt waiver and a substantial refund, she does not fit any of the criteria of our target clients... However, it was important to have a "win" in order to prove my value to the women and to build trust.' (Legal Project Worker Report 2021 p.12). .....

'I saw a client recently and asked her the usual question of who had referred her to me. She told me it was her daughter who I had recently assisted. I said that was great to hear and she went on to say that her daughter had been speaking to another family member about their legal issue and she told them "Just call [Lawyer 6], she will help you" and gave them my mobile number. I do occasionally get random calls on my mobile from someone who said they got my number from someone else. I know other lawyers at HRCLS don't like their work mobile number being widely available but it doesn't worry me. On the contrary, I think actually increases access to justice.'

- Legal Project Worker Report 2021 p.14
\end{abstract}

People who have legal problems, especially if they involve family violence, often do not disclose to family members for a range of reasons, including embarrassment, shame and fear. It is also known in best practice in representing and interviewing young people, that young people will often not speak freely if their family members are present. ${ }^{25}$ Our cultural advisers have noted that young people may wish to avoid being seen visiting the lawyer. For this reason, the physical placement of the lawyer and referral pathways, given the project aims needs to be developed. In the process of deliberating on some of the issues raised by the evaluators in their Interim Report in February 2020, and in discussions with the project team (including the project management), these staff were aware of this complex and vexing issue and ways in which this was to be managed. There are no easy answers, given the nature of family violence and the impacts of past colonial practices that have damaged trust between the Aboriginal community and generalist service providers.

The authors acknowledge the importance of kinship and family relationships as pathways for young people to trust a generalist service, such as the HRCLS and its Invisible Hurdles team. ${ }^{26}$ It is also noted that for cultural reasons family and extended family have a strong part to play in supporting

\footnotetext{
${ }^{25}$ Legal Aid Queensland, 'Guidelines for Working with Children and Young People, http://www.legalaid.qld.gov.au/About-us/Policies-and-procedures/Best-practice-guidelines/Guidelines-forworking-with-children-and-young-people

${ }^{26}$ Liz Curran 'Getting out of Debt: The Road to Recovery for Victim Survivors of Family Violence' ANU for Consumer Action Law Centre (January 2020). Available at SSRN: https://ssrn.com/abstract=3512672
} 
young Aboriginal people due to kinship. ${ }^{27}$ However the authors are concerned that a number of young Aboriginal people may not have familial support ${ }^{28}$ and that some young people may be experiencing family violence from members of family (extended and immediate), the advisers offered a complimentary idea of reaching other vulnerable First Nations young people. For example, through a separate youth-focused Aboriginal agency (one of the Aboriginal advisers on this project is well connected into Aboriginal Youth Networks and could be a link for the Invisible Hurdles staff). This concern was acknowledged by the project staff and the project management team and remains a work in progress. The 2020 circumstances made it impossible to make new connections of this nature.

A significant hurdle to meeting young people at AWAHS is that, AWAHS does not itself have its own youth worker. Nonetheless, given the implications of young Aboriginal people not gaining legal help (outlined for example in Royal Commissions and the Institute of Criminology and Institute of Family Studies, The National Aboriginal Community Controlled Health Organisation (NACCHO) and the Secretariat of National Aboriginal and Islander Child Care (SNAICC) data studies into Young People), considerable work is needed in this space. The WFLC staff reported in interviews that they have many more Aboriginal students enrolled than previously. Given the strong relationship with WFLC, connects have been made with the youth worker at MAC and through the links being made across the sites it may also be that Invisible Hurdles starts to assist more Indigenous youth through the school too. Also the professional journals reflect, attempts at engagement noted above and that inroads are being made to stronger links between AWAHS and WFLC by way of shared service delivery; having AWAHS staff as guest speakers and visitors to the school. In recognition of the increased number of Aboriginal students at WFLC (now at 22\%) when arranging the visit by local police, IH ensured the Aboriginal Liaison Officer also visited.

Given the risk of family violence to young people who come from Aboriginal backgrounds this is a significant gap and needs to be addressed by some specific strategies that are shaped and informed by those who are younger and from Aboriginal backgrounds who may also have some great ideas about how to engage. Music and sport including football and netball, have been ways in which one author has engaged with young Aboriginal people in the past. The journal also reflects that Lawyer 6 has made investigations into the Sporting Change concept.

Importantly, there is no doubt that the Invisible Hurdles Project is reaching many young people than would otherwise be the case, through interactive involvement with the non-legal professionals in secondary consultations. The Invisible Hurdles is, however, an opportunity to amplify the voices of young Aboriginal people, but this first means connecting with them. It may be that the groups of young people who are assisted with legal advice work are different from the groups of young people are involved in systemic advocacy work. Attempts have been made to engage with the Albury Wodonga Koori Youth Network and this work ongoing Often those young people who are being helped with casework are too vulnerable to engage with systemic issues. There are others who will be less vulnerable and abler to engage in this respect. This highlights the challenges involved in engaging young people who are in 'at risk' cohorts. IH tenacity here is to be commended.

\footnotetext{
${ }^{27}$ Rhys Price-Robertson \& Myfanwy McDonald (in partnership with Peter Lewis \& Muriel Bamblett of the Victorian Aboriginal Child Care Agency) 'Working with Indigenous Children, Families, and Communities Lessons from Practice', https://aifs.gov.au/cfca/sites/default/files/publication-documents/ps6.pdf

${ }^{28}$ Child protection and Aboriginal and Torres Strait Islander children, CFCA Resource Sheet - January 2020, https://aifs.gov.au/cfca/publications/child-protection-and-aboriginal-and-torres-strait-islander-children
} 


\section{Closing the gap means listening to young Aboriginal people}

'The voice of youth has to be heard to close the gap. Without hearing the voices of young people, decisions are made that will be ignored or done in a way that aren't applicable to those young people. They are our future.'

- AWAHS staff 2021

\subsubsection{Family Violence services to under 25s}

2021 (to 28 Feb 2021): 6/10 $=60 \%$ clients under 25

2020: $29 / 68=43 \%$ clients under 25

2019: $27 / 65=41 \%$ clients under 25

As noted in the Final Research and Evaluation Report on Stage I of the Invisible Hurdles Project, disclosure of family violence issues and recognition of family violence are difficult. This reason, the Invisible Hurdles Project team, early in Stage I, realised that the best way of reaching young people to find out more about their family violence situation was to provide other legal services.

Building trust of young people so that the partners would be better able to support them in disclosures around family violence and making appropriate interventions was critical. What the data suggests is that this approach has been successful and effective, given the rates of family violence services that the Invisible Hurdles project has now been able to deliver.

Having a community development and professional development approach alongside casework also enables young people to explore more deeply what family violence is, and to create the pathways and confidence in the legal service needed to make family violence disclosures. The below story illustrates the connection between the community development work and family violence disclosures.

\section{She realised it was something called 'domestic violence', from the education sessions}

'One of the students that did see [the lawyer] about this domestic violence issue, l'd tried a few methods of contacting other agencies myself, but nothing was really happening. It was only until one of the lawyers got involved themselves that they were able to help.

In the end the young man ended up on a DVO... and was moved out of the home where she was living with him and that student has made the comment that probably without that lawyer program, she'd still be in that situation. So, it was a really good outcome for her. Now he has access to the child every Saturday and she has her life back.

She's not anxious at all really now. She's very confident now. She's very outspoken. She's realised that she has rights that she didn't realise she had before, because he was verbally abusive and with texting etc. So now she knows that she doesn't have to put up with that. It's definitely changed all her future relationships with sexual partners. And she's sharing that also with the other students in the group. We often sit down and have little discussions about topics but especially when the lawyers are there on a Wednesday... 
[It was] because we'd been having these conversations with [Lawyer 6] each Wednesday, that she'd realised that she didn't have to put up with what her partner was doing, that it was actually something that was called 'domestic violence.' She had no idea before that. And that's actually something that's been encouraged back in 2019 and slowly she's gained the confidence to talk to the lawyers and say I want to change this.'

- Staff 2021.

The percentages of young people in Stage II of the Invisible Hurdles Project that are turning to the service for family violence support has notably increased. This data suggests that the project has been effective in making inroads into a responsiveness to family violence occurring in the lives of young people and their families because of its longitudinal nature and its ability over time to build an understanding of family violence and its manifestations and to provide service pathways both to young people and their trusted intermediaries such as their teachers, health professionals and counsellors and other social service networks.

\subsubsection{Improving health outcomes}

There was consistent and unanimous agreement in all interviews, across the multiple tools for lawyers, partner staff, and across the partnership managers, that legal help can improve health outcomes for individuals. Often this was mental but it could also be physical because a young person starts to eat better, sleep better and experience reduced stress, when their legal problems are being resolved. There was a strong emphasis among interviewees on the interconnected nature of health and legal problems. One participant described that the legal help was capable of 'completely shifting who they are and their sense of importance in the world.' Another participant described that the legal help 'alleviates some of that stress and unknown for them.' This project's power to make a difference to the lives of young people is significant.

\section{Becoming immobilised}

'When some of the young people we're working with have legal issues, it can become a compounding issue... it has an impact on lots of different domains of that person's life. It impacts on physical and mental wellbeing when there's that burden that they're carrying and they feel sometimes immobilised.'

- Staff 2021

Some case examples are below:

\section{It's all connected}

'We had a young father - DV type stuff, with AVOs and mental health deteriorated. He was couch surfing and he really was not looking after himself physically as well. We got some support from the lawyer. Being able to clarify information for him made him less depressed so therefore the work I was doing with him on counselling him about other things becomes more effective. He becomes 
more motivated and therefore starts exercising and eating better. It's all connected.'

- Staff 2021

\section{Seeing Dad}

'It was a pretty sticky situation; it was to do with a family violence order. Dad's actually in jail and it was just about being able to have contact with him and [Lawyer 3] was very, very supportive of the young person in working through those issues with them.'

- Staff 2021

\subsection{Community Development}

Data relating to community legal education and community development activities is extracted in Appendix 2.

One of the authors, has higher qualifications in education as well as law and is a Senior Fellow of the Higher Education Academy. Both authors have had 40 years of educational experience between them. They have also delivered, planned and rolled out various community development programs, based on this experience.

We have used our combined educational and community development practice experience to examine the community development materials and the reflections on their rollout. As educators and evaluators, the processes and steps now undertaken and the willingness of the relevant staff, including the managers and project worker, to talk to others with experience in community development and with community development expertise and training have been impressive.

\subsubsection{A sequenced approach}

A sequenced approach that was undertaken at FLC in relation to police powers was an example of a deepening of the understanding of community development practice.

Community development practice, unlike community legal education, tends to be sequenced and not one-off training. It considers the need of the participating audience in advance and works with them to devise their own way of working and learning. This activity saw students learning about police powers and then putting their learning into practice over a period of time by designing and preparing pocket size 'wallet card.' This will be practical and useable as the young people can carry it with them and have learned through 'doing'. NESAY on hearing about this activity at FLC, has asked that it be replicated for them in 2020 .

The Project Worker had hoped to use the Men's Shed connections to the Youth Justice Worker at Mungabareena Aboriginal Co-operative (MAC) when she delivered a planned series of workshops. Unfortunately, that was cancelled due to COVID-19 restrictions but the evaluators acknowledge that this would have proceeded had the restrictions not been in place, and further that a connection with 
MAC may have been fruitful. It is also evident that the Project Worker has turned her mind to the most efficient means of reaching young people.

\section{Law/Lore Walkabout}

'In late 2019 into early 2020, I continued my weekly attendances at the Men's Shed as set out in my previous Report. A significant development in December was a request by one of the elders, Uncle, that I teach the men about the law during my visits. In January 2020, we set out developing a program which we titled Law/Lore Walkabout. Two of the men designed some artwork for the program said to reflect the meeting of white man's law with traditional lore. The plan was that we would alternate weeks with Karen and I delivering CLE or facilitating guest speakers to do so, with yarns from the men about traditional lore. A copy of our draft program is below. I was aware of collaborations between the Men's Shed and the Youth Justice Worker at MAC and I hoped that the program would form part of that.

However, COVID-19 hit before the program could properly commence. It has not been revisited by me since my return onsite in 2021. I am now of the view that such a program, while fantastic, is not the most efficient way of reaching young people. Instead, I am focusing my energy on engaging with the Albury Wodonga Koori Youth Network and have plans to meet with one of its founding members in the coming weeks.

Despite this, I have recommenced my usual process of baking cupcakes and the like for the Men's Shed. I am doing this for the sake of re-establishing my old routine but also because it has become a crucial component of my engagement with AWAHS staff. As noted earlier in this Report, my baking is a great conversation starter and something I appear to be well-known for at AWAHS.'

- Legal Project Worker report 2021 p.9-10 


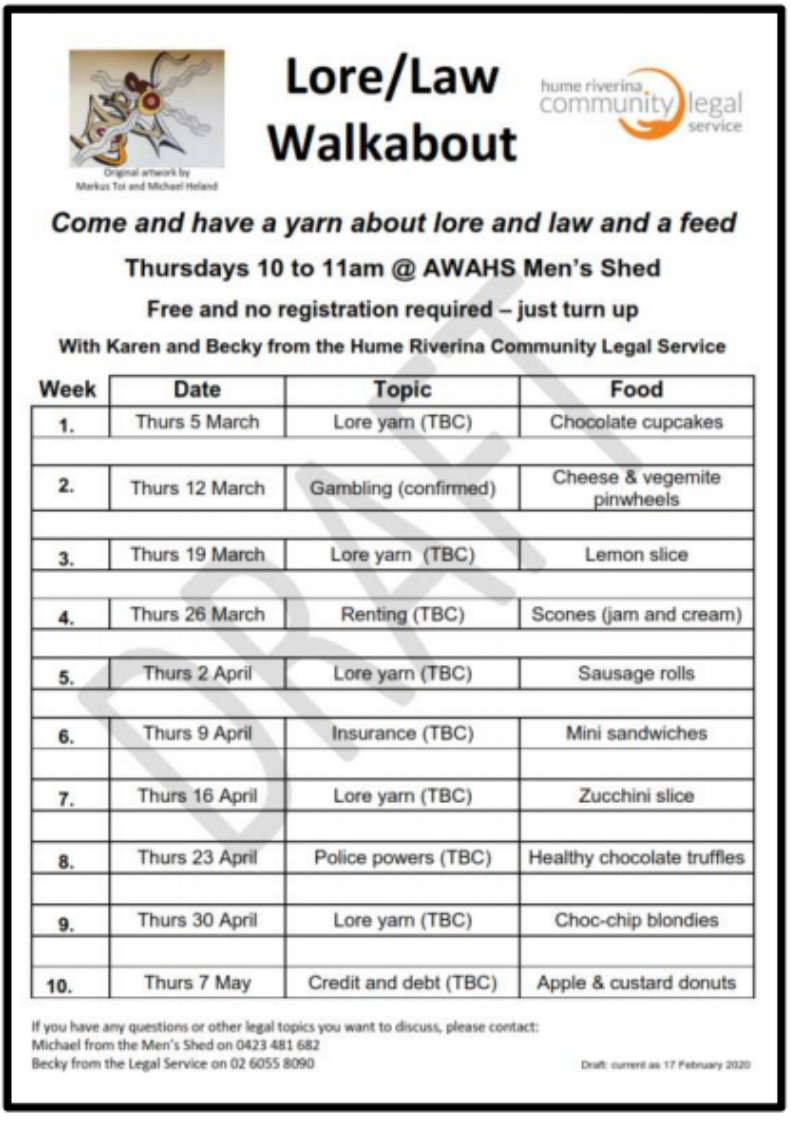

This recognition of community development as more than just conveying legal information but requiring a sequential, engaging, and appropriate manner suitable to the age group and audience was one of the comments made by the research evaluators in the interim report in February 2020. What is clear is that there was a more focussed effort on delivery of community development that led to development of new skills and aptitudes, along with how to apply that information.

When asked about their opinion of the community development work, the WFLC students said, 'It was what we wanted to do' and 'They don't just rock up with something, it's what we enjoy as well' (December 2019 focus group of young people).

On whether the content was interesting, the students agreed that 'I love all of them [the sessions] but some were more interesting than others, some I already knew'. It is natural that some students would have more knowledge than others on particular topics. The challenge for the Invisible Hurdles team will be to inform new students of the same knowledge and skills, while extending the capacity of returning students with new information.

\section{In real life}

'It's information that you could easily digest and its information that can be used in real life, it's fascinating'. 
The students appreciated that by being at WFLC, they were able to reach legal information that other young people may not. The below quotes came out in discussion of their friends' general legal knowledge and demonstrates the need for the Invisible Hurdles legal team to be in the school.

\section{Better than learning the hard way}

'Most people learn from experience. So, they don't get the accessibility of information that we get. People learn about AVOs by going through AVOs.'

- Young person, focus group, Nov 2019

\section{You really don't know what to expect if you've never been educated on it}

'Yeah, we [young people generally] don't have that information just told to us about it... You gotta learn to experience it to even know about it. And you hope not to experience it but when it comes down to having a go like that'll happen [sic], you really don't know what to expect because you've never been educated on it.'

- Young person, focus group, Nov 2019

\subsubsection{Empowering}

Another example of effective community development delivery in 2021 has been the 'Journey to Law Town' sessions, which culminated in a 'You can't ask that' session with a local police officer and an Aboriginal liaison officer. The impact of these sessions was empowering, as evidenced by the teachers' comments.

\section{They belong to those minority groups:}

'We also looked at You Can't Ask That and looked at minority groups. Because some of these kids will belong to those minority groups. So they know that they're not as powerful as they possibly can be, but they know that they do have a voice and are encouraged to use that.'

- Staff 2021

The year 2020 was obviously going to be difficult to deliver community legal education and community development. Term 1 work with the WFLC students included presentations, worksheets and a letter to federal MP Helen Haines from the students. A great outcome!

Once lockdowns were concluded however it appears that things are back to normal from February 2021 when the school reopened, and planning for these sessions occurred in 2020. For example, there is evidence in the Community Development tables in Appendix 2, of the 'You can't ask that' being initially formed as an idea with staff at the school, where students could send in questions to the ABC's 'You can't ask that' show. Subsequently, this evolved into a session where students, having learned about the laws and their rights, wrote questions for their own, local, 'You can't ask 
that' session.

\section{The kids couldn't stop asking questions}

And that trust that when young people bring something up with us, they're happy for us to rely that to [Lawyer 3] and [Lawyer 6]. Even in terms of what we're going to do in the sessions coming up, what they would like to see offered, there's just that understanding that whatever they bring up it will be accepted, it won't be laughed at, it won't be put down.

We did this great 'You can't ask that style of questioning. [Lawyer 6] and [Lawyer 3] have a way of drawing responses out of young people and sitting with their discomfort. '[Lawyer 6] and [Lawyer 3] have a way of drawing responses out of these young people and sitting with their discomfort and sitting with their silence and allowing them just to be them, and getting to a point where they'll offer things up.

To do that process on a small group scale, to have the young person brainstorm questions, then we went to this big room (and most of our kids will only work in small groups), full of people, with police, answering their questions. It went over by half an hour into the morning tea time because the kids couldn't stop asking questions. Having the questions pre-written and hearing the answers, generated the thought processes and the confidence to ask more questions, so it just went on and on. It was goose bump style stuff... They understand our students, they understand what we are trying to do with our students, and therefore, they're supportive of that.'

- Staff 2021

\section{When's that copper returning?}

'Feedback from the teachers and students have been positive, so much so, that one student asked 'when is that copper returning for another session'. Breaking down barriers and perception of lawyers and Police officers $:{ }^{\prime}$

- Lawyer reflection 2021

\subsubsection{Virtual Community Development}

Once the restrictions came in place though, formal CLE stopped but the Invisible Hurdles team made an enormous effort to continue offering informal sessions remotely. The Legal Project Worker's report describes these sessions well. It is a credit to the Invisible Hurdles team that they were so flexible, patient and willing to share of themselves.

\section{Chats from my loungeroom with my dogs}

'As noted above, in late May 2020 we initiated some casual catch-ups with the students via MS Teams. Most students were back onsite despite the government's learn-from-home directive due to their status as vulnerable students. These chats were completely unstructured, occasionally 
awkward and heavily featured discussions about my dogs, who were usually on the couch behind me; in the background to my talking head on the screen.

While it did not seem ideal to be conducting these chats from my lounge room with my dogs, in retrospect, it turned out to be one of the most effective (although unintentional) engagement strategies. The students were able to literally see that I was not sitting in a fancy office in a high rise building like a lawyer on the TV, but instead in my occasionally untidy lounge room that was filled mostly with modest furniture, dog hair and dirty coffee mugs! The dogs were a great icebreaker and gave the students something to focus on and talk about. It was particularly helpful with the Young Parents group, as their babies and toddlers were fascinated by the dogs! Once the young parent saw me interact positively with their child, they then began to trust me.'

- Legal Project Worker report 2021 p.44

\subsubsection{Often informal}

It was initially difficult for the Legal Project Worker to break into the Women's Circle at AWAHS but some exciting advancements were made on this before the COVID restrictions took place, as described below by the Project Worker.

\section{Joining the women's circle}

'I heard about the Women's Circle in around August 2018 and was keen to attend but did not want to do so without an invitation... I contacted the HRCLS team to see if anyone had items that could be used to make the pouches such as old cotton sheets, woollen blankets etc. as I didn't want to turn up with nothing! There was about 6 women in attendance that day including the Aboriginal Liaison Officer from NSW Police. We sewed 39 pouches that day. It was a great opportunity for me to talk about my role, about the Invisible Hurdles Project and about HRCLS generally. Most of those present knew there was a lawyer at AWAHS but were not aware of HRCLS itself. I was invited to continue attending which I did weekly from that first session on 7 January 2020.

In the interests of fairness (given my baking crusade for Men's Shed) but primarily as way of building rapport, showing respect and having something to chat about, I started baking weekly for the Women's Circle as well.

Fortunately, I was able to attend the Women's Circle weekly for 10 consecutive weeks prior to Lockdown 1.0.'

- Legal Project Worker report 2021 p.11

The Legal Project Worker has demonstrated authenticity and an openness to sharing her own culture and personality. This has clearly enabled connection with the Aboriginal clients at AWAHS. And also from the connections made with the young people at FLS.

The Project Worker put time and effort into baking food to share with the Women's Circle and the Men's Shed, which is an action that could be seen and enjoyed by the participants in those circles. This effort is to be commended as is her reflective practice. Just as she noted that the Men's Shed was not reaching the target client group of young Aboriginal people aged under 25 , so too did she 
note that there was not a large amount of young people attending the Women's Circle and that there are other groups which she could attend, such as AWAHS' Boorai Bundles Walking Group for new parents (Legal Project Worker's report p.12). It is not always clear from the outside whether a particular group will provide the most relevant connections. The Legal Project Worker has demonstrated though that she is alert to the need to find the points of most connection with young people. It is highly likely that, had COVID not created a hurdle for connection, the Legal Project Worker would have been able to connect with these younger people's groups.

\section{Food builds relationships}

'Food builds relationships and trust. We used lollies at our CLEs at WFLC to encourage engagement and participation. Consistently baking food for the Men's Shed and Women's Circle was very successful as an engagement strategy. Food is an easy conversation starter ("What are you making next week?" was often yelled out to me from all corners of AWAHS). It is also an opportunity to show respect because most people realise baking takes time and effort, and they appreciate that.'

- Legal Project Worker report, Conclusion 2021

\subsubsection{Engaging}

Comments shared by young people in the WFLC Focus Group and the staff across organisations indicate that both lawyers are very well-received by young people. The young people appreciated the Project Worker's (Lawyer 6) humour and that she shared with them amusing photos, including selfies, and videos that she had made. This indicates engagement with young people, a key proxy for measuring effectiveness in this project.

\section{Humour breaks down barriers}

'One strategy I kept from 2019 was my use of humour in the CLEs. I continue to include silly photos of myself as part of my weekly introduction/reminder of who I am and what my role is. This to me remains a critical part of the process of breaking down the barrier between me as the "professional" and the young people, as well as helping establish a relationship between us as equal partners.'

- Legal Project Worker Report 2021 p.39.

\subsection{Professional Development}

The full of professional development undertaken in this project is laid out in Appendix 3. A summary of professional development for 2020 is provided here:

WFLC:

- 3 formal sessions

- "NSW-VIC COVID-19 Border Restrictions" on 22 July 2020

○ "Fines \& Work Development Permits" for on 2 September 2020 
- "Domestic and Family Violence Orders (IVOs \& AVOs)" on 11 November 2020 (to whole network of Flexible Learning Centres (Wodonga, Benalla, Shepparton and Seymour)

- Teachers were present at the 19 formal CLE sessions conducted for students in Term 1 of 2020

AWAHS:

- 1 formal session

- "Domestic and Family Violence Orders (IVOs \& AVOs)" for AWAHS All Staff Meeting on 12 November 2020

- 1 informal session via "Update to Senior Management" on 21 June 2020 included discussions around family violence and how it was responded to at AWAHS.

NESAY:

- 2 formal sessions

- "Domestic and Family Violence Orders (IVOs \& AVOs)" on 8 September 2020

- "Family law and family violence" on 22 September 2020 (delivered by Jodie Wells, Family Violence Lawyer from HRCLS)

- 9 informal PD sessions delivered via the "Cuppa Dates" referred to above

This exceeded the goal of 1 session per Partner Agency per quarter (total of 12 for the year). There were 6 formal sessions and 10 informal sessions meaning 16 in total (plus the 19 CLEs where teachers were present). All of these were conducted via a video conferencing program (either Microsoft Teams or Zoom) due to the pandemic.

In 2019, 20 staff meetings and 4 community sessions were attended by staff of the Invisible Hurdles project at AWAHS. As highlighted in the Final Research and Evaluation Report for Stage I of the project, visibility of the Invisible Hurdles project team at social events and staff meetings was considered critical to build trust and relationships between the service providers and their clients.

The 2020 table in Appendix 3 amalgamates the professional development work undertaken for Flexible Learning Centre and NESAY. What it shows is again the attendance of staff at joint staff meetings where not only there was visibility of the project staff but where the critical issues of finding workarounds to ensure professional development and engagement with young people could occur, throughout the restrictions.

\subsubsection{Professional Development surveys}

The survey results of Professional Development sessions are found in Appendix 4. The surveys include comments or suggestions as well as numerical measurements of knowledge and skill acquisition resulting from the training.

Each Partner Agency was surveyed once with varying results:

- AWAHS: no responses received to either pre or post session survey

- NESAY: 11 staff participated in the training. 5 pre-session and 2 post-session surveys completed were completed. 
- WFLC: The survey was administered as part of a presentation delivered to not just WFLC staff but the whole North East Flexible Learning Network ('NEFLN'). Some staff from the broader network were aware of the IH Project but others were not all aware of it and it is noted they are not the direct partners in this project. The session was delivered to these two audiences. Accordingly, of 37 pre-session responses, only 15 were from WFLC staff. This may have meant a variation in responses reflective of one group being partners already and other not being existing partners and so there being a varied level of exposure to the IH Project. The service data received 3 post-session responses, all from WFLC including a comment from Leading Teacher that '[she] will know what guidance to give students in terms of how to go about accessing AVO/IVOs for their own safety. [She] will also be confident in how to talk with emotional or heightened parents when they are making demands based on AVO/IVOs'.

Conduct of the survey in conjunction with each formal PD session, at times was considered by the project team as not appropriate due to shortness of time (for example in relation to the Professional Development session to WFLC about the border restrictions.)

More participants in professional development provided feedback in the pre-training surveys, than they did in the post training surveys that were administered. This presents a problem for the research evaluators as it is difficult given the small numbers, because there is a limited comparison point as very few post-training surveys were completed. This means that they are not representative and so make it to make any conclusions about the shifts or changes in practice as a result the training or professional development.

During the project very few of these surveys were administered across the agency partners. This may be a product of the COVID-19 pandemic as well as the non-routinised attitude to taking survey feedback data that was designed to test the elements that the project evaluation is seeking to measure. In addition, staff of the Invisibles Hurdles Project appeared reticent to administer the survey as they feared it would add to the administrative burden of participants. Rather than seeing the administration of such surveys as an important feature in obtaining external, unbiased participant feedback on the effectiveness of the delivery of the professional development and shifts and changes in practice that occur as a result, the staff lacked confidence in explaining the purpose of the survey.

The survey is intended to test the level of knowledge that professional development participants had before they undertook the training and to compare them to the level of knowledge that they had after the training. It was also designed to test whether as a result of the training the participants would behave differently and use their newfound knowledge, if this was attained, differently. Being able to collect this data is a critical element in determining effectiveness of the professional development and its impact. However, the evaluators acknowledge that the Invisible Hurdles team may be concerned that the survey process could be burdensome for participants and this could be discussed for future evaluations. The evaluators acknowledge that not every session may need to be evaluated using the tool as it may not always be appropriate. However, some consistency and effort where its administration is appropriate is required to gauge the effectiveness of the professional development and test it against other tools which may be biased. It loses its veracity if the only data is merely the view of the trainers as to how their sessions went and in assessing what utility the session might have in practice for other professionals. This however, is somewhat ameliorated by the interview data that was obtained from participants in the interview data discussed below and highlights the value of having multiple tools as part of the evaluation approach. It means where one tools such as the pre and post professional development survey is incomplete, there is material that 
can still provide valuable insights by having explicit questions on professional development in the interview questions.

In addition, the survey tool was intended to be delivered in a face-to-face environment. The online environment meant that there was less opportunity for explanation about the survey and adaptation of the instructions as to how it was to be administered in an online setting.

Also, it seems the term 'client' might need to be adapted to 'students', for future WFLC surveys because the term confused one participant. The project staff have in their written material to the evaluators indicated a willingness if 2021 is a more structured year (due to vaccines etc.) to administer the surveys more routinely.

\subsubsection{Visible}

As highlighted in the Final Research and Evaluation Report for Stage I of the project, visibility of the Invisible Hurdles project team at social events and staff meetings was considered critical to build trust and relationships between the service providers and their clients.

It is clear from the secondary consultation, referral and advice data that this visibility around AWAHS locations such as the Men's Shed, has led to an increase in engagement by a staff and consequently by the clients of AWAHS with a growth in work undertaken by the Invisible Hurdles project across these three key areas. This is suggestive of the fact that there is a strengthening of relationships, willingness to attend cross agency events, and be seen at activities engaged in by the Aboriginal community, that is transferring into people turning to the legal service for assistance.

Presence at the agency is important also so that all staff who interact with clients are aware of the resources available. For example, the below quote reminded evaluators that it was important for everyone, from drivers to doctors, to know how to refer to the lawyers.

\section{We've got someone who can help}

'And I think that and why this stuff in the staff meeting... just the fact that our transport drivers, our admin, know what's happened. So, if somebody mentions it, they can say 'oh we've got someone who comes here, go talk to them'

- Staff 2019.

\subsubsection{Responsive}

The 2020 table in Appendix 3 amalgamates the professional development work undertaken for Flexible Learning Centre and NESAY. What it shows again is the attendance of staff at joint staff meetings for visibility of the project staff but also workarounds to ensure professional development and engagement with young people could occur throughout the COVID-19 pandemic.

The shift that is evidenced in March 2020 to working from home and the use of online methods of communication indicates the swift responsiveness, adaptation and flexibility to this new mode of working in an online at home environment by all the agencies concerned. The proxies of reach, 
engagement and empowerment were all evident in the data even with the challenges presented by COVID-19.

Working with NESAY to provide 'Cuppa dates' by Zoom where professional development could occur by Zoom in an engaging and interesting way, and where updates restrictions could be discussed, and strategies developed. As the chronology of restrictions demonstrates, there were frequent changes to the rules and so the ability to convey the changing landscape with a sense of immediacy to the professional staff was important. It seems to have been done with agility and timeliness through these Cuppa Dates. The staff at WFLC have commented similarly on the prompt updates that they received about the legal impacts of changing restrictions, during the weekly staff meetings.

\section{Being more intentional}

'Being unable to attend any of the partner organisations onsite due to COVID-19 was obviously the most significant challenge. It made me more aware of how critical those 'corridor conversations' and 'water-cooler chats' are in developing relationships with new staff and maintaining relationships with existing staff in order to encourage secondary consultations and referrals. This caused us to be more intentional in our relationship management by setting up the NESAY "Cuppa Dates', a weekly catch up with teachers at WFLC, ensuring visibility at AWAHS fortnightly staff meetings, creating social media posts, advertising in partner agency newsletters, connecting directly with new staff, distributing new posters and developing a COVID-19 Legal Health Check.'

- Lawyer 6 reflection

This alternate method of engaging with staff also evidences of the need to tailor Integrated Justice Practice for individual organisations. The next quote reflects how the lawyer had realised that the original model of attending staff meetings was not the right fit for their relationship. Whilst this might indicate, on the one hand, a problem with integration, the authors do not have this concern in this case as other data reflected very good integration at this partner.

\section{The appropriate stepping stone}

'I did feel a level of uncertainty among staff when I attended staff meetings. I felt like they were thinking "why is there a lawyer at our staff meeting?"; "how is our staff kitchen cleaning roster relevant to this lawyer who doesn't work here?"; and "do we have to be careful of what we say in this meeting?". As such, while the goal remains to be included as part of regular staff meetings, the Cuppa Date concept seemed an appropriate stepping stone.'

- Legal Project Worker Report 2021 p.30

The regular Professional development at NESAY and through the WFLC staff meetings also allowed for key learnings about delivering Professional Development, see, for example, Lawyer 6's comments below on repetition of messages.

\section{Repeat, repeat, repeat}

'Repetition of key messages over a long time period is crucial. Not twice, or three times but 10 times! In every Cuppa Date with NESAY staff we reminded them who we were, some key legal issues they could refer to us and how to do so. Repetition of things in short CLEs is much more effective 
than a long and detailed CLE.'

- Legal Project Worker report 2021 p.90

\subsubsection{Engaging}

The cuppa dates allowed for professional development from workers' homes, online via Zoom. They provided updates on changes to legislation and implications of those changes through the pandemic could be discussed, strategies developed and fun had through legal quizzes.

\section{A quiz slide}

\section{True or false}

\section{If you don't pay your phone bill and end up with a default on your credit report, once you pay it the default will be removed.}

The most telling assessment of the effectiveness of these sessions is, as the staff themselves identified, that the workers kept attending these voluntary sessions.

\section{They keep wanting more}

'It was remote for 9 months+. The fact that staff still kept logging in for our catch up, that shows the value of what [Lawyer 6] and [Lawyer 3] were doing.'

- NESAY staff

These Cuppa Dates relied on three factors that the evaluators have observed: structure, relevance and fun. The sessions were also time-boxed, at $\mathbf{3 0}$ minutes or less, making them accessible. 


\subsubsection{Easy to understand}

A common theme from the interviewees was that in all their work (Professional Development, Community Development and Legal Advice/Casework), the lawyers are clear. They speak in plain English which is another essential attribute of a worker in integrated justice practice.

\section{It's not waffle}

'We've had some training on our PD days... The thing with [the lawyers] is that they are able to deliver it at a level where if you don't have any legal terminology in your head, and you're not exposed to that, they deliver it in a way that is easy to understand. So sometimes teachers can go to PDs and it's just waffle, waffle, waffle but this was [not like that].'

- Staff, 2021

One of the most critical components of a learning environment is the freedom to ask questions and clarify things. The qualitative data indicates that this was a routine style of the lawyers.

A good way of learning

'You could ask questions and it was a good way of learning, especially when you're a newbie.'

- Staff 2021

\subsubsection{Relevant}

The data indicates that topics covered in Professional Development were always relevant. The Invisible Hurdles team attended the Flexible Learning Centre network day and presented there, as well as providing routine Professional Development through staff meetings.

\section{Relevant to border issues}

'We had a session at the network. We are one of four Flexible Learning spaces and they talked about AVOs and what that means and what it means for being across the border... that was really good.'

- Staff 2021 
A list of topics from the Cuppa Dates at NESAY is below. It is clear that the topics are varied and relevant to the young people that the workers are helping.

\begin{tabular}{|c|c|c|c|}
\hline$\#$ & DATE & $\begin{array}{l}\text { NUMBER OF NESAY } \\
\text { STAFF IN } \\
\text { ATTENDANCE }\end{array}$ & $\begin{array}{l}\text { TOPICS/DISCUSSION } \\
\text { POINTS }\end{array}$ \\
\hline 1 & 26 May 2020 & 8 & $\begin{array}{l}\text { - Chit chat! } \\
\text { - Draft Legal } \\
\text { Health Check and } \\
\text { feedback } \\
\text { - Centrelink class } \\
\text { action } \\
\text { - Fines where WDP } \\
\text { an option } \\
\text { - Mobile phone } \\
\text { affordability }\end{array}$ \\
\hline 2 & 9 June 2020 & 9 & $\begin{array}{l}\text { - Centrelink } \\
\text { Robodebt class } \\
\text { action }\end{array}$ \\
\hline 3 & 23 June 2020 & 8 & $\begin{array}{l}\text { - Query from } \\
\text { HRCLS as to what } \\
\text { issues NESAY YP } \\
\text { are facing: } \\
\text { o Mobile phone } \\
\text { contracts being } \\
\text { entered into on basis } \\
\text { of COVID supplement } \\
\text { o BNPL } \\
\text { o No scams }\end{array}$ \\
\hline 4 & 7 July 2020 & 7 & $\begin{array}{l}\text { Fairer Fines } \\
\text { system NSW: } \\
50 \% \text { reduction }\end{array}$ \\
\hline 5 & 28 July 2020 & 7 & $\begin{array}{l}\text { - } \text { Cross border } \\
\text { restrictions; } \\
\text { shared HRCLS } \\
\text { fact sheet } \\
\text { - } \quad \text { Raise the Age } \\
\text { Campaign } \\
\text { - Shared link to In } \\
\text { - My Blood It Runs } \\
\text { - Practitioner } \\
\text { Action Group }\end{array}$ \\
\hline
\end{tabular}




\begin{tabular}{|c|c|c|c|}
\hline 6 & 11 Aug 2020 & 6 & $\begin{array}{l}\text { - Masks } \\
\text { - Cross border } \\
\text { restrictions } \\
\text { - Two staff } \\
\text { members raised } \\
\text { issues about their } \\
\text { clients refusing to } \\
\text { comply with } \\
\text { COVID } \\
\text { restrictions }\end{array}$ \\
\hline 7 & 25 August 2020 & 7 & Cuppa Date Law Quiz \\
\hline 8 & \multicolumn{2}{|l|}{8 September 2020} & $\begin{array}{l}\text { Family / Domestic } \\
\text { Violence Orders }\end{array}$ \\
\hline 9 & 22 September 2020 & 11 & $\begin{array}{l}\text { BMS on leave, } \\
\text { presentation by } \\
\text { Jodie Wells and } \\
\text { Lawyer } 3 \text { about } \\
\text { interaction between } \\
\text { IVOs and family law, } \\
\text { Q \& A session } \\
\text { Pre and Post session } \\
\text { surveys }\end{array}$ \\
\hline 10 & 20 October 2020 & 8 & $\begin{array}{l}\text { Questions from } \\
\text { team about MARAM }\end{array}$ \\
\hline 11 & 17 November & 2 & $\begin{array}{l}\text { Cuppa Date Legal } \\
\text { Case studies } \\
\text { PowerPoint } \\
\text { - Employment law } \\
\text { - Street law } \\
\text { - } \text { Consumer law } \\
\end{array}$ \\
\hline
\end{tabular}

\subsubsection{Interview statistical data about training:}

Everyone interviewed by the Invisible Hurdles evaluators had participated in training and found that it had enhanced their ability to assist clients. Importantly, $100 \%$ of participants said that they could recall and had choice in the topics, that it was interesting, useful, relevant and increased their understanding. Professional Development is a capacity-building exercise. Often, not everyone can be engaged by the same means, or the content may not be interesting but that is clearly not the case from the perspective of the non-legal professionals, at the time we interviewed them. 


\section{Non-Legal Professionals: Training (2021)}

\begin{tabular}{|c|c|c|}
\hline $100 \%$ & \multirow[b]{10}{*}{ Yes } & \\
\hline $\begin{array}{l}90 \% \\
8 \%\end{array}$ & & \\
\hline $70 \%$ & & \\
\hline $60 \%$ & & \\
\hline $50 \%$ & & \\
\hline $40 \%$ & & \\
\hline $30 \%$ & & \\
\hline $20 \%$ & & \\
\hline \multirow{2}{*}{$\begin{array}{r}10 \% \\
0 \%\end{array}$} & & \\
\hline & & No \\
\hline $\begin{array}{l}\text { Have you participated in training } \\
\text { by the team? }\end{array}$ & $100.00 \%$ & $0.00 \%$ \\
\hline $\begin{array}{l}\text { Has this enhanced your ability to } \\
\text { assist clients with non legal } \\
\text { needs }\end{array}$ & $100.00 \%$ & $0.00 \%$ \\
\hline
\end{tabular}




\section{Non-Legal Professionals: Training quality and engagement (2021)}

\begin{tabular}{|c|c|c|}
\hline \multicolumn{3}{|l|}{$100 \%$} \\
\hline $90 \%$ & & \\
\hline $80 \%$ & & \\
\hline $70 \%$ & & \\
\hline $60 \%$ & & \\
\hline $50 \%$ & & \\
\hline $40 \%$ & & \\
\hline $30 \%$ & & \\
\hline $20 \%$ & & \\
\hline $10 \%$ & & \\
\hline $0 \%$ & Yes & No \\
\hline Recall what it was about & $100.00 \%$ & $0.00 \%$ \\
\hline Involved in choosing topic & $100.00 \%$ & $0.00 \%$ \\
\hline Training was interesting & $100.00 \%$ & $0.00 \%$ \\
\hline $\begin{array}{l}\text { Increased understanding of the } \\
\text { law }\end{array}$ & $100.00 \%$ & $0.00 \%$ \\
\hline $\begin{array}{l}\text { Increased understanding of rights } \\
\text { and responsibilities }\end{array}$ & $100.00 \%$ & $0.00 \%$ \\
\hline Will use the information & $100.00 \%$ & $0.00 \%$ \\
\hline $\begin{array}{l}\text { Will respond differently as a } \\
\text { result of training }\end{array}$ & $100.00 \%$ & $0.00 \%$ \\
\hline Training was relevant & $100.00 \%$ & $0.00 \%$ \\
\hline
\end{tabular}

\subsection{Systemic work}

Several pieces of effective and outstanding systemic work has been achieved by the Invisible Hurdles team in collaboration with the agencies.

When the authors conducted the mid-project, interim evaluation, they found that the partners had been routinely discussing burning issues for young people in the district in their advisory group. For example, the partners had discussed working together on a letter to a decision-maker collectively calling for a change in policy to better serve young people. This was very encouraging and in applying the Collaboration Measurement Tool, indicated that essential first steps are underway and in planning on systemic reform initiatives. Unfortunately, in 2020 only one formal meeting of the partners was possible, due to COVID-19. For the rest of 2020 and 2021, meetings were held one-on- 
one with each of the partners and the Invisible Hurdles' management. This did mean that systemic work as a collective was not achieved.

It is also that it is not always practicable for all partners to be involved in law reform. This is because of sensitivities that may exist for one or more partners either with their individual funders or by advocating with a specific decision-maker that may be put off-side and jeopardise their relationship in terms of service provision to young people.

A list of the systemic work that the Invisible Hurdles team has completed is below:

\section{Child protection Leaving Care Panel}

- Attended to raise potential of a birth certificate project

Consumer leases and payday loan advocacy

- Review of consumer leases \& payday loans and a letter to Dr Helen Haines MP (March 2020)

\section{Victoria Police survey}

- Victoria Police Community Connection Survey (2020)

\section{Youth consultation}

- Youth in Politics (youth meeting with service providers) (2020)

\section{COVID-19 restrictions advocacy}

- Learner Driver letter to Minister for Health, Victorian Cross-Border Commissioner, Member for Benambra and subsequently Minister for Roads, Road Safety \& TAC and Minister for Regional Development (8 May 2020)

\section{Victorian Government Youth Strategy}

- Participation in community forum for Victorian government youth strategy (Oct 2020)

- Assisting young people to complete electronic surveys for Victorian government youth strategy (Oct-Nov 2020)

- Consultation with youth advisory committee (NESAY) on youth strategy

- 8-page submission signed by all partners (Jan 2021)

\subsubsection{Examples of systemic impact}

The first example of systemic work to highlight is at the WFLC where the lawyers asked students to complete the National Youth Survey. The impact of this work with students was significant, as described in the quote here from a teacher.

\section{Introducing the idea that young people have a voice}

'With the National Youth Survey that they got the young people to fill in last year and with the Community Police Survey that the young people did, that's the stuff that starts creating agency in the young people and then actually identifying the fact that they do possibly have a voice that could contribute to change if they wanted to go down that path. Previous to that, I don't think our young people would feel like they would be listened to, and they're not the kind of kids who would be aspirational... They're not going to go and join the youth council committee. Whereas, this way, they were introduced to the idea that they could have a voice in change or that their voice would go 
towards something that would be considered.'

- Teacher at WFLC 2021

Evidence that the students had progressed in their understanding came from interviewees describing how students had started to try to advocate for themselves. This evidence of empowerment of young people in the project demonstrates that the model of work in the Invisible Hurdles Integrate Justice Practice is not only effective, it achieves impact with one of the most disadvantaged groups, which is an outstanding success. This group of young people are some of the most disenfranchised young people in the nation, and therefore are often too stressed by their own daily concerns and too disempowered to engage politically. To improve the young people's understanding of their political system and how to have a voice is a victory.

\section{He knew he could have a voice:}

'They know Scomo, and they know Canberra. But that's about it... [when the Victorian Education Department banned mobile phones], one of my autistic kids, he was furious. He was like 'No, I am not doing this'. And I said 'Well, we can write a letter.' And he said 'No, I am going to ring.' And he got so in the moment, he rang Parliament House. But not even knowing that it was a State Government thing and he needed to ring Melbourne, he went to the top. He rang Parliament House. Someone answered, and he said 'My name is such and such and I'm from Wodonga Flexible Learning Centre and I'm going to tell you that, you know what, banning phones in schools is not good. I'm autistic and my mum needs to be able to, blah blah blah blah blah.' And the guy on the end of the phone said 'Look mate, I'm really sorry, I'm just the receptionist. I can put you through to Melbourne and you can talk to someone', 'No, no, I want you to take my call to Scomo.' He was quite passionate about it and that's because he had been to Invisible Hurdles and knew that he could use a voice, even though it was the wrong way to do it. But at least he thought he could have that right... This particular student would attend Invisible Hurdles, and he was a part of the Helen Haines letter as well, so I can only assume that's where he got it from. He knew that he had some sort of fundamental human right to speak and to be heard.'

- Teacher at WFLC 2021

\section{We had that letter written:}

'We got the kids to write a letter to the local member, Helen Haines... It's very hard to try and get our kids to think in an advocacy way because they're always being advocated for. But for them to think outside the square and get them to do some of that work, it's very hard. But [Lawyer 6] worked very hard and we had that letter written.'

- Teacher at WFLC 2021

\section{There's snakes in the playground:}

'One of our students wrote a letter to the council about a playground. That was last term. But the 
council responded that they're not changing anything. The student has a young daughter and there were snakes in the native grasses near the playground... and so she feels she couldn't utilise the playground. At least she was made to feel that she had a voice and that she could approach the council. That's something that she would never have done without that confidence... It's something that will probably make her more politically active in the future, that she has a voice, that her say is important.'

- Teacher at WFLC 2021

The second example of systemic advocacy giving voice to young people was through a submission to the Victorian Government's Youth Strategy. The momentum described in the next quote is clear. The lawyers' determination to have young people from all three organisations heard is noticeable. This evidences collaboration across all partners and HRCLS, capacity-building, empowerment and engagement - key indicators of success of an integrated justice practice. This is a first-class example of integrated justice practice and illustrates profound success of the Invisible Hurdles program, now in its sixth year with deep connections and relationships.

\section{An 8 page submission, all partners, with youth advisory:}

'We also made a submission to the Victorian Government's Youth Strategy. I participated in one of their community workers' forums and out of that we used that as the basis for some CLE sessions at Flexi... they [the young people] had some really great ideas about a youth centre in Wodonga, some interesting ideas about public transport, they gave some feedback about the skate park as being a place they don't feel safe... All three classes that we work with were involved (VCAL, Middle years, and Young Parents). We kept coming back to it.

We did a lot of background work as to what it was, what the point of it was, what it would inform, which the government had said the next ten years of their policy across the whole of the government. Again, that kind of foundational work [with the students] about what is the law? What is the government? And then to get up to 'What are your thoughts? What's your feedback?'

We made it into a workbook for the school to use and there was a survey, discussion questions (which was a bit more advanced) and also a 'if you were Premier for the day' question. We provided it as a workbook and they printed it out and gave it to the students. We got all their survey responses and submitted them through the online portal. Then we got all their responses that they'd given us, which most of them were verbal, not many of them do a lot of writing, we collated that and then in conjunction with that we consulted with NESAY's Youth Advisory Committee for their thoughts on the discussion questions and then our submission to the government was in two parts. One was the direct responses from the Flexi students and the YAC. The YAC is mostly former NESAY clients who apply to be part of the YAC.

All of the partners contributed to the submissions. A couple of the students at Flexi were also patients at AWAHS so we were able to get that feedback from Aboriginal kids as well. Then all the partners got on board as well. Our submission was the Integrated justice practices work, this is something that should be rolled out across Victoria and this is something you should be thinking about when funding other things. It was an 8-page submission and we were able to provide copies to the students to say 'This is what you've done.' This morning I got a response back from the Minister 
for Youth in relation to that.

- Lawyer 2021

There are also links between learnings in the systemic work above and professional development. As a result of the feedback from NESAY's Youth Advisory Committee, the lawyers identified gaps in teacher professional development and submitted an application for funding of family violence training for four schools in the region.

\section{Young people identify the gaps:}

We collated the feedback from WFLC and YAC into a written submission... It was particularly to note the comments of the young people about family violence (on page 6 of the letter). As a result of their comments, we have made an application for funding for a family violence training program for teachers to be rolled out at four high schools in the area.'

- Legal Project Worker Report 2021 p.57

The third example of systemic work happened around the border closure issues and young people not being able to practice driving on their Learner permits. Having a licence is essential in many regional areas because public transport can be scarce in some areas. Therefore, there is a direct link between having a drivers' licence and employability. The lawyers wrote a letter about this issue addressed to to the Minister for Health, the Victorian Cross-Border Commissioner, and the Member for Benambra. The Cross-Border Commissioner then forwarded the letter to the Minister for Regional Development and the Minister for Roads, Road Safety and the TAC,

A few days' later the law was changed. They suspect that they added voice to others who were also advocating on the issue, which is important to elevate the importance of the issue in the minds of government. The most inspiring part of this advocacy was that the lawyers asked two young people for their contributions and then, when the rule was successfully changed, they were able to celebrate the success with the young people - demonstrating to the young people that democratic action can be effective.

\section{'You've done this':}

'We did some advocacy in relation to the restrictions on learner drivers, during lockdown. So we had a teacher approach us to say 'I've got some students, they need to practice on their Ls. They need to get their licence when they turn 18 in order to be able to work. The current restrictions are that they can't go on practice drives which is affecting their ability to get their hours up. What can we do? I said righto, let's write a letter. We spoke to two of the students directly and said 'What's the impact on you?' and did a letter from us and Flexi at that stage. We go the letter out on the Friday and the rules were changed on the Monday. We're calling that a win [laughs]. I'm not sure of the impact of the letter but they certainly got it [the letter] and it was pretty awesome in being able to get the young people involved in it, get their comments about the impact on them, get them a copy to say 'You've done this'. We've since had that particular student reach out twice about other things.'

- Lawyer 2021 
The fourth example the authors would like to highlight is one of the lawyer using her role to advocate about the experiences of her clients occurred early in Stage II. The lawyer arranged a visit to and attended the 'Leaving Care' panel of the Department of Health and Human Services, to provide the panel with evidence of her experience of challenges with the birth certificate system. The use of case studies is persuasive in systemic advocacy and the lawyers' files are replete with case studies of young people without birth certificates and who have extreme struggles receiving one and living without one.

\subsubsection{Casework leads to systemic action}

The integrated practice model has allowed the lawyers to provide advice and casework assistance to many students in this situation, which has then led to them being experts in the topic and being able to advocate at a systemic level about the issue. The two quotes below illustrate how the lawyer came to be able to give evidence to the Leaving Care panel, as a direct result of her casework.

\section{Breakthrough outcome in casework leads to systemic action}

'So DHS have a kind of child protection, so the young person was "aging out of the system"... they were seventeen, turning eighteen...The impact on this young person was they did not have a birth certificate because they not registered. So they had been in and out of child protection systems since they were a baby and they were now 17 ...It seemed to me that it was basically we'll just pass the buck on to this agency to try to resolve... And I thought "Oh, I'm intrigued, there's an administrative issue here." So this young person is not registered and they need their birth registered... The young person can't do anything, they can't even get a bank account. They can't get Centrelink... because you needed a birth certificate, because you needed a tax file number.

When I spoke to the social worker, we had a discussion how "if you are struggling, how is the child? How is a young person going to do this?"

So despite the fact that we had to deal with one government department to get the young person's birth registered, we had to prove their footprint in the community. We had to go back get medical, get letters from schools, from doctors, from dentists, from people that knew this person and send that in. We then had to get mum to sign the original form because it's that restrictive that if mum doesn't sign the registration, that cannot be registered. So in my head, I was always thinking, all right, we're going to have to do an application to the Family Law Courts. And that was my plan B. But eventually, mum agreed.

We then went into Centrelink, and I said to them, the birth certificate stuff has been approved. It's got to go through the special specialist section that you can't even call on the phone, they don't call you and you don't call them. You just have to go through their call centre. It was insane what I had to do. Then Centrelink said 'we need a tax file number before we can actually release the payment. All right. So then I had to call the tax office and they like we need a birth certificate to prove who the young person is. And I said I don't have that. This young person with Aboriginal and they said oh, we have a different way of doing it, but the form is not available to download. It has to be sent to you or you have to collect it in person. 
So I got the form - I went in and picked it up from one of their tax shops, organized for a teacher who was retiring to be the person because they had to have a witness or a person who had known this person this many years to complete that, and then I had to post it because you can't fax a form, you can't email a form, you have to post a form. So I posted it.

I called them a week later. 'Oh, it's not in our system.' Give me an email address. I emailed it. I called them a week later. 'It's still not in our system'. And I was pulling my hair out, thinking 'what are you guys doing? It's almost like a reverse discrimination. You try to make it easier for this population to get their tax file number. Yet you've made it so archaic by having to do everything in paper form'. And Centrelink had said, if you get me a reference number of you submitting this, we can make the payment. Had the young person not been Aboriginal and submitted it online, we could have got a reference number. But because they are Aboriginal, yes there's a form, awesome, but you can't submit it online. It was astounding. In the end, I pressed them. We've got a fax number, an email address and I posted it again. So third time lucky. And I just got really quite annoying. And I even went into the Albury 'My Gov' and got the tax person to call her contacts within the tax office to get someone's number to ensure that this gets registered...

I'd gotten the birth certificate two days before the young person's 18th birthday. And when I rang to tell the news, it sounds funny but you could hear the smile on their face, through the phone call, you could hear the smile.

And it just made me go, wow. So, for that young person, it allowed them to get Centrelink to become independent, to not couch surf... It just gave an option. And getting a tax file number to actually work and to get a bank account, because even getting her Centrelink before the tax-file number came through, it had to go into a friend's account... So red tape just gets in the way. $\cdots$

'I was just thinking that a worker couldn't have even spent that time to do that... It showed me that there's this hole in that system. So the worker and I had few discussions about this and they had identified to say, well it's not a common thing, but we have got concerns it could be for these this cohort of young people. So how do we get around that? So she gave me the contact details first as a DHS person who organizes the Leaving Care panel. So I was able to go to that panel and raise this as an issue. Which was great. They listened and they were responsive to it. But then, you know, I got busy at my, you know, in my practice, picked up another best certificate one, so I have now got two case studies but that one wasn't as bad.'

- Lawyer 2021

\subsubsection{Systemic data}

Whereas at end- 2019 only $65 \%$ of non-legal professionals indicated that they agreed with the statement that they look to change systemic causes of problems, by the end of the project, in 2021, this had increased to $87 \%$. Likewise, there was a $20 \%$ increase in Managers identifying that they look to change systemic causes of problems.

In a huge improvement on the Interim (end 2019) data, 75\% of non-legal professionals interviewed said they had collaborated on advocating for systemic reform, as compared with $33 \% 14$ months 
earlier. Participants also reported a marked increase in being asked for their views (62\% in February 2021, compared to $22 \%$ in November 2019). This is impressive and against the indicators of capacity, engagement and empowerment is a significant step especially given the COVID-19 restrictions. (See Appendix 5 for 2019 data).

\begin{tabular}{|c|c|}
\hline \multicolumn{2}{|c|}{$\begin{array}{l}\text { Non-legal professionals: Systemic change } \\
\qquad \text { (2021) }\end{array}$} \\
\hline \multirow{7}{*}{$\begin{array}{r}100 \% \\
90 \% \\
80 \% \\
70 \% \\
60 \% \\
50 \% \\
40 \% \\
30 \% \\
20 \% \\
10 \% \\
0 \%\end{array}$} & \\
\hline & \\
\hline & \\
\hline & \\
\hline & \\
\hline & \\
\hline & $\begin{array}{l}\text { I not only examine the individual client's problems but look to change the } \\
\text { systemic causes of problems including the laws and how they are } \\
\text { administered }\end{array}$ \\
\hline - Strongly Disagree & $0.00 \%$ \\
\hline Disagree & $0.00 \%$ \\
\hline Neutral & $12.50 \%$ \\
\hline Agree & $25.00 \%$ \\
\hline Strongly Agree & $62.50 \%$ \\
\hline N/A & $0.00 \%$ \\
\hline
\end{tabular}




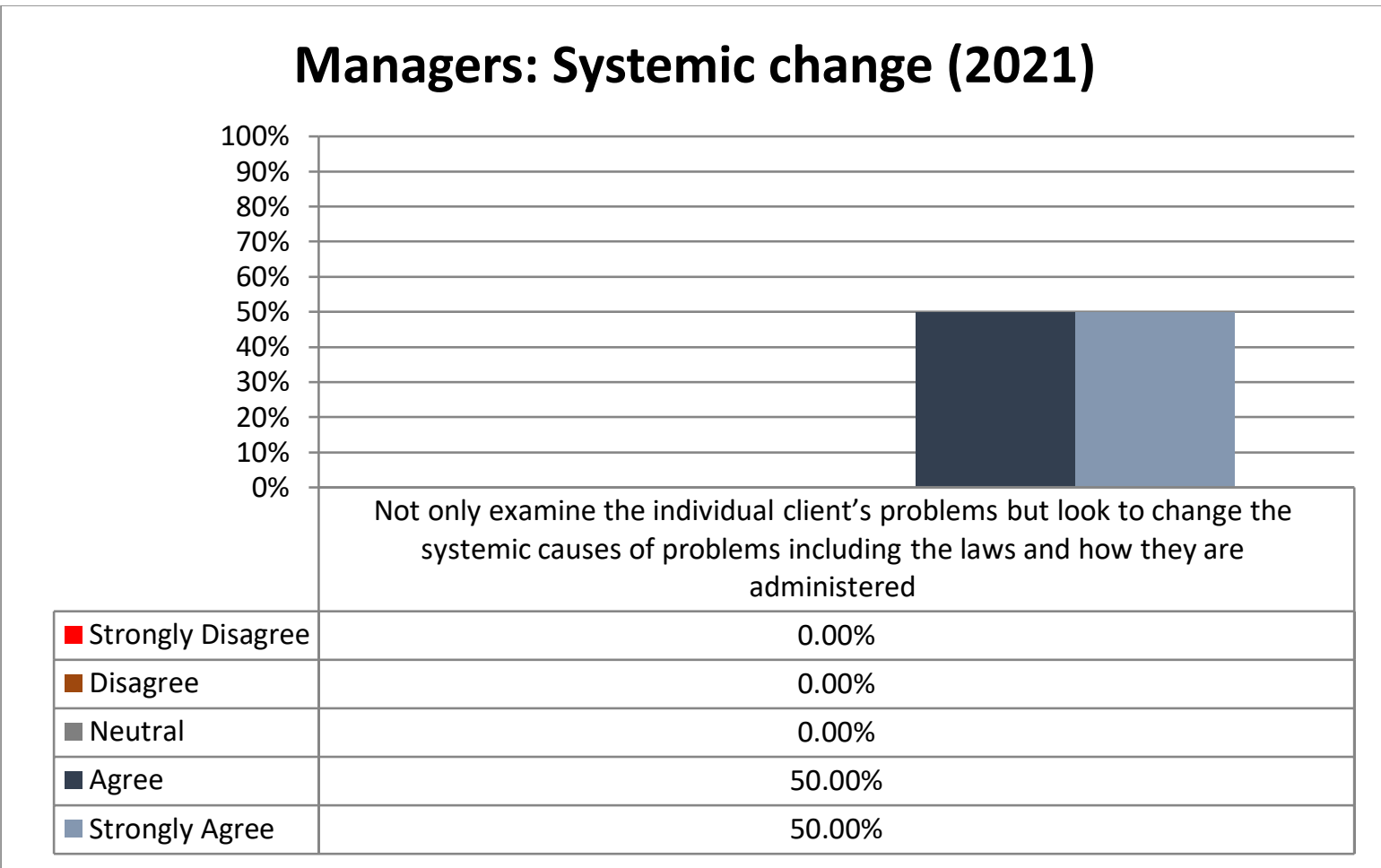

\section{Non-Legal Professionals: Collaborated on systemic reform (2021)}

\begin{tabular}{|c|c|c|}
\hline $100 \%$ & & \\
\hline $90 \%$ & & \\
\hline $80 \%$ & & \\
\hline $70 \%$ & & \\
\hline $60 \%$ & & \\
\hline $50 \%$ & & \\
\hline $30 \%$ & & \\
\hline $20 \%$ & & \\
\hline $10 \%$ & & \\
\hline $0 \%$ & & \\
\hline & Yes & No \\
\hline $\begin{array}{l}\text { Collaborated on advocating for } \\
\text { systemic reform as joint action }\end{array}$ & $75.00 \%$ & $25.00 \%$ \\
\hline $\begin{array}{c}\text { Asked for views or to participate } \\
\text { in work on changing laws that } \\
\text { affect youth }\end{array}$ & $62.50 \%$ & $37.50 \%$ \\
\hline $\begin{array}{l}\text { Would like to be asked for views } \\
\text { or participate in future }\end{array}$ & $100.00 \%$ & $0.00 \%$ \\
\hline
\end{tabular}




\subsection{Integration}

The authors are impressed by the level of integration in this project having measured it against the Collaborative Measurement Tool. The HRCLS operates far more than an outreach service to the partner agencies. The workers at each agency see the lawyers as a regular part of their workplaces, their interaction is seamless and integrated. The data consistently indicated that it is as normal for them to refer a client to the lawyer as it is for them to refer to one of their other specialist colleagues. One non-legal professional described how, in this final evaluation, a new staff member had joined one of the agencies, during remote working. She was excited to hear that the team had a lawyer and had sought secondary consultations, despite never having met in person. Likewise, below we see a second instance of a new staff member, this time making referrals. This evidences, firstly, borrowed trust between colleagues but secondly, that the presence of the lawyer in the team is now an ordinary part of the on-boarding of new staff. This is an immense change in practice from the commencement of the project in 2015 when the lawyers were separate and less integrated. This is indicative of positive impact given in public health discourse, changes in practice are indicators of impact. (See Final Research and Evaluation Report for Stage 1 for further discussion).

\section{They're a part of the family}

'The connection with the Invisible Hurdles program is seen as such a part of NESAY that new people are just seeing it "as a part of NESAY"... It's like the cousin in the family, they're a part of the family.'

-Manager 2021

\section{They're a part of the school}

'We have a whole school lunch on a Wednesday, and they join in on that. They are a part of the school.'

- Staff 2021

\section{A new relationship, from an old one}

'I obtained a number of referrals from a new AWAHS worker whom I am yet to meet in person which I am quite chuffed about because it shows that a relationship can be built even in the virtual world!'

- Lawyer 2021 reflections 


\subsubsection{Reciprocity}

The evaluators measure reciprocity as a further indicator of collaboration as the trust between professionals grows as each sees that they respect what each other has to offer. This reciprocity was evident in the data from the interviews. From Stage 1 data this element of reciprocity is much more evident. This suggests not only a growth in trust but is a pre-condition for greater collaboration. ${ }^{29}$ $100 \%$ of non-legal professionals interviewed agree that they have gained an understanding of other professions' ethics and boundaries (e.g. understanding lawyers' ethical obligations). And further, all staff and management interviewed agree that Lawyers 3 and 6 utilise their expertise. It is clear that the lawyers have worked hard to build these relationships, and also that the non-legal professionals themselves have been committed to equally putting in time to sharing their knowledge with the lawyers, to upskill them.

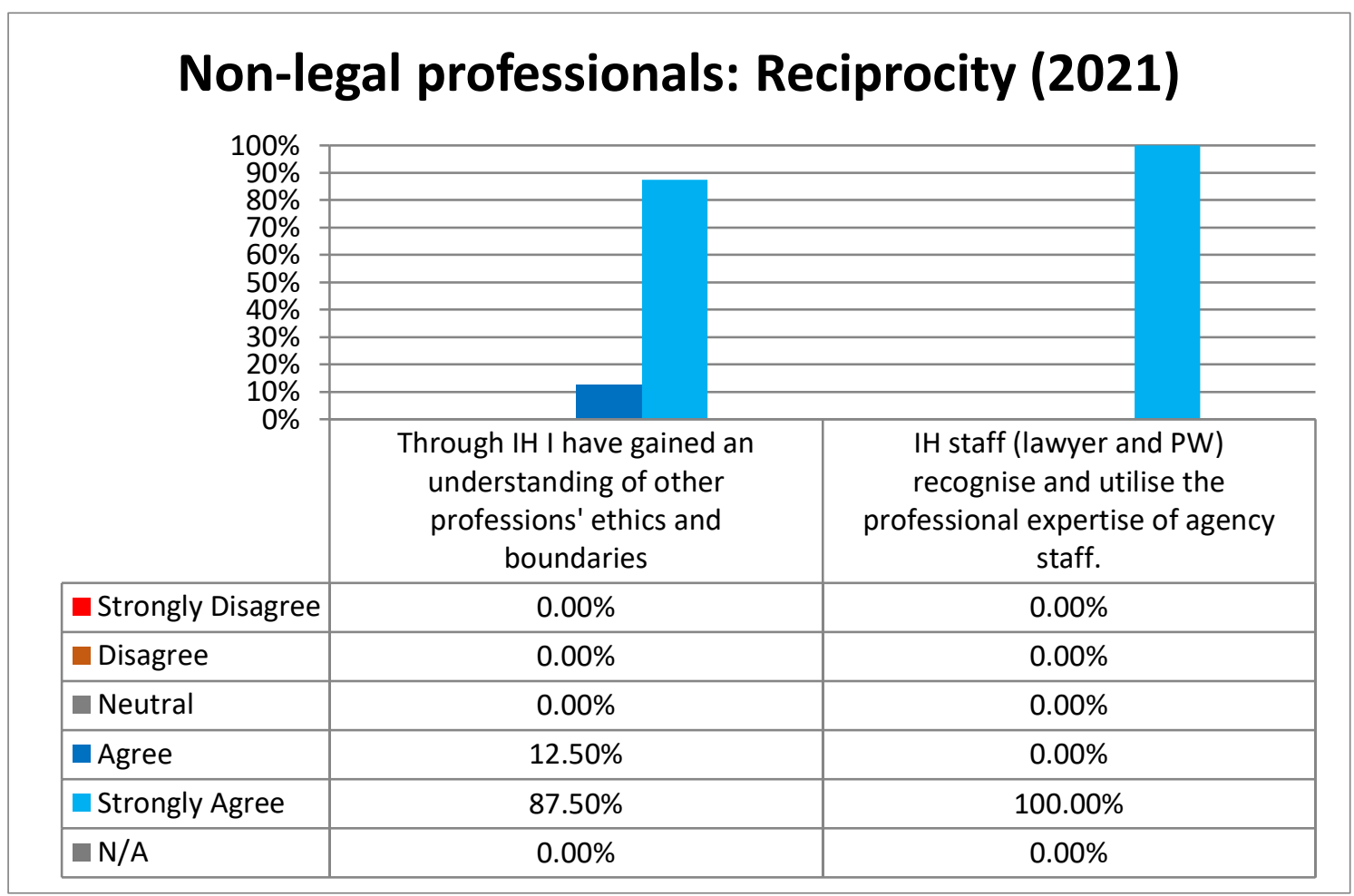

\footnotetext{
${ }^{29}$ Falkman AK, Tviet B, Sverdrup S (2019) 'Leadership in Interprofessional Collaboration in HealthCare', 12, Journal of Multidisciplinary Healthcare, 97-107.
} 


\begin{tabular}{|c|c|c|}
\hline \multicolumn{3}{|c|}{ Managers: reciprocity (2021) } \\
\hline \multirow[t]{2}{*}{$\begin{array}{r}100 \% \\
90 \% \\
80 \% \\
70 \% \\
60 \% \\
50 \% \\
40 \% \\
30 \% \\
20 \% \\
10 \% \\
0 \%\end{array}$} & & \\
\hline & $\begin{array}{l}\text { High level of mutual } \\
\text { understanding and trust between } \\
\text { the IH And my agency }\end{array}$ & $\begin{array}{l}\text { The staff involved in the IH } \\
\text { recognise and utilise the } \\
\text { professional expertise of other } \\
\text { staff }\end{array}$ \\
\hline - Strongly Disagree & $0.00 \%$ & $0.00 \%$ \\
\hline Disagree & $0.00 \%$ & $0.00 \%$ \\
\hline Neutral & $0.00 \%$ & $0.00 \%$ \\
\hline Agree & $0.00 \%$ & $0.00 \%$ \\
\hline Strongly Agree & $100.00 \%$ & $100.00 \%$ \\
\hline
\end{tabular}

One of the lawyers, in particular, spoke about taking the time to observe how the non-legal professionals work with and speak to young people, and that she has modelled her own practice on that. It is clear that the lawyers' identities have developed through the course of this project, to now have a specialised set of expertise and that they have changed their practice accordingly.

\section{I'm a youth lawyer}

'Lawyering in a different way is what my learnings are. I was your generalist community lawyer before I became a youth lawyer. That's what I'd term myself now. Because you've got to re-think the way you speak to young people, the way that you engage with young people, the way you talk to them, the way they talk to you. So it's a very different way from community lawyering. I've learned a different skillset arising from working with young people.'

- Lawyer 2021

\section{I listen}

'It made me improve, my practice, I believe, especially working with people who had some time, no or little literacy and reading and writing skills... And probably the biggest thing for me personally as far as my practice is concerned [is] that I think that it has added to my skills that as a listener, to listen. To listen.'

- Lawyer 2019

The data indicates that the model of integrated justice that HRCLS has adopted with the partners fosters reciprocity, and therefore collaboration and capacity building between agencies. These 
attributes of effective integration are working to reach and have impact with vulnerable young people by creating links between the community development and educational programs. Further, the data provided above indicates an improvement in democratic participation of young people in the program. In this aspect, the model appears to support and empower young people while providing support and legal help.

\section{They created educational opportunities}

'I actually think we've got a model... I think this does a lot more [compared to some other school lawyer programs] in terms of education. They create educational opportunities for us then to in turn link back to the schoolwork so we can use that to tick off outcomes.'

- Staff 2021

\subsubsection{Trust}

One interviewee shared a story about a staff member who may have also been initially hesitant about, or lacked understanding of the lawyers' work, but who no longer is. The willingness of this staff member to change their timetable to fit in with the scheduled sessions indicates trust in the lawyers. Also, such a change does not come without inconvenience, which is a sacrifice on the staff members' part.

\section{Convinced}

'We had teacher had been at the school for three years and he hasn't really engaged in our sessions. He had a new student and he brought the student in. Then he sat in on the session and then said 'Oh I'm going to change my timetable around now to ensure that my kids go to your sessions.'

- Staff 2021

Often we speak of trust being borrowed - for example, from a client trusts the lawyer because they trust the worker but in the final interviews, there was evidence of the opposite also occurring, where trust was able to be built by the lawyer, that resulted in positive outcome for the agency's ability to help the young person. This seems to evidence the greater levels of engagement, reach and capability that can result for clients from the relationships being established. Further, the evaluators have considered that the success of the story below may also be attributable to the extensive commitment by the Invisible Hurdles team, and the HRCLS more broadly, to understanding Aboriginal culture and historical wrongs, such that the lawyers have humility and compassion needed for successful outcomes. This demonstrates the effectiveness of having an Aboriginal organisation included in the partnership through the proxy of engagement and reach being evidence in the data. That is, that the benefits flow beyond AWAHS clients. The reliance upon one another has become evident, further evidencing full integration and collaboration with many of the indicators in the Collaborative Measurement tool being evidenced as present. 


\section{Relational trust and knowledge base: two key aspects}

'We really rely on the Invisible Hurdles program to help do the things for our young people that we can't do... but also a way to connect these young people to services outside of the school and make them feel comfortable talking with professionals out in the community. And knowing that they are worthy of having help.

We have a really difficult parent at the moment and I teach her young daughter. It came to light that even though she's been involved with child protection and removed from home as a baby, her birth has never been registered. So she's desperate to get a part time job, but she can't because she 'doesn't exist'. So I don't know how you can be involved in child protection, and enrolled in a school, and be 15 years old and not 'exist'. But her mum who is very, very volatile, didn't want anyone to know because she was scared she could get a fine. The other thing is this family is also Indigenous. That's what she had been led to believe - that because she hadn't registered the birth, she'd get a fine. As they're Indigenous and child protection has been involved, there's that other fear and trauma of having your child taken away and all that sort of stuff.

So to have [the lawyers] on hand to speak with the young person, to liaise with the parents... [Lawyer 3] has this really beautiful, supportive working relationship with this mum. She went into the Hume Riverina Legal Service, the mother did, and filled out all the paperwork and has dropped off everything. I can't reach this young person's parent, but I know someone who can. They just have a way of making the kids and the parents feel safe and supported. So I think that relational trust and that knowledge base are two really key aspects in our relationship.'

- Staff 2021

\subsubsection{At a management level}

The evaluators observed that there has been a reduction in managers meeting to collaborate at an advisory level. This has been largely made up for by the strength of collaborative effort amongst the lawyers and the staff at agencies. This collaboration is, of course, also because the managers of each individual organisation worked hard to make sure that their staff treated the Invisible Hurdles lawyers as part of the family, as was so aptly put in the above quote about integration. The evaluators are also advised that individual meetings continued to take place through the restrictions, but that group meetings did not.

The evaluators have no concerns about the level of commitment to Invisible Hurdles by the managers. Again, COVID-19 restrictions seriously dampened the opportunities to meet and support one another. The NESAY CEO's attendance at the WFLC presentation night is notable, particularly because she would have had to drive an hour each way to attend the event, likely after a full working day.

\section{Steering but not in an operational sense}

'We had steering group committee meetings here and there's been a steering group connection but not in an operational sense.' 


\section{Business focussed}

'We've only met a few times and when we do meet it's quite business focussed so there hasn't really been an opportunity to build a relationship outside of the practicalities of Invisible Hurdles.'

- Manager 2021

\section{Potential}

'At the end of 2019, we had some really great chats about ways we could work with NESAY and AWAHS. The NESAY CEO came to our presentation night.... We're getting more Koori students. The potential for the yarning circles. And to be honest, it's all fallen by the wayside. The potential is there but it was slowed down.'

- Manager 2021

Although things are ticking along with the managers guiding the project from their own corners, the evaluators' view is that there may be missed opportunities if these meetings are not re-started. Efforts into relationship building at a management level will reap rewards. Some partners did feel, however, that there was an absence of commonality between the organisations (or aspects of their work). They felt that more commonality might lead to easier connections, and therefore more efficient progress on matters like systemic reform. The evaluators appreciate these concerns. There is evidence that the Invisible Hurdles has, however, been a highly effective Integrated Justice Practice. Difficulties may lie only in the partnership arrangement, rather than the model itself.

From HRCLS's perspective, one manager commented 'I think it (having partners) just keeps us on track with what our mission is as a CLC. It gives us a better depth of insight into how we can effectively serve the needs of our clients.' The work of the partners is highly appreciated and valued by the HRCLS.

If Invisible Hurdles continues in its current structure, we encourage the expansion of the advisory group to include youth and Aboriginal people, or at least to consult with separate advisory groups made up of these cohorts. 


\section{Case studies}

The below de-identified case studies have been extracted from the data. Some have been included in the above sections and are included again here.

A teacher came up to me and said this student had been banned from a local plaza. I met with this student who told me what happened. He had been disruptive in the plaza and annoying the security guards and shop owners. The security guards said if you keep doing this you are going to have to leave. He did it. Called the police, had a bad interaction with the police. A week later... he was banned for twelve months... I had a talk to him about what this meant. And he actually then realized that "I can't go there. I was about to go for a job interview at [the centre],... I got banned. I can't go there. That's where my grandma and I have coffee. It's up the road from my house." He said I just didn't realize the impact. So, I called their manager and the manager said if he writes or comes in, writes a letter of apology or comes in and talks to me, I'll lift it. So, I went back and said to the young person this is the offer. And him and a teacher actually worked on the apology together. He wrote it from his words... He wrote it and the teacher went with him to the plaza and [the student] read it.

But in between that, I was actually sick one day and I asked [the Project Worker] to check in with him to see how he was going. And [the Project Worker] and him had a chat and he was really nervous about giving that. And [the Project Worker] did a mock interview with him. And just took him through it as if she was the guy and talked him about appearance, eye contact, ran through the mock interview. And we caught up with him a week later after the interview and you should have just seen a smile on his face and even the teacher... She was just like "You empowered him to do it himself"... This is the Invisible Hurdles project. Then and there, working with the professional who brought the young person in. I could have written it for him. I could have gone to bat for him. But then I was like, no.

A client moved into a transitional housing property in March 2018 that is owned by DHHS Vic. The gas heater was decommissioned in May. The client was given an oil heater as a replacement and borrowed an electric heater to keep him and his 18 month of daughter warm. A new heater was installed in September 2018. The client incurred significantly high electricity bills over this 4 month period- \$2883.77 in total. HRCLS calculated the liability of the client and the housing agency for the usage. After some negotiations, the housing agency agreed to pay off the debt directly to the electricity company.

'I've had a young person mention that the mediation that one of the lawyers was able to organise with the father of her child was really beneficial, because she just didn't know how to go about it. And without them coming in regularly, she told me, she would never have sought legal advice.'

Ellie was referred to the HRCLS by a worker from a local youth support agency. Ellie was receiving support from the youth agency in order to stabilise her living situation, reduce her risk of homelessness and improve her level of engagement with work and participating in the local community. 
Ellie was referred to HRCLS as her case practitioner identified that she had a significant debt that was in her name and it was impacting on her ability to be financially secure and seeking gainful employment. Ellie also suffered from and brain injury and several mental health disorders.

Ellie's legal issue arose when her boyfriend, Greg, compelled Ellie into applying for a \$8000 loan with a bank. Once Ellie got the money, Greg took majority of the money from her used it for his own benefit. Not long after, Ellie lost her job and Greg started being both physically and emotional violence towards Ellie. They eventually broke up and Ellie returned home to live with her mother. Unfortunately, Ellie's mother suffers from alcoholism and perpetrated family violence against Ellie. Ellie was forced to flee her mother's home in order to avoid any further physical abuse, which resulted in her becoming transient and homeless.

By the time Ellie was referred to the HRCLS, the debt had arisen to over $\$ 11,000$

HRCLS wrote to a bank and made several compelling arguments on the basis that the loan was unsuitable, a potential irresponsible lending claim, that she did not receive any benefit from the contract, that she was the victim of family violence and she had exceptional circumstances. The bank eventually agreed to waive the debt.

Throughout the time Ellie worked with HRCLS, the lawyer also offered to provide advice to Ellie on victim's compensation arising from the family violence she experienced. Ellie was not ready to discuss this with the HRCLS.

Several months after the HRCLS closed Ellie's file, Ellie contacted the HRCLS herself and was ready to talk about what family violence she experienced and discuss any potential legal options or solutions. Ellie had expressed that when this was raised with her initially, she was not ready to talk about it but that the offer by HRCLS to talk about it when she was ready was at the back of her mind and she felt she was in the right place to do it now. Ellie has chosen not to proceed with any potential action, but she appreciated being told what legal avenues were available to her.

'I've had one student that has a learning difficulty that owed like $\$ 3000$ for child-care placement for her child. The child got taken off her and yet the child was still going to the day care centre. And she hadn't filled out the paperwork and so she got this massive debt at the end of it. Of course, she couldn't pay it. That was [Lawyer 3] who sorted that one out.'

'One of the students that did see [the lawyer] about this domestic violence issue, I' $d$ tried a few methods of contacting other agencies myself, but nothing was really happening. It was only until one of the lawyers got involved themselves that they were able to help.

In the end the young man ended up on a DVO... and was moved out of the home where she was living with him and that student has made the comment that probably without that lawyer program, she'd still be in that situation. So, it was a really good outcome for her. Now he has access to the child every Saturday and she has her life back.

She's not anxious at all really now. She's very confident now. She's very outspoken. She's realised that she has rights that she didn't realise she had before, because he was verbally abusive and with texting etc. So now she knows that she doesn't have to put up with that. It's definitely changed all her future relationships with sexual partners. And she's sharing that also with the other students in 
the group. We often sit down and have little discussions about topics but especially when the lawyers are there on a Wednesday...

[It was] because we'd been having these conversations with [Lawyer 6] each Wednesday, that she'd realised that she didn't have to put up with what her partner was doing, that it was actually something that was called 'domestic violence.' She had no idea before that. And that's actually something that's been encouraged back in 2019 and slowly she's gained the confidence to talk to the lawyers and say I want to change this.'

'We had a young father - DV type stuff, with AVOs and mental health deteriorated. He was couch surfing and he really was not looking after himself physically as well. We got some support from the lawyer. Being able to clarify information for him made him less depressed so therefore the work I was doing with him on counselling him about other things becomes more effective. He becomes more motivated and therefore starts exercising and eating better. It's all connected.'

'It was a pretty sticky situation; it was to do with a family violence order. Dad's actually in jail and it was just about being able to have contact with him and [Lawyer 3] was very, very supportive of the young person in working through those issues with them.'

Jacob was referred to the HRCLS by a non-legal professional. Jacob had mentioned to them that he was wanted to look for a job for when he was not at school. Jacob said he needed his birth certificate but did not have the original.

The professional referred him to HRCLS as they identified that he may have some difficulties in getting the certificate as he is living with his sibling.

HRCLS helped Jacob in completing the application to obtain a copy of their birth certificate from Birth Death and Marriages. HRCLS was able to seek a waiver of the standard fee based on Jacob being of Aboriginal and Torres Strait Islander decent and being on a Centrelink benefit.

During the time HRCLS was helping Jacob, it was discovered that Jacob was eligible to apply for his own Medicare card. HRCLS was prevented from attending the school due to COVID-19 pandemic and instead collaborated with a support teacher and supported them in assisting Jacob in applying for his own Medicare card.

Jacob was estastic when he got his own birth certificate and his own Medicare card.

Throughout the time that HRCLS worked with Jacob, Jacob disclosed that his parents has perpetrated family violence against him and that was why he was no longer living with them and was now living with his sibling.

'So DHS have a kind of child protection, so the young person was "aging out of the system"... they were seventeen, turning eighteen...The impact on this young person was they did not have a birth certificate because they not registered. So they had been in and out of child protection systems since they were a baby and they were now 17 .... It seemed to me that it was basically we'll just pass 
the buck on to this agency to try to resolve... And I thought "Oh, I'm intrigued, there's an administrative issue here." So this young person is not registered and they need their birth registered... The young person can't do anything, they can't even get a bank account. They can't get Centrelink... because you needed a birth certificate, because you needed a tax file number.

When I spoke to the social worker, we had a discussion how "if you are struggling, how is the child? How is a young person going to do this?"

So despite the fact that we had to deal with one government department to get the young person's birth registered, we had to prove their footprint in the community. We had to go back get medical, get letters from schools, from doctors, from dentists, from people that knew this person and send that in. We then had to get mum to sign the original form because it's that restrictive that if mum doesn't sign the registration, that cannot be registered. So in my head, I was always thinking, all right, we're going to have to do an application to the Family Law Courts. And that was my plan B. But eventually, mum agreed.

We then went into Centrelink, and I said to them, the birth certificate stuff has been approved. It's got to go through the special specialist section that you can't even call on the phone, they don't call you and you don't call them. You just have to go through their call centre. It was insane what I had to do. Then Centrelink said 'we need a tax file number before we can actually release the payment. All right. So then I had to call the tax office and they like we need a birth certificate to prove who the young person is. And I said I don't have that. This young person with Aboriginal and they said oh, we have a different way of doing it, but the form is not available to download. It has to be sent to you or you have to collect it in person.

So I got the form - I went in and picked it up from one of their tax shops, organized for a teacher who was retiring to be the person because they had to have a witness or a person who had known this person this many years to complete that, and then I had to post it because you can't fax a form, you can't email a form, you have to post a form. So I posted it.

I called them a week later. 'Oh, it's not in our system.' Give me an email address. I emailed it. I called them a week later. 'It's still not in our system'. And I was pulling my hair out, thinking 'what are you guys doing? It's almost like a reverse discrimination. You try to make it easier for this population to get their tax file number. Yet you've made it so archaic by having to do everything in paper form'. And Centrelink had said, if you get me a reference number of you submitting this, we can make the payment. Had the young person not been Aboriginal and submitted it online, we could have got a reference number. But because they are Aboriginal, yes there's a form, awesome, but you can't submit it online. It was astounding. In the end, I pressed them. We've got a fax number, an email address and I posted it again. So third time lucky. And I just got really quite annoying. And I even went into the Albury 'My Gov' and got the tax person to call her contacts within the tax office to get someone's number to ensure that this gets registered...

I'd gotten the birth certificate two days before the young person's 18th birthday. And when I rang to tell the news, it sounds funny but you could hear the smile on their face, through the phone call, you could hear the smile.

And it just made me go, wow. So, for that young person, it allowed them to get Centrelink to become independent, to not couch surf... It just gave an option. And getting a tax file number to actually work and to get a bank account, because even getting her Centrelink before the tax-file number came through, it had to go into a friend's account... So red tape just gets in the way. 
II was just thinking that a worker couldn't have even spent that time to do that... It showed me that there's this hole in that system. So the worker and I had few discussions about this and they had identified to say, well it's not a common thing, but we have got concerns it could be for these this cohort of young people. So how do we get around that? So she gave me the contact details first as a DHS person who organizes the Leaving Care panel. So I was able to go to that panel and raise this as an issue. Which was great. They listened and they were responsive to it. But then, you know, I got busy at my, you know, in my practice, picked up another best certificate one, so I have now got two case studies but that one wasn't as bad.'

Bianca was referred to the HRCLS by a worker from a local youth support agency. Bianca was receiving support from the youth agency in order to stabilise her living situation, improve her level of engagement with work, education, and training and participate in the local community.

Bianca was referred to HRCLS as her case practitioner identified that she was under a lot of stress and pressure as a result of a debt that was in her name. Bianca suffered from mental health disorders and the amount of stress she was under further exacerbated her already fragile condition.

Bianca's legal issue arose when her then boyfriend, Jason, coerced her into entering into a mobile phone contract with a telecommunications company and put the contract in her name. Jason purposefully took advantage of Bianca when she was at her most vulnerable, that is, when she was experiencing a mental health episode. Jason called the telecommunications company, passed the phone to Bianca and pressured her into following her answers whilst on loud speaker.

HRCLS wrote to the telecommunications company on behalf of Bianca and made several compelling arguments on the basis that the contract was void, she did not receive any benefit from the contract, that she was the victim of family violence and she had exceptional circumstances. The telecommunications company eventually agreed to waive the debt. Throughout the time that HRCLS worked with Bianca, Bianca also raised a number of other legal problems (referred to by HRCLS as "cluster issues") that we were able to assist her in, including fines and victims of crime compensation.

We have a really difficult parent at the moment and I teach her young daughter. It came to light that even though she's been involved with child protection and removed from home as a baby, her birth has never been registered. So she's desperate to get a part time job, but she can't because she 'doesn't exist'. So I don't know how you can be involved in child protection, and enrolled in a school, and be 15 years old and 'exist'. But her mum who is very, very volatile, didn't want anyone to know because she was scared she could get a fine. The other thing is this family is also Indigenous. That's what she had been led to believe - that because she hadn't registered the birth, she'd get a fine. As they're Indigenous and child protection has been involved, there's that other fear and trauma of having your child taken away and all that sort of stuff.

So to have [the lawyers] on hand to speak with the young person, to liaise with the parents... [Lawyer 3] has this really beautiful, supportive working relationship with this mum. She went into the Hume Riverina Legal Service, the mother did, and filled out all the paperwork and has dropped 
off everything. I can't reach this young person's parent, but I know someone who can. They just have a way of making the kids and the parents feel safe and supported. So I think that relational trust and that knowledge base are two really key aspects in our relationship.' 


\section{Recommendations}

\section{That Invisible Hurdles be given long-term funding}

Over five years of funding from multiple sources, the Invisible Hurdles team has delivered a first-class, fully integrated legal practice despite threats to the end to its funding presented by short term funding from time to time. This uncertainty makes it hard to reassure partners and young people that the service is there for the long haul and to retain staff as was highlighted in Stage 1. The extensions of funding for Stage 2 saw a more consistent staff that enabled traction. Longer term funding certainty should be a priority to ensure the projects significant gains are not lost and momentum continues to build. Such long term 5-8 year funding (with evaluation to ensure and test ongoing effectiveness) should form part of governments' stated commitments to family violence, regional people, to closing the gap and to breaking the cycle of poverty.

\section{That Invisible Hurdles continues the momentum of giving voice to young people in systemic work}

The Invisible Hurdles team has made excellent contributions to systemic work by young people. The most important advancement about this work is that some of the young people involved have started to use their voice to self-advocate. The evaluators would like to see this aspect of the project to continue. Collaboration in systemic advocacy that enables multiple voices, varied agency expertise across disciplines and perspective to occur in such partnerships (based on the outcomes of other evaluative studies and in the research literature) is especially rare. The project has the capacity to be an authoritative advocate for the needs of regional youth.

\section{That the cuppa date model be extended to AWAHS staff}

Cuppa dates could be offered to staff at AWAHS, on an opt-in basis, and perhaps in an even more condensed way (e.g. 15 minutes) to entice time-poor professionals. This would ease pressure on the need to fit in information in staff meetings, which already have a full agenda. This is not necessarily to replace Lawyer 6's slot on the agenda in staff meetings, but rather to complement that slot.

\section{That a focus on Aboriginal youth be cornerstone of future stages of Invisible Hurdles}

There is a risk that Aboriginal young people may shy away from seeking legal advice about family violence from the Invisible Hurdles' lawyer because they could perceive the lawyer to be aligned with someone who is a perpetrator, or at least someone who is friends with a perpetrator. This is a risk, given the research on perpetrators often being known to the victim and in intimate family violence, creates an impediment to young people reaching out for independent advice and it also risks conflict of interest or appearance of bias.

We recommend that the HRCLS consider how best to engage more Aboriginal young people. Several participants in the interim interviews suggested that AWAHS needs funding for a youth worker. The interviewees explained that the Mungabareena Aboriginal Cooperative (MAC) receives funding for a youth worker. The two organisations have distinct directions and areas of focus and there is a Memorandum of Understanding between AWAHS and MAC. This option could be explored to ensure a safe space for disclosures by young people. 


\section{That an Aboriginal person sit on the Advisory group}

An Aboriginal person should be invited to join the Advisory Group to enable the project's goals of reaching young Aboriginal people. It is not culturally respectful or appropriate to be endeavouring to reach Aboriginal young people without such participation and cultural advice.

Our Aboriginal advisers have said 'There's obviously [young Aboriginal] leaders in there, they're just not visible.' The authors suggest that it be a goal of this project to find those emerging leaders and include them.

\section{That a young person sit on the Advisory group}

The Advisory group would benefit from either a young person's engagement on the group. Alternatively, the Invisible Hurdles team might consider setting up an Advisory group of young people specifically for the project, similar to the YAC model at NESAY. It would be appropriate for this group to be paid for their time.

\section{That community development be prioritised through NESAY}

The community development opportunities and plans with NESAY were not able to be brought to fruition due to the COVID-19 restrictions. Although many changed practices continue due to COVID-19, the data indicates that the Invisible Hurdles team have been flexible and adaptable. Therefore, we suggest that building up a program of community development work with NESAY be prioritised in 2021.

\section{That the Invisible Hurdles model be rolled out in other schools around Australia}

The Invisible Hurdles services one school and two other agencies. Its success at the school is outstanding. It is an integrated justice model with some important and sophisticated developments, practices and effective approaches that can inform other school lawyer models. The model should be thoroughly documented and replicated in other schools. Especially in schools that have 'at risk' cohorts as a priority, given the early intervention opportunities that the data demonstrates are a consequence of such interventions.

9. That the legal profession more broadly takes up the opportunity to hear from Aboriginal locals

The HRCLS is ideally positioned with its volunteer lawyer service to make introductions between AWAHS and the local lawyers' network groups and can be instrumental in building on new networks given the difficulty in accessing legal assistance services. The HRCLS and AWAHS could also jointly train other lawyers to ensure they become more culturally competent. 


\section{Conclusion}

The connections between the Invisible Hurdles program and the agencies are vital to the communities they serve. Without the program, many Aboriginal clients would experience reduced access to justice and many young people would continue to experience the complications of their ongoing, complex legal problems. When applying the collaborative measurement tool, the evaluators found near full integration by the Invisible Hurdles program and the individual agencies. There is evidence of continuing collaboration despite some the setbacks of COVID-19. The longer term nature of the project enabled it to use the trust and relationships already established to ride the COVID-19 storm and not only continue service but make necessary adaptations, innovate, and continuously reach young people and their supports. Many other agencies may also take some lessons from the elements discussed in this report, evidenced in the data that enabled the Invisible Hurdles project to go from strength to strength and built the service responsive. This was despite all the challenged presented to the partner agencies.

The legal and non-legal professionals work seamlessly to identify and assist clients, referral pathways are clear and functional, and a high level of reflective practice is occurring. They demonstrated innovation, changed their practice and were flexible and available continuing to build relationships of trust and finding 'work arounds' when confronted with problems. The evaluators commend the Invisible Hurdles model to other services hoping to find an effective model that could be replicated. Multiple participants told us that they could not imagine the service not being there - it is now, to coin a COVID term, an 'essential service'. 


\section{APPENDIX}

12.1 APPENDIX 1: Service delivery

1 January 2019 to 31 December 2019

\begin{tabular}{|c|c|c|c|c|c|c|c|}
\hline \multirow[b]{2}{*}{ Problem Types } & \multicolumn{2}{|c|}{ AWAHS } & \multicolumn{2}{|c|}{ FLC } & \multicolumn{2}{|c|}{ NESAY } & \multirow{2}{*}{$\begin{array}{l}\text { Granc } \\
\text { Total }\end{array}$} \\
\hline & $\begin{array}{l}\text { Legal } \\
\text { Task }\end{array}$ & $\begin{array}{l}\text { Case } \\
\text { work }\end{array}$ & $\begin{array}{l}\text { Legal } \\
\text { Task }\end{array}$ & $\begin{array}{l}\text { Case } \\
\text { work }\end{array}$ & $\begin{array}{l}\text { Legal } \\
\text { Task }\end{array}$ & $\begin{array}{l}\text { Case } \\
\text { work }\end{array}$ & \\
\hline Acts intended to cause injury & 0 & 0 & 0 & 0 & 2 & 0 & 2 \\
\hline Child contacts or contact orders & 1 & 0 & 0 & 0 & 0 & 0 & 1 \\
\hline $\begin{array}{l}\text { Consumer complaints fair } \\
\text { trade/trade/sell practice }\end{array}$ & 0 & 0 & 0 & 0 & 0 & 3 & 3 \\
\hline $\begin{array}{l}\text { Consumer complaints } \\
\text { financial/insurance/super etc }\end{array}$ & 3 & 0 & 0 & 0 & 0 & 0 & 3 \\
\hline Consumer complaints products & 1 & 0 & 0 & 0 & 0 & 0 & 1 \\
\hline Consumer credit & 0 & 2 & 0 & 0 & 0 & 0 & 2 \\
\hline Credit and debt collection & 0 & 1 & 0 & 0 & 0 & 0 & 1 \\
\hline Credit and debt Other & 1 & 0 & 0 & 0 & 0 & 0 & 1 \\
\hline Credit and debt owed by client & 1 & 3 & 0 & 0 & 0 & 7 & 11 \\
\hline Credit and debt owed to client & 0 & 0 & 0 & 0 & 1 & 0 & 1 \\
\hline Discrimination race & 1 & 1 & 0 & 0 & 0 & 0 & 2 \\
\hline Family or domestic violence order & 0 & 0 & 0 & 1 & 1 & 0 & 2 \\
\hline $\begin{array}{l}\text { Govt pensions/benefits allowances- } \\
\text { recovery overpayment }\end{array}$ & 0 & 1 & 0 & 0 & 0 & 0 & 1 \\
\hline $\begin{array}{l}\text { Govt/admin complaints - govt } \\
\text { processes/procedures }\end{array}$ & 0 & 0 & 0 & 0 & 0 & 1 & 1 \\
\hline $\begin{array}{l}\text { Govt/admin complaints/issues } \\
\text { relating to govt Other }\end{array}$ & 1 & 0 & 0 & 0 & 0 & 0 & 1 \\
\hline Govt/admin issues relating to fines & 2 & 0 & 0 & 0 & 6 & 2 & 10 \\
\hline Injuries assaults & 0 & 0 & 0 & 3 & 0 & 0 & 3 \\
\hline Injuries sexual assaults, including rape & 0 & 0 & 0 & 0 & 1 & 0 & 1 \\
\hline Motor vehicle Other & 0 & 0 & 0 & 0 & 0 & 1 & 1 \\
\hline Motor vehicle property damage & 0 & 2 & 0 & 1 & 0 & 0 & 3 \\
\hline Other civil & 1 & 0 & 1 & 0 & 0 & 0 & 2 \\
\hline Other civil legal system or process & 2 & 0 & 0 & 0 & 2 & 0 & 4 \\
\hline Other civil property disputes & 0 & 1 & 0 & 0 & 1 & 0 & 2 \\
\hline Other civil violence/restraining orders & 1 & 0 & 0 & 0 & 0 & 0 & 1 \\
\hline Other criminal law problem type & 0 & 0 & 0 & 0 & 1 & 0 & 1 \\
\hline Registration & 0 & 0 & 0 & 0 & 0 & 2 & 2 \\
\hline $\begin{array}{l}\text { Road traffic and motor vehicle } \\
\text { regulatory offences }\end{array}$ & 0 & 0 & 0 & 0 & 0 & 1 & 1 \\
\hline Tenancy Other & 1 & 0 & 0 & 0 & 0 & 1 & 2 \\
\hline Tenancy termination by lessor & 1 & 0 & 0 & 0 & 0 & 0 & 1 \\
\hline Victim compensation & 1 & 1 & 0 & 1 & 1 & 0 & 4 \\
\hline Wills/probate Other & 1 & 0 & 0 & 0 & 0 & 0 & 1 \\
\hline
\end{tabular}




\begin{tabular}{|c|c|c|c|c|c|c|c|}
\hline \multicolumn{8}{|c|}{$\begin{array}{c}\text { Problem Type (Casework) } \\
1 \text { January } 2020 \text { to } 31 \text { December } 2020\end{array}$} \\
\hline \multirow[b]{2}{*}{ Problem Types } & \multicolumn{2}{|c|}{ AWAHS } & \multicolumn{2}{|c|}{ FLC } & \multicolumn{2}{|c|}{ NESAY } & \multirow{2}{*}{$\begin{array}{l}\text { Grand } \\
\text { Total }\end{array}$} \\
\hline & $\begin{array}{l}\text { Legal } \\
\text { Task }\end{array}$ & $\begin{array}{l}\text { Case } \\
\text { work }\end{array}$ & $\begin{array}{l}\text { Legal } \\
\text { Task }\end{array}$ & $\begin{array}{l}\text { Case } \\
\text { work }\end{array}$ & $\begin{array}{l}\text { Legal } \\
\text { Task }\end{array}$ & $\begin{array}{l}\text { Case } \\
\text { work }\end{array}$ & \\
\hline Child contacts or contact orders & 4 & 1 & 0 & 0 & 1 & 0 & 6 \\
\hline Child protection application/orders & 2 & 0 & 0 & 0 & 0 & 0 & 2 \\
\hline Child protection other & 1 & 0 & 0 & 0 & 0 & 0 & 1 \\
\hline Child support declaration & 0 & 0 & 0 & 0 & 0 & 1 & 1 \\
\hline Child support other & 1 & 0 & 0 & 0 & 0 & 0 & 1 \\
\hline $\begin{array}{l}\text { Consumer complaints } \\
\text { financial/insurance/super etc }\end{array}$ & 0 & 0 & 0 & 0 & 0 & 1 & 1 \\
\hline $\begin{array}{l}\text { Consumer complaints medical, } \\
\text { including psychiatric }\end{array}$ & 1 & 0 & 0 & 0 & 0 & 0 & 1 \\
\hline Consumer complaints services & 0 & 0 & 0 & 0 & 1 & 0 & 1 \\
\hline Consumer credit & 0 & 8 & 0 & 0 & 1 & 1 & 10 \\
\hline Credit and debt owed by client & 0 & 1 & 0 & 1 & 2 & 6 & 10 \\
\hline Credit and debt owed to client & 0 & 0 & 0 & 0 & 0 & 1 & 1 \\
\hline Divorce & 2 & 0 & 0 & 0 & 0 & 0 & 2 \\
\hline Family or domestic violence order & 0 & 0 & 1 & 0 & 2 & 0 & 3 \\
\hline $\begin{array}{l}\text { Govt pensions/benefits allowances } \\
\text { Other }\end{array}$ & 0 & 0 & 0 & 0 & 0 & 1 & 1 \\
\hline $\begin{array}{l}\text { Govt pensions/benefits allowances- } \\
\text { recovery overpayment }\end{array}$ & 0 & 1 & 0 & 0 & 0 & 1 & 2 \\
\hline $\begin{array}{l}\text { Govt pensions/benefits allowances- } \\
\text { refusal eligibility }\end{array}$ & 0 & 0 & 1 & 0 & 0 & 0 & 1 \\
\hline $\begin{array}{l}\text { Govt/admin complaints/issues } \\
\text { relating to govt Other }\end{array}$ & 1 & 0 & 2 & 1 & 2 & 1 & 7 \\
\hline Govt/admin disputes etc with schools & 2 & 0 & 0 & 0 & 0 & 0 & 2 \\
\hline Govt/admin issues relating to fines & 2 & 0 & 3 & 0 & 7 & 6 & 18 \\
\hline Injuries assaults & 2 & 0 & 0 & 0 & 0 & 0 & 2 \\
\hline Injuries sexual assaults, including rape & 0 & 0 & 1 & 0 & 0 & 0 & 1 \\
\hline Other civil & 1 & 0 & 0 & 0 & 0 & 1 & 2 \\
\hline Other civil violence/restraining orders & 2 & 0 & 1 & 0 & 0 & 0 & 3 \\
\hline Property damage & 0 & 0 & 0 & 0 & 1 & 0 & 1 \\
\hline Registration & 0 & 0 & 0 & 0 & 0 & 2 & 2 \\
\hline $\begin{array}{l}\text { Tenancy general rights and } \\
\text { responsibilities }\end{array}$ & 0 & 0 & 0 & 0 & 0 & 2 & 2 \\
\hline Tenancy Other & 0 & 0 & 0 & 0 & 0 & 2 & 2 \\
\hline Tenancy repairs & 1 & 0 & 0 & 0 & 0 & 0 & 1 \\
\hline Tenancy termination by lessor & 0 & 0 & 0 & 0 & 2 & 0 & 2 \\
\hline Theft and related offences & 0 & 0 & 1 & 0 & 0 & 0 & 1 \\
\hline Victim compensation & 2 & 1 & 0 & 0 & 0 & 1 & 4 \\
\hline
\end{tabular}




\begin{tabular}{|c|c|c|c|c|c|c|c|}
\hline $\begin{array}{l}\text { Wills/probate making/contest/obtain } \\
\text { benefit under }\end{array}$ & 0 & 0 & 1 & 0 & 3 & 0 & 4 \\
\hline Grand Total & 24 & 12 & 11 & 2 & 22 & 27 & 98* \\
\hline
\end{tabular}

\begin{tabular}{|l|c|c|c|c|c|}
\hline \multicolumn{5}{|c|}{$\begin{array}{c}\text { Problem Type (Casework) } \\
\text { 1 January 2021 to 28 February 2021 }\end{array}$} & \multirow{2}{*}{$\begin{array}{c}\text { Grand } \\
\text { Total }\end{array}$} \\
\cline { 2 - 6 } Problem Types & \multicolumn{2}{|c|}{ AWAHS } & \multicolumn{2}{c|}{ NESAY } \\
\cline { 2 - 5 } & $\begin{array}{c}\text { Legal } \\
\text { Task }\end{array}$ & $\begin{array}{c}\text { Other } \\
\text { rep }\end{array}$ & $\begin{array}{c}\text { Legal } \\
\text { Task }\end{array}$ & $\begin{array}{c}\text { Other } \\
\text { Rep }\end{array}$ & \\
\hline Change name or birth records & 0 & 0 & 1 & 0 & 1 \\
\hline Divorce & 0 & 1 & 0 & 0 & 1 \\
\hline Employment Other & 1 & 0 & 0 & 0 & 1 \\
\hline Family or domestic violence order & 0 & 0 & 2 & 0 & 2 \\
\hline $\begin{array}{l}\text { Govt/admin complaints/issues relating to } \\
\text { govt Other }\end{array}$ & 0 & 0 & 1 & 0 & 1 \\
\hline Injuries assaults & 1 & 0 & 0 & 0 & 1 \\
\hline Injuries employment & 1 & 0 & 0 & 0 & 1 \\
\hline Other civil legal system or process & 1 & 0 & 0 & 0 & 1 \\
\hline Other civil violence/restraining orders & 1 & 0 & 0 & 0 & 1 \\
\hline Road traffic and motor vehicle regulatory & & & & & \\
offences & 0 & 0 & 0 & 1 & 1 \\
\hline Victim compensation & 0 & 1 & 0 & 0 & 1 \\
\hline Grand Total & $\mathbf{5}$ & $\mathbf{2}$ & $\mathbf{4}$ & $\mathbf{1}$ & $\mathbf{1 2 *}$ \\
\hline
\end{tabular}

*NB: Problem type figure is higher than client advice or casework figure as clients may have been given advice or representation in more than one problem type 


\subsection{APPENDIX 2: CLE and CD activities}

$\underline{2019}$

\begin{tabular}{|c|c|c|}
\hline $13 / 02 / 19$ & FLC & $\begin{array}{l}\text { Spoke to two students and their teachers (individually) on the legal } \\
\text { implications of cyber bullying. Young People is referred to as YP in this } \\
\text { table. }\end{array}$ \\
\hline $19 / 02 / 19$ & $\mathrm{FLC}$ & $\begin{array}{l}\text { spoke to } 4 \text { students and } 2 \text { teachers on various legal topics- gun laws, } \\
\text { sexting, criminal records and how long convictions stay on there, } \\
\text { diversion program and if warrants show up on criminal record/police } \\
\text { check }\end{array}$ \\
\hline $17 / 07 / 19$ & $\mathrm{FLC}$ & $\begin{array}{l}\text { Journey to law-town Session: what is the law-presented to } 33 \text { people } \\
\text { (students and teachers) }\end{array}$ \\
\hline $17 / 07 / 19$ & FLC & $\begin{array}{l}\text { Journey to law-town Session: what is the law- presented to } 4 \text { (students } \\
\text { and teacher) }\end{array}$ \\
\hline \multirow[t]{2}{*}{$14 / 08 / 19$} & WFLC & $\begin{array}{l}\text { Journey to law-town Session: Police powers- presented to } 14 \text { people } \\
\text { (students and teachers) }\end{array}$ \\
\hline & & $\begin{array}{l}\text { Journey to law-town Session: Police powers- presented to } 3 \text { people } \\
\text { (students and teachers) }\end{array}$ \\
\hline \multirow[t]{2}{*}{ 07/09/19 } & WFLC & $\begin{array}{l}\text { Journey to law-town Session: Tenancy- presented to } 22 \text { people (students } \\
\text { and teachers) }\end{array}$ \\
\hline & & $\begin{array}{l}\text { Journey to law-town Session: Tenancy- presented to } 6 \text { people (students } \\
\text { and teachers) }\end{array}$ \\
\hline \multirow[t]{2}{*}{$11 / 09 / 19$} & WFLC & $\begin{array}{l}\text { Journey to law-town Session: Family \& Domestic Violence- presented to } \\
17 \text { people (students and teachers) }\end{array}$ \\
\hline & & $\begin{array}{l}\text { Journey to law-town Session: Family \& Domestic Violence- presented to } \\
5 \text { people (students and teachers) }\end{array}$ \\
\hline $18 / 09 / 19$ & WFLC & $\begin{array}{l}\text { Journey to law-town Session: Recap- presented to } 18 \text { people (students } \\
\text { and teachers) }\end{array}$ \\
\hline $16 / 10 / 19$ & WFLC & $\begin{array}{l}\text { Work with students on tasks from learnings from term 3-police powers } \\
\text { wallet card or brochure of what to do in an accident, living } \\
\text { independently tips or create a movie. }\end{array}$ \\
\hline 23/10/19 & WFLC & $\begin{array}{l}\text { Movies with students and YP lunch (YP put on a lunch for teachers and I } \\
\text { was asked to come along) }\end{array}$ \\
\hline $30 / 10 / 19$ & WFLC & $\begin{array}{l}\text { Police powers recap and developed a quiz for the students to do. } \\
\text { Presented this to VCAL, Middles Years and Young Parents }\end{array}$ \\
\hline 20/11/19 & WFLC & $\begin{array}{l}\text { Went over driving laws presentation again with VCAL, Middle Years and } \\
\text { Young parents. Discussion on what things would need to go into a } \\
\text { brochure if you have an accident }\end{array}$ \\
\hline
\end{tabular}

\section{0 (Provided to WFLC only in Term 1)}

\begin{tabular}{|c|c|c|c|c|c|c|c|}
\hline \# & Date & Topic & Resources & VCAL & $\begin{array}{l}\text { Middle } \\
\text { Years }\end{array}$ & $\begin{array}{l}\text { Young } \\
\text { Parents }\end{array}$ & $\begin{array}{l}\text { TOTAL } \\
\text { PARTICIPANTS }\end{array}$ \\
\hline & $\begin{array}{l}05 / 02 / \\
2020\end{array}$ & $\begin{array}{l}\text { Introduction to } \\
\text { Consumer Law } \\
\text { \& Camp Chaos } \\
\text { worksheet }\end{array}$ & $\begin{array}{l}\text { PowerPoint } \\
\& \text { 3rd party } \\
\text { worksheet }\end{array}$ & $\begin{array}{l}6 \\
\text { students } \\
3 \\
\text { teachers }\end{array}$ & $\begin{array}{l}2 \text { students } \\
1 \text { teacher }\end{array}$ & $\begin{array}{l}2 \text { students } \\
1 \text { teacher }\end{array}$ & 15 \\
\hline
\end{tabular}




\begin{tabular}{|c|c|c|c|c|c|c|c|}
\hline 2 & $\begin{array}{l}12 / 02 / \\
2020\end{array}$ & $\begin{array}{l}\text { Introduction to } \\
\text { Consumer } \\
\text { Finance \& How } \\
\text { to Pay } \\
\text { worksheet }\end{array}$ & $\begin{array}{l}\text { PowerPoint } \\
\text { \& 3rdparty } \\
\text { worksheet }\end{array}$ & $\begin{array}{l}4 \\
\text { students } \\
2 \\
\text { teachers }\end{array}$ & $\begin{array}{l}2 \text { students } \\
1 \text { teachers }\end{array}$ & $\begin{array}{l}2 \text { students } \\
1 \text { teacher }\end{array}$ & 12 \\
\hline 3 & $\begin{array}{l}19 / 02 / \\
2020\end{array}$ & $\begin{array}{l}\text { Consumer } \\
\text { Leases \& short } \\
\text { answer activity } \\
\text { worksheet }\end{array}$ & $\begin{array}{l}\text { PowerPoint } \\
\text { \& worksheet } \\
\text { created by } \\
\text { BMS }\end{array}$ & $\begin{array}{l}11 \\
\text { students } \\
5 \\
\text { teachers }\end{array}$ & $\begin{array}{l}2 \text { students } \\
1 \text { teachers }\end{array}$ & On excursion & 19 \\
\hline 4 & $\begin{array}{l}26 / 02 / \\
2020\end{array}$ & $\begin{array}{l}\text { Payday loans \& } \\
\text { short answer } \\
\text { activity } \\
\text { worksheet }\end{array}$ & $\begin{array}{l}\text { PowerPoint } \\
\text { \& worksheet } \\
\text { created by } \\
\text { BMS }\end{array}$ & $\begin{array}{l}7 \\
\text { students } \\
4 \\
\text { teachers }\end{array}$ & $\begin{array}{l}3 \text { students } \\
2 \text { teachers }\end{array}$ & $\begin{array}{l}2 \text { students } \\
2 \text { teachers }\end{array}$ & 20 \\
\hline 5 & $\begin{array}{l}04 / 03 / \\
2020\end{array}$ & $\begin{array}{l}\text { Review of } \\
\text { consumer leases } \\
\text { \& payday loans } \\
\text { plus writing } \\
\text { letter to Dr } \\
\text { Helen Haines }\end{array}$ & PowerPoint & $\begin{array}{l}8 \\
\text { students } \\
3 \\
\text { teachers }\end{array}$ & $\begin{array}{l}1 \text { student } \\
1 \text { teacher }\end{array}$ & $\begin{array}{l}2 \text { students } \\
2 \text { teachers }\end{array}$ & 17 \\
\hline 6 & $\begin{array}{l}11 / 03 / \\
2020\end{array}$ & $\begin{array}{l}\text { Review and sign } \\
\text { letter to Dr } \\
\text { Haines, watch } \\
\text { episodes of The } \\
\text { Checkout and } \\
\text { eat popcorn! }\end{array}$ & None & $\begin{array}{l}4 \\
\text { students } \\
1 \text { teacher }\end{array}$ & $\begin{array}{l}2 \text { students } \\
2 \text { teachers }\end{array}$ & $\begin{array}{l}1 \text { students } \\
2 \text { teachers }\end{array}$ & 12 \\
\hline r & $\begin{array}{l}18 / 03 / \\
2020\end{array}$ & $\begin{array}{l}\text { Consumer } \\
\text { Guarantees plus } \\
\text { discussion } \\
\text { about changes } \\
\text { to HRCLS service } \\
\text { due to } \\
\text { coronavirus }\end{array}$ & PowerPoint & $\begin{array}{l}6 \\
\text { students } \\
1 \text { teacher }\end{array}$ & $\begin{array}{l}2 \text { students } \\
2 \text { teachers }\end{array}$ & On excursion & 11 \\
\hline
\end{tabular}

2021

\begin{tabular}{|l|l|l|}
\hline $03 / 02 / 2021$ & WFLC & $\begin{array}{l}\text { Session with VCAL students- spoke about project and } \\
\text { did Lawtown picture (identify everyday legal issues)- } 6 \\
\text { students and 2 teachers }\end{array}$ \\
\hline $03 / 02 / 2021$ & WFLC & $\begin{array}{l}\text { Session with Middle Years students- spoke about } \\
\text { project and did Lawtown picture (identify everyday } \\
\text { legal issues)- 3 students and 2 teachers }\end{array}$ \\
\hline $03 / 02 / 2021$ & WFLC & $\begin{array}{l}\text { Session with Young Parents students- spoke about } \\
\text { project and did Lawtown picture (identify everyday } \\
\text { legal issues)- 3 students and 1 teacher }\end{array}$ \\
\hline $10 / 02 / 2021$ & WFLC & $\begin{array}{l}\text { Session with VCAL students- Journey to law town (what } \\
\text { is the law, where law comes from, areas of law, Q\&A } \\
\text { with Lawyer 3)- 8 students and 2 teachers }\end{array}$ \\
\hline $10 / 02 / 2021$ & WFLC & $\begin{array}{l}\text { Session with Middles Years students- Journey to law } \\
\text { town (what is the law, where law comes from, areas of } \\
\text { law, Q\&A with Lawyer 3)- 2 students and 2 teachers }\end{array}$ \\
\hline
\end{tabular}




\begin{tabular}{|l|l|l|} 
& WFLC & $\begin{array}{l}\text { Session with Young parents- Journey to law town } \\
\text { (areas of law based on flash cards, what is love } \\
\text { worksheet)- 2 students and 1 teachers }\end{array}$ \\
\hline $24 / 02 / 2021$ & WFLC & $\begin{array}{l}\text { Session with VCAL students- Jackie Youth Police Officer } \\
\text { and Aboriginal Liaison Officer came and met with } \\
\text { students and answered any questions- 8 students and } 3 \\
\text { teachers }\end{array}$ \\
\hline $24 / 02 / 2021$ & WFLC & $\begin{array}{l}\text { Session with Middle Years students- Youth Police } \\
\text { Officer and Aboriginal Liaison Officer came and met } \\
\text { with students and answered any questions- } 3 \text { students } \\
\text { and 3 teachers }\end{array}$ \\
\hline $24 / 02 / 2021$ & WFLC & $\begin{array}{l}\text { Session with Young parents- Youth Police Officer and } \\
\text { aboriginal Liaison Officer came and met with students } \\
\text { and answered any questions- 1 student and 2 teachers }\end{array}$ \\
\hline
\end{tabular}




\subsection{APPENDIX 3: Professional Development}

$\underline{2019}$

\begin{tabular}{|c|c|c|}
\hline $\begin{array}{l}23 / 01 \\
/ 2019\end{array}$ & WFLC & $\begin{array}{l}\text { Meeting with Head FLC to discuss IH project and things to focus } \\
\text { on for 2019- CLE to students on independent living topics, } \\
\text { cyberbullying, sex and consent. Legal Health check to be finalised } \\
\text { and incorporated into student induction process }\end{array}$ \\
\hline $\begin{array}{l}06 / 02 \\
/ 2019\end{array}$ & WFLC & $\begin{array}{l}\text { Attended staff meeting- discussed topics to present to YP } \\
\text { (cyberbullying, social media, consent) and working on a legal } \\
\text { health check document }\end{array}$ \\
\hline $\begin{array}{l}21 / 02 \\
/ 2019\end{array}$ & NESAY & discussion with staff member about 'Heal Program' \\
\hline $\begin{array}{l}26 / 02 \\
/ 2019\end{array}$ & $\begin{array}{l}\text { Ovens } \\
\text { Murray } \\
\text { Leaving Care } \\
\text { Panel }\end{array}$ & $\begin{array}{l}\text { Discussion about HRCLS and IH and idea around birth certificate } \\
\text { project }\end{array}$ \\
\hline $\begin{array}{l}14 / 03 \\
/ 2019\end{array}$ & FLC & Finalised legal health check form \\
\hline $\begin{array}{l}04 / 04 \\
/ 2019\end{array}$ & NESAY & $\begin{array}{l}\text { Spoke to new worker at NESAY about IH project, what legal issues } \\
\text { project can assist with and referral process. }\end{array}$ \\
\hline $\begin{array}{l}11 / 04 \\
/ 2019 \\
\end{array}$ & NESAY & Worked on first draft of 'Legal Health Check' \\
\hline $\begin{array}{l}11 / 04 \\
/ 2019\end{array}$ & NESAY & $\begin{array}{l}\text { Attended Family Services team meeting and explained new } \\
\text { project worker role and plan for future }\end{array}$ \\
\hline $\begin{array}{l}02 / 05 \\
/ 2019 \\
\end{array}$ & FLC & $\begin{array}{l}\text { Attended staff meeting and explained new project worker role } \\
\text { and plan for future }\end{array}$ \\
\hline $\begin{array}{l}22 / 05 \\
/ 2019\end{array}$ & FLC & $\begin{array}{l}\text { Attended love bites session at Latrobe Uni with } 15 \text { students, } 7 \\
\text { teachers organised by staff member (school nurse) }\end{array}$ \\
\hline $\begin{array}{l}23 / 07 \\
/ 2019\end{array}$ & WFLC & Attended respectful relationships session with Nurse \\
\hline $\begin{array}{l}31 / 07 \\
/ 2019\end{array}$ & WFLC & Band showcase \\
\hline $\begin{array}{l}07 / 08 \\
/ 2019\end{array}$ & NESAY & Homelessness walk with NESAY and other services \\
\hline $\begin{array}{l}07 / 08 \\
/ 2019\end{array}$ & NESAY & VoCAT presentation by staff member \\
\hline $\begin{array}{l}20 / 08 \\
/ 2019 \\
\end{array}$ & HJA Training & HJA training- building and managing a health justice partnership \\
\hline $\begin{array}{l}21 / 08 \\
/ 2019\end{array}$ & Carevan & Meeting with staff members from Carevan about WDP \\
\hline $\begin{array}{l}01 / 09 \\
/ 2019 \\
\end{array}$ & NESAY & $\begin{array}{l}\text { meeting with NESAY staff member \& manager about IH project } \\
\text { plan and future collaboration between IH and NESAY }\end{array}$ \\
\hline $\begin{array}{l}03 / 10 \\
/ 2019\end{array}$ & NESAY & $\begin{array}{l}\text { Discussion with worker about Renters program and how CD } \\
\text { worker and lawyer can be involved in group work }\end{array}$ \\
\hline
\end{tabular}




\begin{tabular}{|c|c|c|}
\hline $\begin{array}{l}09 / 10 \\
/ 2019\end{array}$ & FLC & $\begin{array}{l}\text { Meet with new acting Principal to discuss IH project- really } \\
\text { positive response and wished program was in every school }\end{array}$ \\
\hline $\begin{array}{l}09 / 10 \\
/ 2019\end{array}$ & FLC & Meeting with staff members about what we can do this term \\
\hline $\begin{array}{l}09 / 10 \\
/ 2019\end{array}$ & FLC & $\begin{array}{l}\text { Meeting/discussion with Principal about FLC student } \\
\text { comprehension, capacity, understanding }\end{array}$ \\
\hline $\begin{array}{ll}16 / 10 / \\
2019\end{array}$ & FLC & $\begin{array}{l}\text { Worked with students on tasks- police wallet card, living independently } \\
\text { factsheet, car accident brochure }\end{array}$ \\
\hline $\begin{array}{l}17 / 10 / \\
2019\end{array}$ & $\begin{array}{l}\text { GoTAFE } \\
\text { Wang }\end{array}$ & $\begin{array}{l}\text { meeting with Kim and John about WDP scheme and fines and 'GoTAFE' } \\
\text { becoming an accredited sponsor }\end{array}$ \\
\hline $\begin{array}{l}18 / 10 / \\
2019\end{array}$ & FLC & $\begin{array}{l}\text { Meeting with staff members about working with Middle Years for term } \\
\text { 4- recap police powers and driving CLE and do a worksheet }\end{array}$ \\
\hline $\begin{array}{l}23 / 10 / \\
2019\end{array}$ & FLC & $\begin{array}{l}\text { Attended staff meeting to discuss project, plan for Term } 4 \text { and whether } \\
\text { to revisit/ redo legal health check }\end{array}$ \\
\hline $\begin{array}{l}31 / 10 / \\
2019\end{array}$ & NESAY & $\begin{array}{l}\text { Attended NESAY AGM- several IH clients were present and spoke of the } \\
\text { support they received from NESAY- client story. Wonder if these clients } \\
\text { will comment on relationship between HRCLS and NESAY and IH referral }\end{array}$ \\
\hline $\begin{array}{l}14 / 11 / \\
2019\end{array}$ & NESAY & $\begin{array}{l}\text { Participated in NESAY staff lunch (staff rotate making lunch for other } \\
\text { staff) }\end{array}$ \\
\hline $\begin{array}{l}14 / 11 / \\
2019\end{array}$ & NESAY & $\begin{array}{l}\text { Discussion with staff members and manager about whether NESAY } \\
\text { are required to record FV stats }\end{array}$ \\
\hline $\begin{array}{l}11 / 12 / \\
2019\end{array}$ & FLC & See Us Hear Us- end of year school event \\
\hline
\end{tabular}

AWAHS

\begin{tabular}{|l|l|}
\hline $10-J a n-19$ & Attended Staff meeting \\
\hline $24-J a n-19$ & Attended Staff meeting \\
\hline $07-$-Feb-19 & Attended Staff meeting \\
\hline $21-$ Feb-19 & Passport to Better Health at AWAHS \\
\hline $07 / 03 / 2019$ & Attended Staff meeting \\
\hline $21 / 03 / 2019$ & Attended Staff meeting \\
\hline $04 / 04 / 2019$ & Attended Staff meeting \\
\hline $18 / 04 / 2019$ & Attended Staff meeting \\
\hline $16 / 05 / 2019$ & Attended Staff meeting \\
\hline $30 / 05 / 2019$ & Attended Staff meeting \\
\hline $13 / 06 / 2019$ & Attended Staff meeting \\
\hline $13 / 06 / 2019$ & FV Research Project meeting with University of Melbourne team \\
\hline $27 / 06 / 2019$ & Attended Staff meeting \\
\hline $11 / 07 / 2019$ & Attended Staff meeting \\
\hline $08 / 08 / 2019$ & Attended Staff meeting \\
\hline $22 / 08 / 2019$ & Attended Staff meeting \\
\hline $05 / 09 / 2019$ & Attended Staff meeting \\
\hline $19 / 09 / 2019$ & Attended Staff meeting \\
\hline $03 / 10 / 2019$ & Attended Staff meeting \\
\hline $17 / 10 / 2019$ & Attended Staff meeting \\
\hline
\end{tabular}




\begin{tabular}{|l|l|}
\hline $17 / 10 / 2019$ & Promotion of service and LHC introduction \\
\hline $30 / 10 / 2019$ & Mens Health Day at Men's Shed \\
\hline $31 / 10 / 2019$ & Attended Staff meeting \\
\hline $07 / 11 / 2019$ & Morning Tea Men's Shed \\
\hline $14 / 11 / 2019$ & Attended Staff meeting \\
\hline
\end{tabular}

\begin{tabular}{|c|c|c|}
\hline $\begin{array}{l}28 / 01 / \\
2020\end{array}$ & WFLC & $\begin{array}{l}\text { Meeting with teachers to discuss IH program for term } 1 \text {. Team member from } \\
\text { IG Project to work with school nurse and provision of legal advice on } \\
\text { Tuesdays. Other team members to attend WFLC on Wednesdays and } \\
\text { continue on with legal information session programs }\end{array}$ \\
\hline $\begin{array}{l}30 / 01 / \\
2020\end{array}$ & NESAY & $\begin{array}{l}\text { Meet with CEO to discuss moving days between staff of the IH Project.. Also } \\
\text { spoke about WDP. Want Fines Vic WDP person to come to North East and } \\
\text { answer specific questions }\end{array}$ \\
\hline $\begin{array}{l}04 / 02 / \\
2020\end{array}$ & WFLC & $\begin{array}{l}\text { Attended wellbeing team meeting- Principal, Leading teacher, wellbeing } \\
\text { team teachers, school nurse and me- Discussion about co-facilitating } \\
\text { sessions with school nurse }\end{array}$ \\
\hline $\begin{array}{l}11 / 02 / \\
2020\end{array}$ & WFLC & $\begin{array}{l}\text { Attended wellbeing team meeting- Principal, Leading teacher, wellbeing } \\
\text { team teachers, school nurse and me. }\end{array}$ \\
\hline $\begin{array}{l}26 / 02 / \\
2020\end{array}$ & NESAY & $\begin{array}{l}\text { Attended staff meeting to discuss referrals to IH project and priority of giving } \\
\text { advice to YP over parent/family referrals. Turned into a discussion on what a } \\
\text { conflict of interest is and explained the definition that lawyers but abide by, } \\
\text { as opposed to NESAY definition and board member definitions }\end{array}$ \\
\hline \multicolumn{3}{|r|}{ COVID-19: work from home } \\
\hline $\begin{array}{l}28 / 04 / \\
2020\end{array}$ & WFLC & Attended staff meeting \\
\hline $\begin{array}{l}26 / 05 / \\
2020\end{array}$ & NESAY & $\begin{array}{l}\text { Organised 'cuppa date'- Amanda mentioned YP got letter from Centrelink } \\
\text { Class Action and Robo debt, discussed to still refer and that I am available } \\
\text { for SC! }\end{array}$ \\
\hline $\begin{array}{l}03 / 06 / \\
2020\end{array}$ & WFLC & Attended staff meeting \\
\hline $\begin{array}{l}09 / 06 / \\
2020\end{array}$ & NESAY & Cuppa date- mini PD on Robo-debt and class action \\
\hline $\begin{array}{l}10 / 06 / \\
2020\end{array}$ & WFLC & $\begin{array}{l}\text { Teams session with } 2 \text { VCAL students- discussed Black Lives Matter } \\
\text { movement, protests in Australia, protesting vs restrictions on being in } \\
\text { groups, COVID-19 conspiracy theories }\end{array}$ \\
\hline $\begin{array}{l}23 / 06 / \\
2020\end{array}$ & NESAY & $\begin{array}{l}\text { Cuppa date- discussion on scams and how there are specific ones targeted at } \\
\text { COVID-19. Discussion on the types of preventative measures that could be } \\
\text { undertaken in order to support YP to spot scams }\end{array}$ \\
\hline $\begin{array}{l}14 / 07 / \\
2020\end{array}$ & NESAY & $\begin{array}{l}\text { Cuppa date- discussed IH poster that Lawyer } 6 \text { created and changes to fines } \\
\text { collection process in NSW }\end{array}$ \\
\hline $\begin{array}{l}28 / 07 / \\
2020\end{array}$ & NESAY & $\begin{array}{l}\text { Cuppa date- discussed cross border permit issues, raise the age campaign } \\
\text { the IH poster and Practitioner Action Groups }\end{array}$ \\
\hline $\begin{array}{l}28 / 07 / \\
2020\end{array}$ & WFLC & $\begin{array}{l}\text { Meeting with teachers to discuss info sessions with students. Decided to } \\
\text { focus on the following for term: } \\
\text { 1. You can't ask that ABC TV series- Drag Queens with VCAL and 'Showies' } \\
\text { with Middle Years } \\
\text { 2. 'Raise the Age' Campaign } \\
\text { 3. Vic Pol Community Care Survey } \\
\text { 4. Videos about masks and Human Rights }\end{array}$ \\
\hline
\end{tabular}




\begin{tabular}{|c|c|c|}
\hline & & $\begin{array}{l}\text { 5. 'Black Lives Matter' } \\
\text { 6. Cross border permit info session }\end{array}$ \\
\hline $\begin{array}{l}29 / 07 / \\
2020\end{array}$ & WFLC & $\begin{array}{l}\text { Staff meeting- discussion around cross border permits and impact on } \\
\text { teachers and students. Focussed on reason for traveling and border bubble } \\
\text { and changed to } 2 \mathrm{~km} \text {. referred to HRCLS factsheet and need to lobby MPS }\end{array}$ \\
\hline $\begin{array}{l}04 / 08 / \\
2020\end{array}$ & WFLC & $\begin{array}{l}\text { Meeting with teachers to discuss info sessions with students- now remote } \\
\text { learning- change to 'on demand' Police unit. Do survey, discuss article and } \\
\text { Young aboriginal children treatment }\end{array}$ \\
\hline $\begin{array}{l}11 / 08 / \\
2020\end{array}$ & NESAY & $\begin{array}{l}\text { Cuppa date ( } 7 \text { people)- discussed cross border permit changes, mask } \\
\text { wearing and discrimination and human rights and Vic Government } \\
\text { restrictions and difficulty of YP abiding by rules }\end{array}$ \\
\hline $\begin{array}{l}18 / 08 / \\
2020\end{array}$ & WFLC & $\begin{array}{l}\text { Meeting with teachers to discuss info sessions with students- now remote } \\
\text { learning- change to 'on demand' Police unit. Doing survey }\end{array}$ \\
\hline $\begin{array}{l}19 / 08 / \\
2020\end{array}$ & WFLC & Attended staff meeting and reminded staff to refer YP \\
\hline $\begin{array}{l}25 / 08 / \\
2020\end{array}$ & WFLC & $\begin{array}{l}\text { Meeting with teachers to discuss info sessions with students- now remote } \\
\text { learning- } 21 \text { surveys completed, great discussions on treatment of police. } \\
\text { Questions from students to send to ABC You can't ask that }\end{array}$ \\
\hline $\begin{array}{l}25 / 08 / \\
2020\end{array}$ & NESAY & Cuppa date- Quiz \\
\hline $\begin{array}{l}26 / 08 / \\
2020\end{array}$ & WFLC & $\begin{array}{l}\text { Attended staff meeting and discussed cross border permits, Vic Government } \\
\text { restrictions and if any YP have fines- please refer to HRCLS. }\end{array}$ \\
\hline $\begin{array}{l}01 / 09 / \\
2020\end{array}$ & WFLC & $\begin{array}{l}\text { Meeting with teachers to discuss info sessions with students- now remote } \\
\text { learning. Policing unit- still enough work to keep students engaged to end of } \\
\text { term. }\end{array}$ \\
\hline $\begin{array}{l}02 / 09 / \\
2020\end{array}$ & WFLC & $\begin{array}{l}\text { Attend staff meeting and did mini CLE on fines and options available. } \\
\text { Mentioned WDP scheme and teachers sounded really interested in } \\
\text { becoming a sponsor }\end{array}$ \\
\hline $\begin{array}{l}08 / 09 / \\
2020\end{array}$ & NESAY & Cuppa date- IVO/AVO presentation (11 people) \\
\hline $\begin{array}{l}09 / 09 / \\
2020\end{array}$ & WFLC & $\begin{array}{l}\text { Attended staff meeting- } 2 \text { new students and LHC completed. FLC on board to } \\
\text { sign up with Fines Vic WDP }\end{array}$ \\
\hline $\begin{array}{l}22 / 09 / \\
2020\end{array}$ & NESAY & Guest speaker and discussion IVO and family law Q\&A- 11 NESAY staff \\
\hline $\begin{array}{l}29 / 09 / \\
2020\end{array}$ & NESAY & $\begin{array}{l}\text { Attended Community services team meeting and discussed whether YP are } \\
\text { having issues obtaining photo ID }\end{array}$ \\
\hline $\begin{array}{l}7 / 10 / 2 \\
5020\end{array}$ & WFLC & $\begin{array}{l}\text { Attended staff meeting- IH to present at NEFLN day and discussion on } \\
\text { supporting students obtain identity documents }\end{array}$ \\
\hline $\begin{array}{l}14 / 10 / \\
2020\end{array}$ & NESAY & New staff member catch up- went through IH, gave them project docs, \\
\hline $\begin{array}{l}14 / 10 / \\
2020\end{array}$ & WFLC & Attended staff meeting- IH to present at NEFLN day. \\
\hline $\begin{array}{l}19 / 10 / \\
2020\end{array}$ & $\begin{array}{l}\text { CBA } \\
\text { meeting }\end{array}$ & $\begin{array}{l}\text { Attended CBA Financial Counsellor meeting to discuss issue with CBA not } \\
\text { accepting authority from legal professional. This issue has prompted CBA to }\end{array}$ \\
\hline
\end{tabular}




\begin{tabular}{|c|c|c|}
\hline & & $\begin{array}{l}\text { look at their processes and instigate a new process to accept authorities } \\
\text { from legal practitioners= law reform }\end{array}$ \\
\hline $\begin{array}{l}20 / 10 / \\
2020\end{array}$ & WFLC & $\begin{array}{l}\text { Attended staff meeting- discussed Vic Youth strategy, FLC will sign up as } \\
\text { WDP sponsor, decision to do IVO/AVO training at NEFLN }\end{array}$ \\
\hline $\begin{array}{l}20 / 10 / \\
2020\end{array}$ & NESAY & 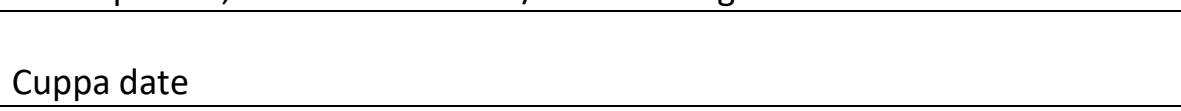 \\
\hline $\begin{array}{l}21 / 10 / \\
2020\end{array}$ & WFLC & $\begin{array}{l}\text { Attended staff meeting- NAIDOC week, can local business refuse money as } \\
\text { legal tender. FLC got approval from Vern to sign up at WDP sponsor }\end{array}$ \\
\hline $\begin{array}{l}03 / 11 / \\
2020\end{array}$ & WFLC & Attended staff meeting- Magpie Goose \\
\hline $\begin{array}{l}11 / 11 / \\
2020\end{array}$ & $\begin{array}{l}\text { WFLC/ } \\
\text { NEFLN }\end{array}$ & $\begin{array}{l}\text { IVO/AVO PD session delivered to NEFLN network- approx. } 30-44 \text { people in } \\
\text { attendance }\end{array}$ \\
\hline $\begin{array}{l}17 / 11 / \\
2020\end{array}$ & NESAY & Cuppa date- working with Boorinya- could collaborate? \\
\hline $\begin{array}{l}17 / 11 / \\
2020\end{array}$ & WFLC & $\begin{array}{l}\text { Attended staff meeting- discussion on how to assist young mums and } \\
\text { potential DHHS/CP involvement. }\end{array}$ \\
\hline $\begin{array}{l}18 / 11 / \\
2020\end{array}$ & $\begin{array}{l}\text { Youth in } \\
\text { Politics } \\
\text { Event }\end{array}$ & $\begin{array}{l}\text { Attended Youth in Politics event by Alpine Council Youth team. IH staff } \\
\text { presented on IH and HRCLS. } 15 \text { attendees }\end{array}$ \\
\hline $\begin{array}{l}24 / 11 / \\
2020\end{array}$ & WFLC & Meeting with teacher to discuss Police session tomorrow \\
\hline $\begin{array}{l}09 / 12 / \\
2020\end{array}$ & WFLC & Attended WFLC 'See Us Hear Us' event \\
\hline $\begin{array}{l}14 / 12 / \\
2020\end{array}$ & SLFG & $\begin{array}{l}\text { School lawyer reference group meetings- discussion of children being fined } \\
\text { and appropriate course of action by Police }\end{array}$ \\
\hline
\end{tabular}




\subsection{APPENDIX 4: Professional Development survey feedback}

Survey Feedback from Participants- Professional Development Sessions 2020 Pre-and Post-training

Pre-survey results FLC 2020

\begin{tabular}{|c|c|c|c|c|c|c|}
\hline $\begin{array}{l}\text { 1. I am } \\
\text { aware of } \\
\text { the } \\
\text { Invisible } \\
\text { Hurdles } \\
\text { (IH) and } \\
\text { how it } \\
\text { relates to } \\
\text { my role. }\end{array}$ & $\begin{array}{l}\text { 2. I have a } \\
\text { good } \\
\text { understandin } \\
\mathrm{g} \text { of the } \\
\text { differences } \\
\text { and } \\
\text { similarities in } \\
\text { ethical } \\
\text { obligations of } \\
\text { lawyers and } \\
\text { ethical } \\
\text { obligations of } \\
\text { other } \\
\text { professionals }\end{array}$ & $\begin{array}{l}\text { 3. An } \\
\text { importan } \\
\text { t part of } \\
\text { my role } \\
\text { at is to } \\
\text { identify } \\
\text { social, } \\
\text { economic } \\
\text { or legal } \\
\text { issues } \\
\text { that } \\
\text { impact } \\
\text { on a } \\
\text { client's } \\
\text { health } \\
\text { and } \\
\text { wellbeing }\end{array}$ & $\begin{array}{l}\text { 4. I am } \\
\text { confident } \\
\text { in my } \\
\text { knowledg } \\
\text { e and } \\
\text { awarenes } \\
\text { s of how } \\
\text { legal } \\
\text { problems } \\
\text { impact on } \\
\text { the health } \\
\text { and } \\
\text { wellbeing } \\
\text { of clients }\end{array}$ & $\begin{array}{l}5 . \text { I believe I } \\
\text { have the } \\
\text { required } \\
\text { skills and } \\
\text { knowledge } \\
\text { to effectively } \\
\text { identify legal } \\
\text { issues } \\
\text { experienced } \\
\text { by clients }\end{array}$ & $\begin{array}{l}6 . \\
\text { Lawyers } \\
\text { have an } \\
\text { important } \\
\text { role to } \\
\text { play in } \\
\text { ensuring } \\
\text { better } \\
\text { health } \\
\text { outcomes } \\
\text { for clients }\end{array}$ & $\begin{array}{l}\text { 7. The } \\
\text { Professional } \\
\text { Developmen } \\
\text { t session } \\
\text { that I am } \\
\text { being } \\
\text { trained in } \\
\text { will be } \\
\text { practically } \\
\text { useful to my } \\
\text { work }\end{array}$ \\
\hline \multicolumn{7}{|l|}{$\begin{array}{l}\text { Strongly } \\
\text { Agree }\end{array}$} \\
\hline \multicolumn{7}{|l|}{ Agree } \\
\hline \multicolumn{7}{|l|}{ Neutral } \\
\hline \multicolumn{7}{|l|}{ Disagree } \\
\hline $\begin{array}{l}\text { Strongly } \\
\text { Disagree }\end{array}$ & & & & & & \\
\hline
\end{tabular}

\section{Comments or suggestions on course content}

* Looking forward to come away with new tools to support community members

* I am looking forward to exploring the content and gaining more insight into domestic and family violence orders (IVOs \& AVOs.)

* A better understanding of AVO's and AVI's will enable more efficient time management of staff trying to advise students/parents who are involved in this process or need to be involved in the process.

* Wanted to know the differences between AVO, DVO \& IVO's

\section{After Training Results FLC 2020}

\section{Responses}




\begin{tabular}{|c|c|c|c|c|}
\hline Program/Session) & $\begin{array}{c}\text { Domestic and } \\
\text { family violence } \\
\text { orders (IVOs \& } \\
\text { AVOs) }\end{array}$ & $\begin{array}{l}\text { Young Parents } \\
\text { Program }\end{array}$ & $\begin{array}{l}\text { Invisible } \\
\text { Hurdles }\end{array}$ & \\
\hline Date: & $\begin{array}{c}\text { November } 11, \\
2020 \\
\end{array}$ & $\begin{array}{c}\text { November } 11, \\
2020 \\
\end{array}$ & $\begin{array}{c}\text { November } \\
11,2020 \\
\end{array}$ & \\
\hline $\begin{array}{l}\text { 1. I am aware of } \\
\text { the Invisible } \\
\text { Hurdles (IH) and } \\
\text { how it relates to } \\
\text { my role. }\end{array}$ & $\begin{array}{l}\text { 2. I have a good } \\
\text { understanding of } \\
\text { the differences } \\
\text { and similarities in } \\
\text { ethical obligations } \\
\text { of lawyers and } \\
\text { ethical obligations } \\
\text { of other } \\
\text { professionals }\end{array}$ & $\begin{array}{l}\text { 3. An important } \\
\text { part of my role at } \\
\text { is to identify } \\
\text { social, economic } \\
\text { or legal issues that } \\
\text { impact on a } \\
\text { client's health and } \\
\text { wellbeing }\end{array}$ & $\begin{array}{c}4 . \text { I am } \\
\text { confident in } \\
\text { my } \\
\text { knowledge } \\
\text { and } \\
\text { awareness } \\
\text { of how legal } \\
\text { problems } \\
\text { impact on } \\
\text { the health } \\
\text { and } \\
\text { wellbeing of } \\
\text { clients }\end{array}$ & $\begin{array}{l}\text { 5. I believe I have } \\
\text { the required skills } \\
\text { and knowledge to } \\
\text { effectively identify } \\
\text { legal issues } \\
\text { experienced by } \\
\text { clients }\end{array}$ \\
\hline $\begin{array}{l}\text { Strongly Agree } \\
3\end{array}$ & $\begin{array}{c}\text { Strongly Agree } \\
3\end{array}$ & $\begin{array}{c}\text { Strongly Agree } \\
3\end{array}$ & $\begin{array}{c}\text { Strongly } \\
\text { Agree } \\
3\end{array}$ & $\begin{array}{c}\text { Strongly Agree } \\
0\end{array}$ \\
\hline $\begin{array}{l}\text { 6. Lawyers have an } \\
\text { important role to } \\
\text { play in ensuring } \\
\text { better health } \\
\text { outcomes for } \\
\text { clients }\end{array}$ & $\begin{array}{l}\text { 7. The Professional } \\
\text { Development } \\
\text { session that I am } \\
\text { being trained in } \\
\text { will be practically } \\
\text { useful to my work }\end{array}$ & $\begin{array}{l}\text { 8. As a result of } \\
\text { the Professional } \\
\text { Development } \\
\text { training of this } \\
\text { session/s I think I } \\
\text { will be able to } \\
\text { better assist my } \\
\text { clients }\end{array}$ & $\begin{array}{l}\text { 9. As a } \\
\text { result of } \\
\text { what you } \\
\text { have } \\
\text { learned in } \\
\text { Professional } \\
\text { Developme } \\
\text { nt (PD), do } \\
\text { you think } \\
\text { you will } \\
\text { know how } \\
\text { to take the } \\
\text { next steps } \\
\text { to } \\
\text { implement } \\
\text { your } \\
\text { learnings } \\
\text { with } \\
\text { clients? } \\
\text { If so, what } \\
\text { will you do } \\
\text { next to } \\
\text { operationali } \\
\text { se your } \\
\text { learnings in } \\
\text { practice? } \\
\text { If not, why } \\
\text { not? }\end{array}$ & $\begin{array}{l}\text { 10. As a result of } \\
\text { what you have } \\
\text { learned in PD will } \\
\text { it change in any } \\
\text { way how you } \\
\text { intend to } \\
\text { work/practice/eng } \\
\text { age with your } \\
\text { clients? }\end{array}$ \\
\hline
\end{tabular}




\begin{tabular}{|c|c|c|c|c|}
\hline $\begin{array}{l}\text { Strongly Agree } \\
3\end{array}$ & $\begin{array}{c}\text { Strongly Agree } \\
3\end{array}$ & $\begin{array}{c}\text { Strongly Agree } \\
\text { N/A }\end{array}$ & $\begin{array}{l}\text { Strongly } \\
\text { Agree } \\
\mathrm{n} / \mathrm{a}\end{array}$ & $\begin{array}{l}\text { Yes } 1 \\
\text { No2 }\end{array}$ \\
\hline $\begin{array}{l}\text { 11. As a result of } \\
\text { what you have } \\
\text { learned in } \\
\text { training/PD will it } \\
\text { change in any way } \\
\text { how you intend to } \\
\text { work/practice/eng } \\
\text { age with you with } \\
\text { other } \\
\text { services/agencies? }\end{array}$ & $\begin{array}{l}\text { 12. As a result of } \\
\text { what you have } \\
\text { learned in PD will } \\
\text { it change in any } \\
\text { way how you } \\
\text { intend to } \\
\text { work/practice/eng } \\
\text { age in advocacy on } \\
\text { behalf of } \\
\text { clients/patients? }\end{array}$ & $\begin{array}{l}\text { 13. As a result of } \\
\text { what you have } \\
\text { learned in PD will } \\
\text { it change in any } \\
\text { way how you } \\
\text { intend to } \\
\text { work/practice/eng } \\
\text { age in } \\
\text { collaborations } \\
\text { with IH to make } \\
\text { systems change by } \\
\text { way of letters, } \\
\text { submissions, } \\
\text { involvement in } \\
\text { legal cases or } \\
\text { strategic problem } \\
\text { solving to bring } \\
\text { about reforms and } \\
\text { improvements to } \\
\text { the system }\end{array}$ & & \\
\hline Yes 1 & & & & \\
\hline No 2 & & & & \\
\hline
\end{tabular}

\section{Comments from Professional Development Participants}

* Clear and concise information, engaging and presented extremely well to the audience.

* Our clients are young teenage women with babies who are often out of home and need to know their rights and appropriate legal pathways they need to follow if they have any legal issues they need to deal with.

* I feel confident that I could direct students to the appropriate legal help.

* Ensure that students have regular exposure to PD so that they know their rights.

* After our PD session we now have a greater depth of understanding of DVO's and AVO's.

* Before sharing information, I will know it is always important to check first with the professionals to ensure we are giving the correct advice.

* The PD has given us a greater understanding of what our clients are going through and the steps they need to follow.

* Invisible Hurdles is an invaluable asset to our school community. Education around law and individual rights is empowering our students to engage in preventative decision making. Our students also feel safe to know they will be able to access advice when they do find themselves in a legal situation. The professional development with teachers enabled us to be upskilled in our knowledge of the different legal safeguards. AVI's and AVO's are issues 
that we deal with consistently, we need to interpret them for our school, with our students and their care givers. I feel as though the professional development has enabled me as educator to feel confident in answering questions on seeking one, and in some cases the demands of people dealing with an AVI. The IH lawyers/CD team have a unique ability in using student interest and voice to challenge/extend thinking around laws their effectiveness and the thought of reform. Collaborating with them and the students has given me the confidence to discuss the notion of agency with the students.

* By having clear communication with the IH team at Flexi and collaboration of ideas, we have built up a successful and worthy program that supports our students.

\section{Pre training Survey Results NESAY}

\begin{tabular}{|c|c|c|c|c|c|}
\hline $\begin{array}{l}\text { 1. I am aware of the } \\
\text { Invisible Hurdles (IH) } \\
\text { and how it relates to } \\
\text { my role. }\end{array}$ & $\begin{array}{l}\text { Strongly } \\
\text { Agree } \\
1\end{array}$ & $\begin{array}{c}\text { Agree } \\
4\end{array}$ & $\begin{array}{c}\text { Neutral } \\
0\end{array}$ & $\begin{array}{c}\text { Disagree } \\
0\end{array}$ & 0 \\
\hline $\begin{array}{l}\text { 2. I have a good } \\
\text { understanding of } \\
\text { the differences and } \\
\text { similarities in } \\
\text { ethical obligations } \\
\text { of lawyers and } \\
\text { ethical obligations } \\
\text { of other } \\
\text { professionals }\end{array}$ & $\begin{array}{c}\text { Strongly } \\
\text { Agree } \\
1\end{array}$ & $\begin{array}{l}\text { Agree } \\
4\end{array}$ & $\begin{array}{c}\text { Neutral } \\
0\end{array}$ & $\begin{array}{c}\text { Disagree } \\
0\end{array}$ & $\begin{array}{c}\text { Strongly } \\
\text { disagree } \\
0\end{array}$ \\
\hline $\begin{array}{l}\text { 3. An important part } \\
\text { of my role at is to } \\
\text { identify social, } \\
\text { economic or legal } \\
\text { issues that impact } \\
\text { on a client's health } \\
\text { and wellbeing }\end{array}$ & $\begin{array}{l}\text { Strongly } \\
\text { Agree } \\
3\end{array}$ & $\begin{array}{l}\text { Agree } \\
2\end{array}$ & $\begin{array}{c}\text { Neutral } \\
0\end{array}$ & $\begin{array}{c}\text { Disagree } \\
0\end{array}$ & $\begin{array}{c}\text { Strongly } \\
\text { disagree } \\
0\end{array}$ \\
\hline $\begin{array}{l}\text { 4. I am confident in } \\
\text { my knowledge and } \\
\text { awareness of how } \\
\text { legal problems } \\
\text { impact on the } \\
\text { health and } \\
\text { wellbeing of clients }\end{array}$ & $\begin{array}{l}\text { Strongly } \\
\text { Agree } \\
2\end{array}$ & $\begin{array}{c}\text { Agree } \\
3\end{array}$ & $\begin{array}{c}\text { Neutral } \\
0\end{array}$ & $\begin{array}{c}\text { Disagree } \\
0\end{array}$ & $\begin{array}{c}\text { Strongly } \\
\text { disagree } \\
0\end{array}$ \\
\hline $\begin{array}{l}5 . \text { I believe I have } \\
\text { the required skills } \\
\text { and knowledge to } \\
\text { effectively identify } \\
\text { legal issues } \\
\text { experienced by } \\
\text { clients }\end{array}$ & $\begin{array}{l}\text { Strongly } \\
\text { Agree } \\
1\end{array}$ & $\begin{array}{c}\text { Agree } \\
3\end{array}$ & $\begin{array}{c}\text { Neutral } \\
1\end{array}$ & $\begin{array}{c}\text { Disagree } \\
0\end{array}$ & $\begin{array}{c}\text { Strongly } \\
\text { disagree } \\
0\end{array}$ \\
\hline $\begin{array}{l}\text { 6. Lawyers have an } \\
\text { important role to } \\
\text { play in ensuring } \\
\text { better health } \\
\text { outcomes for clients }\end{array}$ & $\begin{array}{l}\text { Strongly } \\
\text { Agree } \\
2\end{array}$ & $\begin{array}{l}\text { Strongly } \\
\text { Agree } \\
3\end{array}$ & $\begin{array}{c}\text { Neutral } \\
0\end{array}$ & $\begin{array}{c}\text { Disagree } \\
0\end{array}$ & $\begin{array}{c}\text { Strongly } \\
\text { disagree } \\
0\end{array}$ \\
\hline
\end{tabular}




\begin{tabular}{|c|c|c|c|c|c|}
\hline $\begin{array}{l}\text { 7. The Professional } \\
\text { Development } \\
\text { session that I am } \\
\text { being trained in will } \\
\text { be practically useful } \\
\text { to my work }\end{array}$ & $\begin{array}{c}\text { Strongly } \\
\text { Agree } \\
3\end{array}$ & $\begin{array}{c}\text { Strongly } \\
\text { Agree } \\
2\end{array}$ & $\begin{array}{c}\text { Neutral } \\
0\end{array}$ & $\begin{array}{c}\text { Disagree } \\
0\end{array}$ & $\begin{array}{c}\text { Strongly } \\
\text { disagree } \\
0\end{array}$ \\
\hline
\end{tabular}

\section{Post-training Survey NESAY}

\begin{tabular}{|c|c|c|}
\hline $\begin{array}{l}\text { Your role (e.g nurse, teacher, doctor, } \\
\text { social worker etc.) }\end{array}$ & NESAY & $\begin{array}{l}\text { School Focused Youth } \\
\text { Services Coordinator }\end{array}$ \\
\hline Date: & $22 / 09 / 2020$ & $22 / 09 / 2020$ \\
\hline \multicolumn{3}{|l|}{ Facilitator/Trainer: } \\
\hline $\begin{array}{l}\text { 1. I am aware of the Invisible Hurdles } \\
\text { (IH) and how it relates to my role. }\end{array}$ & $\begin{array}{c}\text { Strongly Agree } \\
0\end{array}$ & $\begin{array}{l}\text { Agree } \\
2\end{array}$ \\
\hline $\begin{array}{l}\text { 2. I have a good understanding of } \\
\text { the differences and similarities in } \\
\text { ethical obligations of lawyers and } \\
\text { ethical obligations of other } \\
\text { professionals }\end{array}$ & $\begin{array}{c}\text { Strongly Agree } \\
1\end{array}$ & $\begin{array}{c}\text { Agree } \\
1\end{array}$ \\
\hline $\begin{array}{l}\text { 3. An important part of my role at is } \\
\text { to identify social, economic or legal } \\
\text { issues that impact on a client's } \\
\text { health and wellbeing }\end{array}$ & $\begin{array}{c}\text { Strongly Agree } \\
0\end{array}$ & $\begin{array}{l}\text { Agree } \\
2\end{array}$ \\
\hline $\begin{array}{l}\text { 4. I am confident in my knowledge } \\
\text { and awareness of how legal } \\
\text { problems impact on the health and } \\
\text { wellbeing of clients }\end{array}$ & $\begin{array}{c}\text { Strongly Agree } \\
0\end{array}$ & $\begin{array}{l}\text { Agree } \\
2\end{array}$ \\
\hline $\begin{array}{l}5 . \text { I believe I have the required skills } \\
\text { and knowledge to effectively identify } \\
\text { legal issues experienced by clients }\end{array}$ & $\begin{array}{c}\text { Strongly Agree } \\
0\end{array}$ & $\begin{array}{l}\text { Agree } \\
2\end{array}$ \\
\hline $\begin{array}{l}\text { 6. Lawyers have an important role to } \\
\text { play in ensuring better health } \\
\text { outcomes for clients }\end{array}$ & $\begin{array}{c}\text { Strongly Agree } \\
0\end{array}$ & $\begin{array}{l}\text { Agree } \\
2\end{array}$ \\
\hline $\begin{array}{l}\text { 7. The Professional Development } \\
\text { session that I am being trained in will } \\
\text { be practically useful to my work }\end{array}$ & $\begin{array}{c}\text { Strongly Agree } \\
0\end{array}$ & $\begin{array}{l}\text { Agree } \\
2\end{array}$ \\
\hline $\begin{array}{l}\text { 8. As a result of the Professional } \\
\text { Development training of this } \\
\text { session/s I think I will be able to } \\
\text { better assist my clients }\end{array}$ & 0 & 0 \\
\hline
\end{tabular}


9. As a result of what you have learned in Professional Development (PD), do you think you will know how to take the next steps to implement your learnings with clients? If so, what will you do next to

Not in direct service $\mathrm{N} / \mathrm{A}$
The knowledge is certainly something that I will refer back to when needed. operationalise your learnings in practice?

If not, why not?

10. As a result of what you have learned in PD will it change in any way how you intend to work/practice/engage with your clients?

If the answer is Yes, explain in what way.

11. As a result of what you have learned in training/PD will it change in any way how you intend to work/practice/engage with you with other services/agencies?

If the answer is Yes, explain in what way.

12. As a result of what you have learned in PD will it change in any way how you intend to work/practice/engage in advocacy on behalf of clients/patients?

If the answer is Yes, explain in what way.

13. As a result of what you have learned in PD will it change in any way how you intend to work/practice/engage in collaborations with IH to make systems change by way of letters, submissions, involvement in legal cases or strategic problem solving to bring about reforms and improvements to the system? If the answer is Yes, explain in what way.

\begin{tabular}{|c|c|}
\hline Yes & No \\
\hline $\begin{array}{c}\text { Offer support in any way to IH to } \\
\text { ensure best legal outcomes for } \\
\text { women and children }\end{array}$ & 0 \\
\hline
\end{tabular}

\section{$\underline{\text { AWAHS }}$}

\section{$\underline{2020}$}

Pre and post surveys not completed. 
12.5 APPENDIX 5: Interim evaluation data

$\underline{\text { Referral process interview data } 2019}$

Non-Legal Professionals: Referral process (2019)

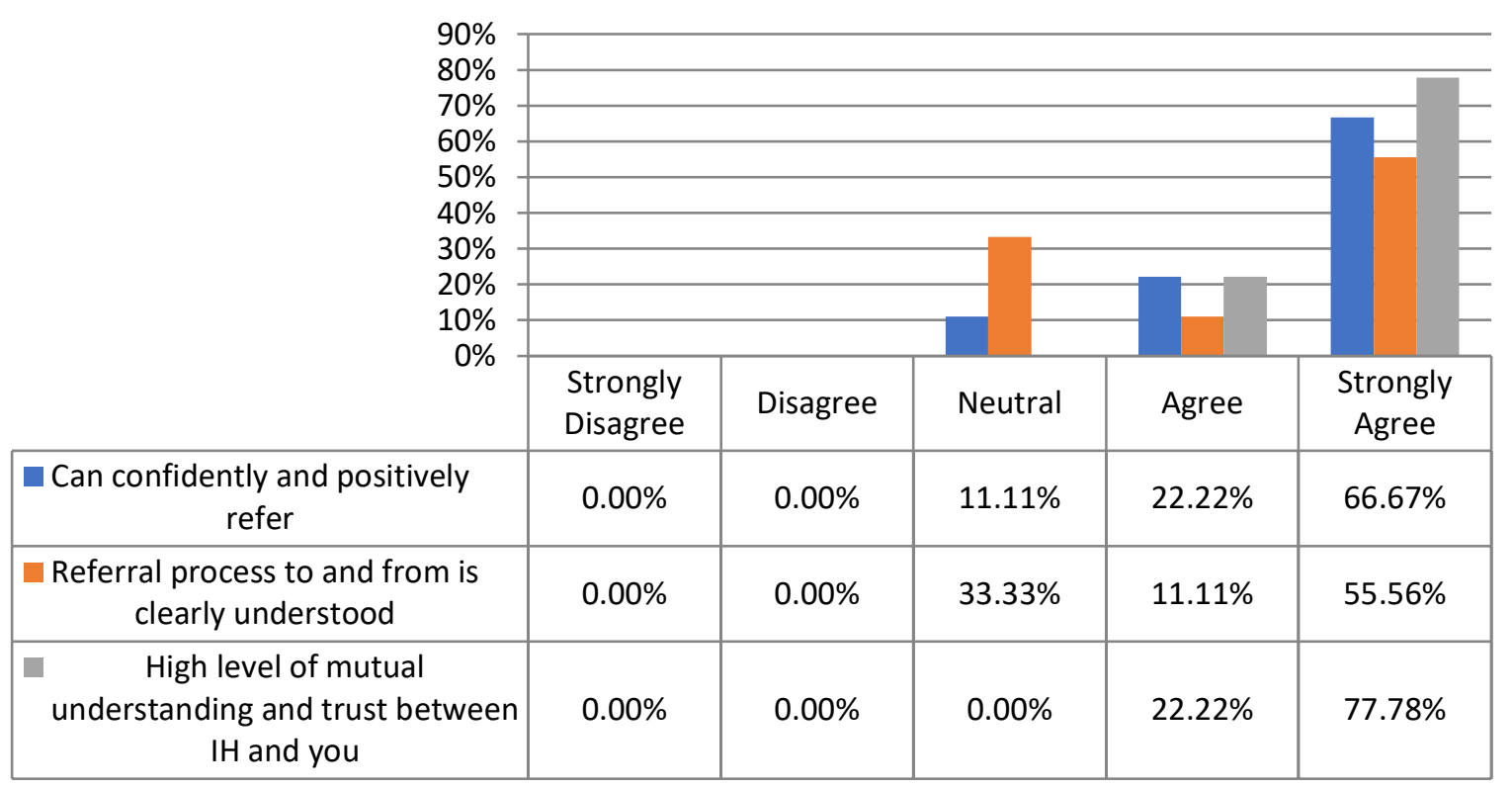

\begin{tabular}{|c|c|c|c|c|c|}
\hline \multicolumn{6}{|c|}{ Managers: Referral process (2019) } \\
\hline \multirow{8}{*}{$\begin{array}{r}100 \% \\
90 \% \\
80 \% \\
70 \% \\
60 \% \\
50 \% \\
40 \% \\
30 \% \\
20 \% \\
10 \% \\
0 \%\end{array}$} & & & & & \\
\hline & & & & & \\
\hline & & & & & \\
\hline & & & & & \\
\hline & & & & & \\
\hline & & & & & \\
\hline & & & & & \\
\hline & $\begin{array}{l}\text { Strongly } \\
\text { Disagree }\end{array}$ & Disagree & Neutral & Agree & $\begin{array}{c}\text { Strongly } \\
\text { Agree }\end{array}$ \\
\hline $\begin{array}{c}\text { - Can confidently and positively } \\
\text { refer }\end{array}$ & $0.00 \%$ & $0.00 \%$ & $0.00 \%$ & $0.00 \%$ & $100.00 \%$ \\
\hline $\begin{array}{l}\text { Referral process to and from is } \\
\text { clearly understood }\end{array}$ & $0.00 \%$ & $0.00 \%$ & $0.00 \%$ & $40.00 \%$ & $60.00 \%$ \\
\hline
\end{tabular}

Systemic change: 


\section{Non-Legal Professionals: Systemic change \\ (2019)}

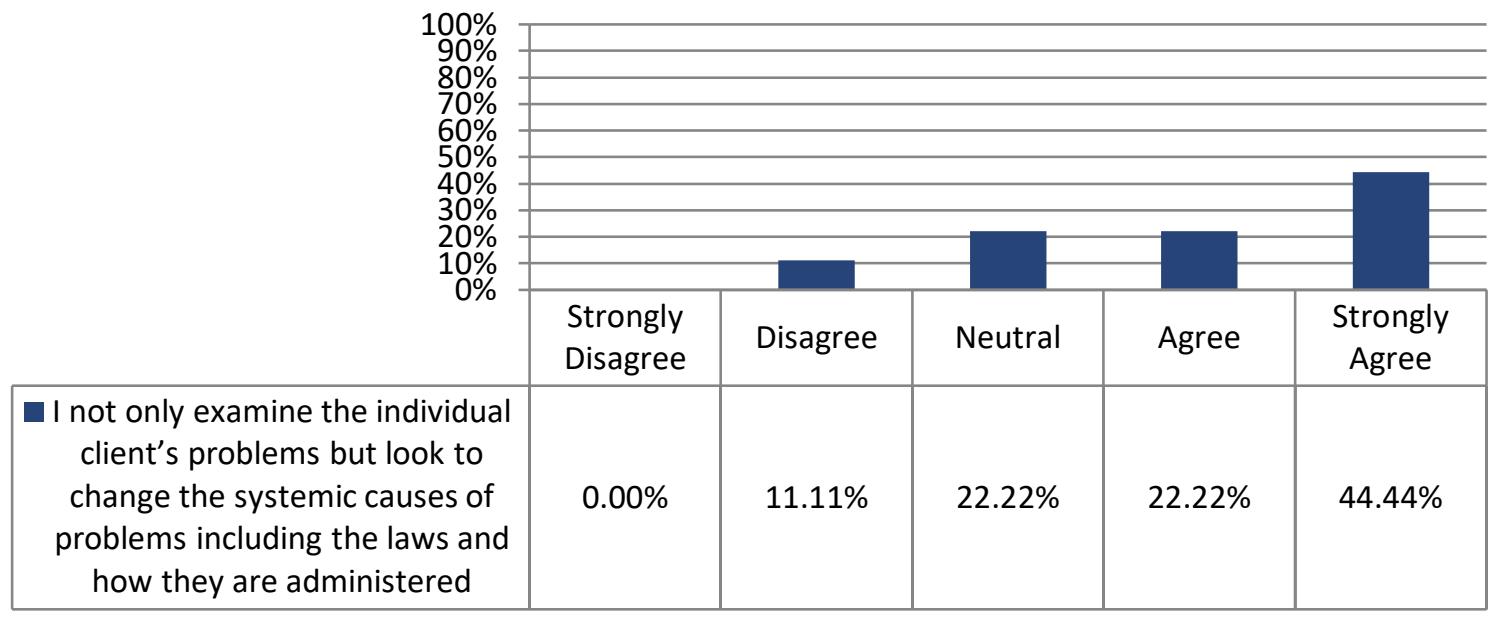

\section{Managers: Systemic change (2019)}

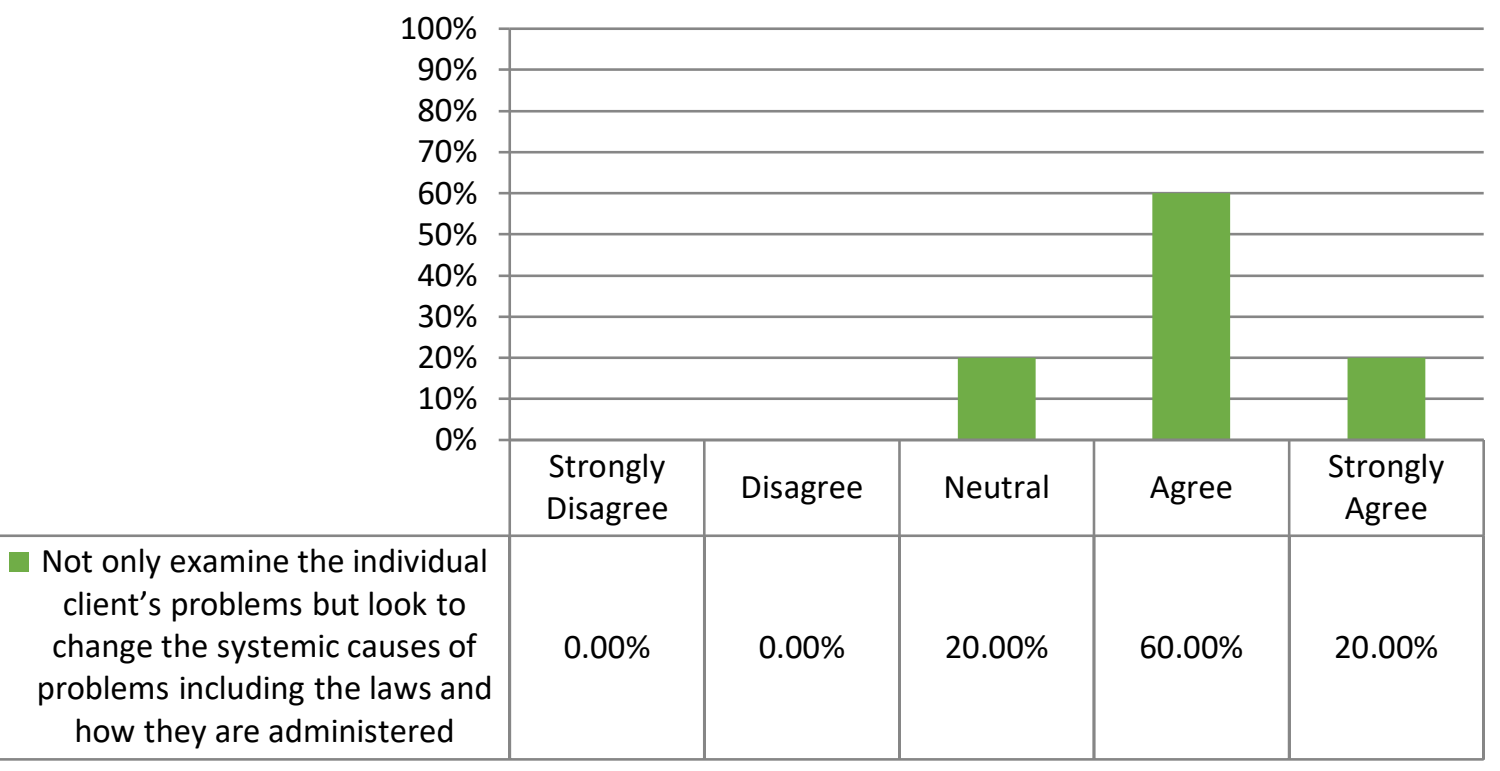




\section{Non-Legal Professionals: Collaborated on Systemic Reform (2019)}

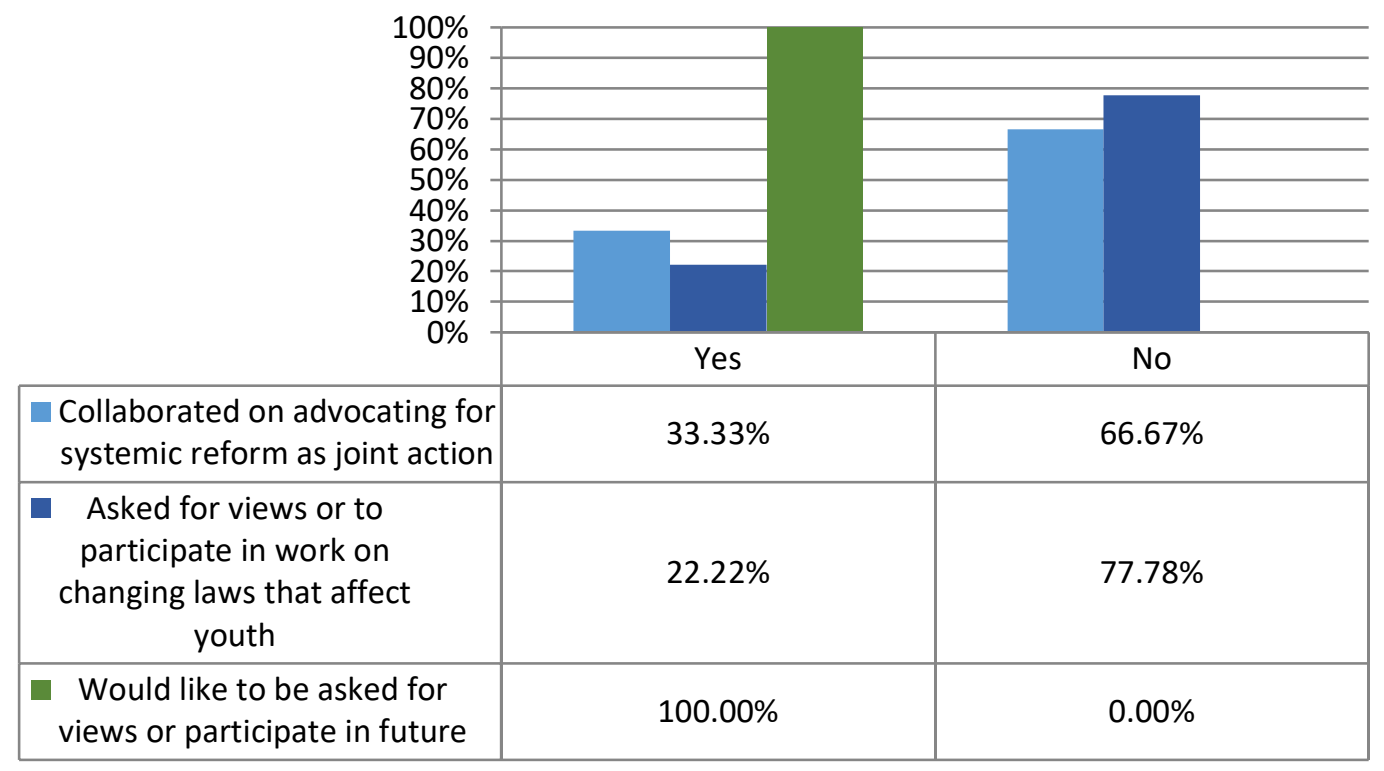

\begin{tabular}{|c|c|c|c|}
\hline \multicolumn{4}{|c|}{$\begin{array}{c}\text { Non-Legal Professionals: Importance and } \\
\text { Impact of Systemic Reform (2019) }\end{array}$} \\
\hline \multirow[t]{2}{*}{$\begin{array}{r}100 \% \\
90 \% \\
80 \% \\
70 \% \\
60 \% \\
50 \% \\
40 \% \\
30 \% \\
20 \% \\
10 \% \\
0 \%\end{array}$} & & & \\
\hline & N/A & Yes & No \\
\hline $\begin{array}{l}\text { Does systemic reform have an } \\
\text { impact? }\end{array}$ & $22.22 \%$ & $77.78 \%$ & $0.00 \%$ \\
\hline $\begin{array}{l}\text { Is systemic reform important } \\
\text { to support your clients? }\end{array}$ & $0.00 \%$ & $100.00 \%$ & $0.00 \%$ \\
\hline $\begin{array}{c}\text { Is systemic reform important } \\
\text { to support young people in } \\
\text { general? }\end{array}$ & $0.00 \%$ & $88.89 \%$ & $11.11 \%$ \\
\hline
\end{tabular}


Secondary Consultations

\section{Non-Legal Professionals: Secondary Consultations (2019)}

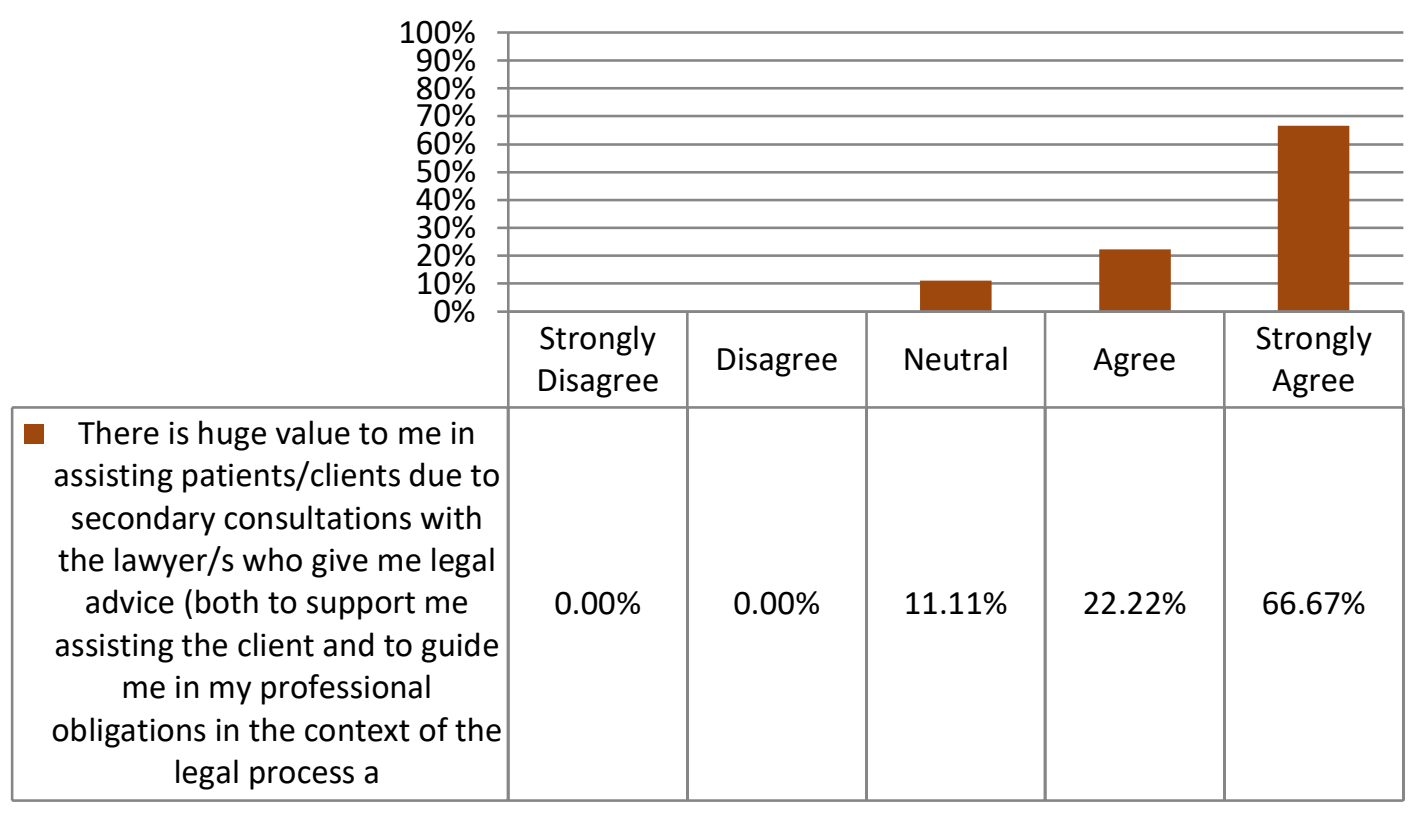

\section{Training}

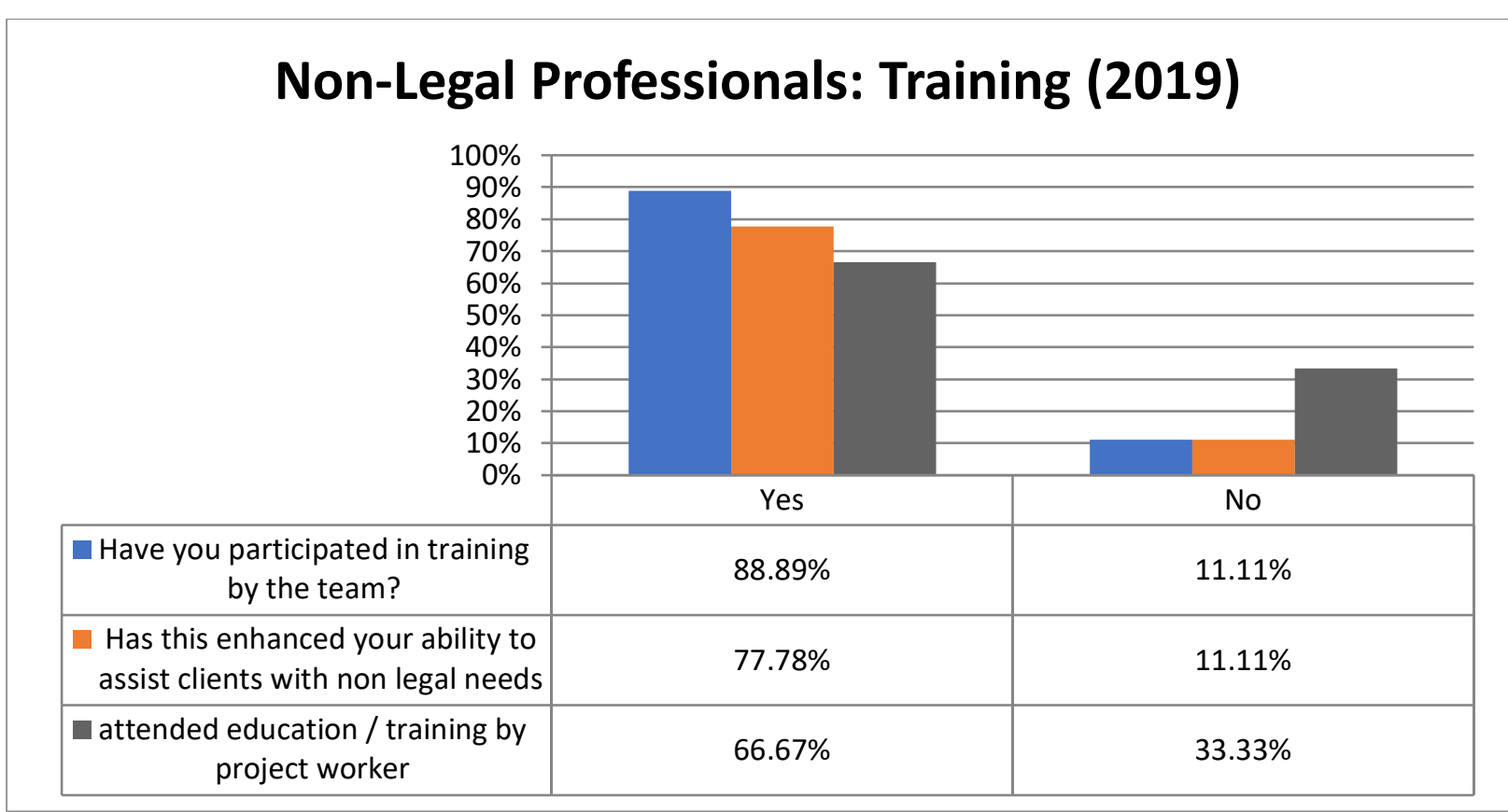


Non-Legal Professionals: Training quality and engagement (2019)

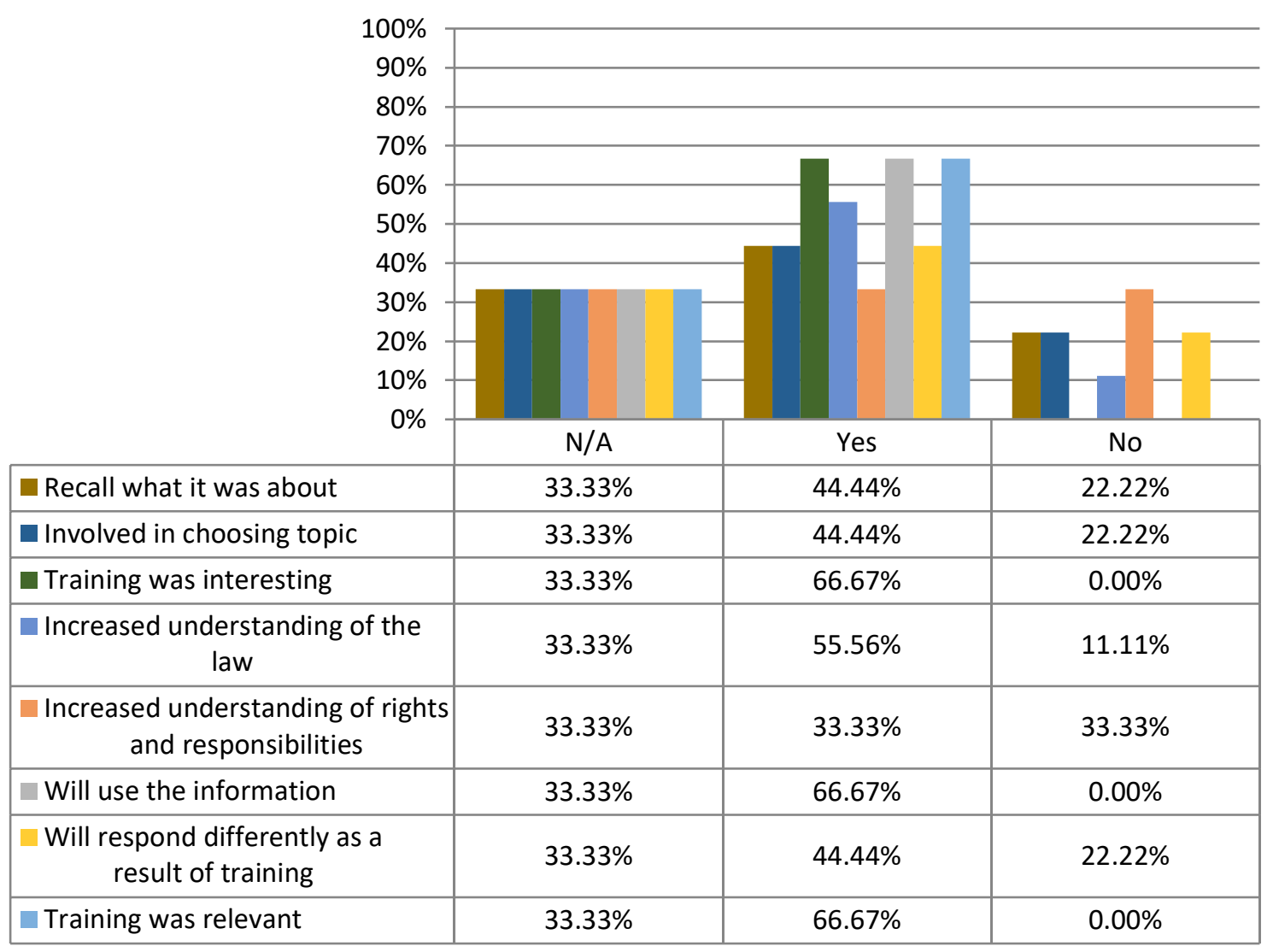


$\underline{\text { Reciprocity }}$

\section{Non-Legal Professionals: Reciprocity (2019)}

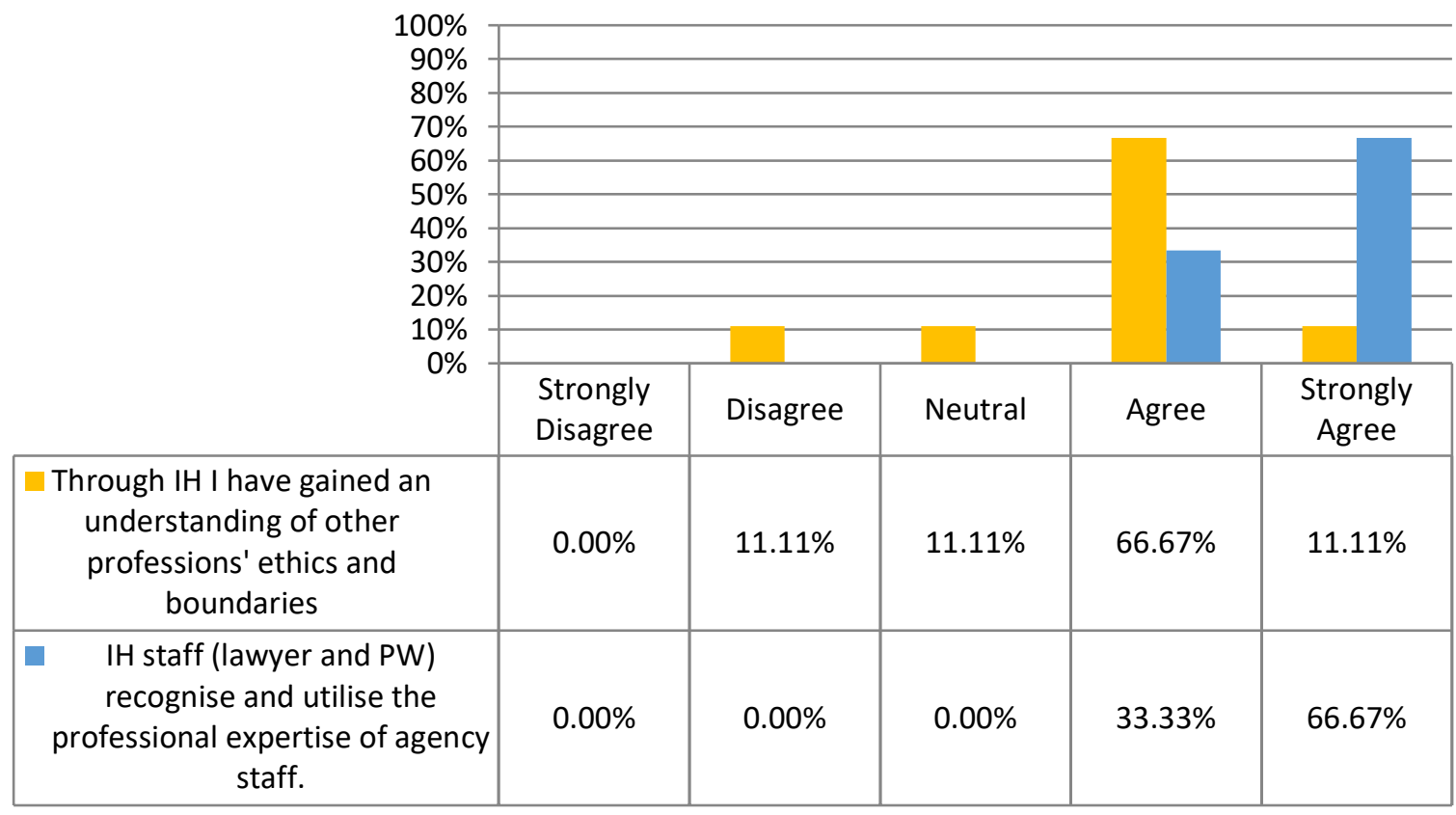

\section{Managers: Reciprocity (2019)}

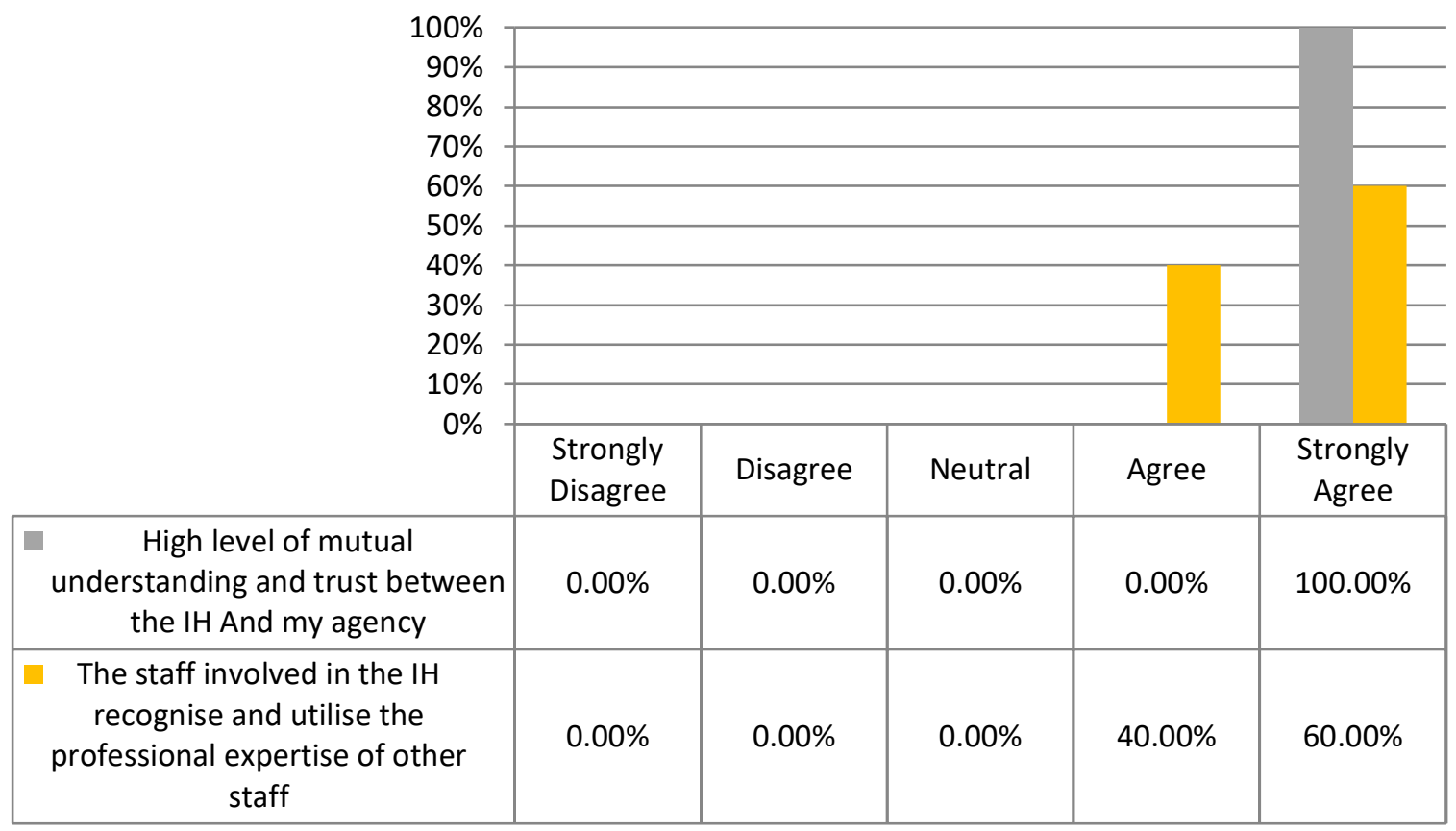


$\underline{\text { Responsiveness }}$

\section{Non-Legal Professionals: Responding to client need (2019)}

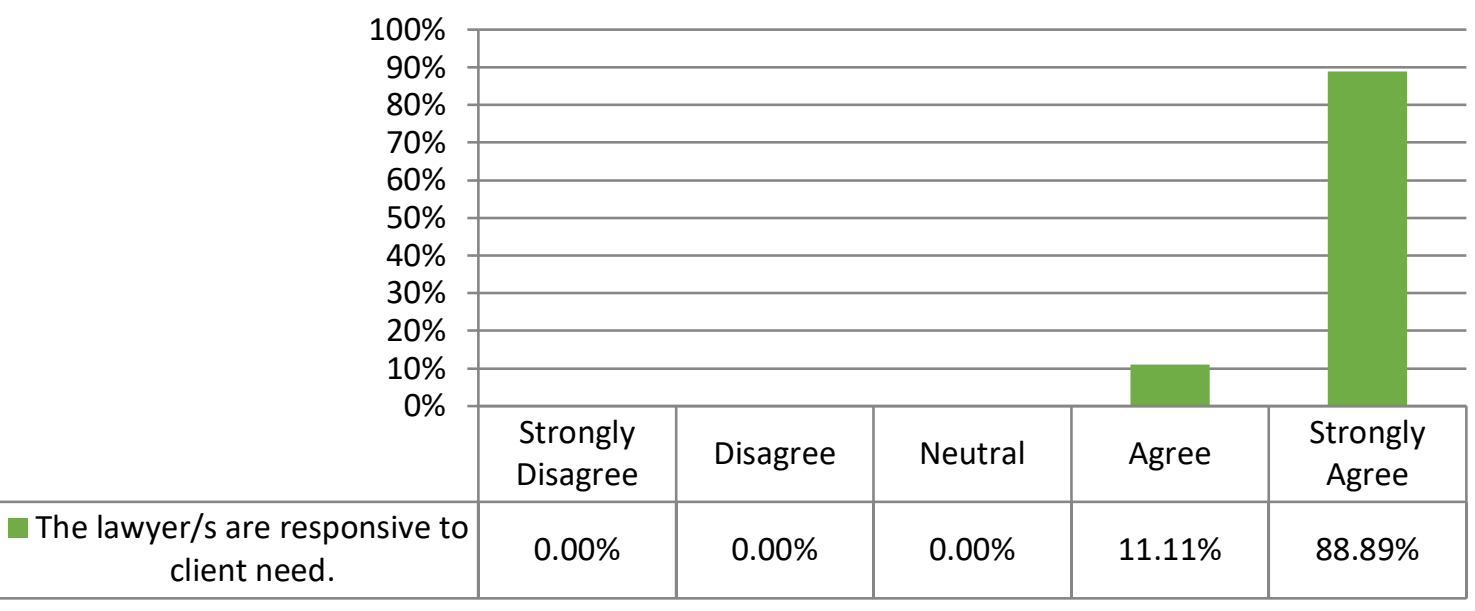

\section{Managers: Responding to client need (2019)}

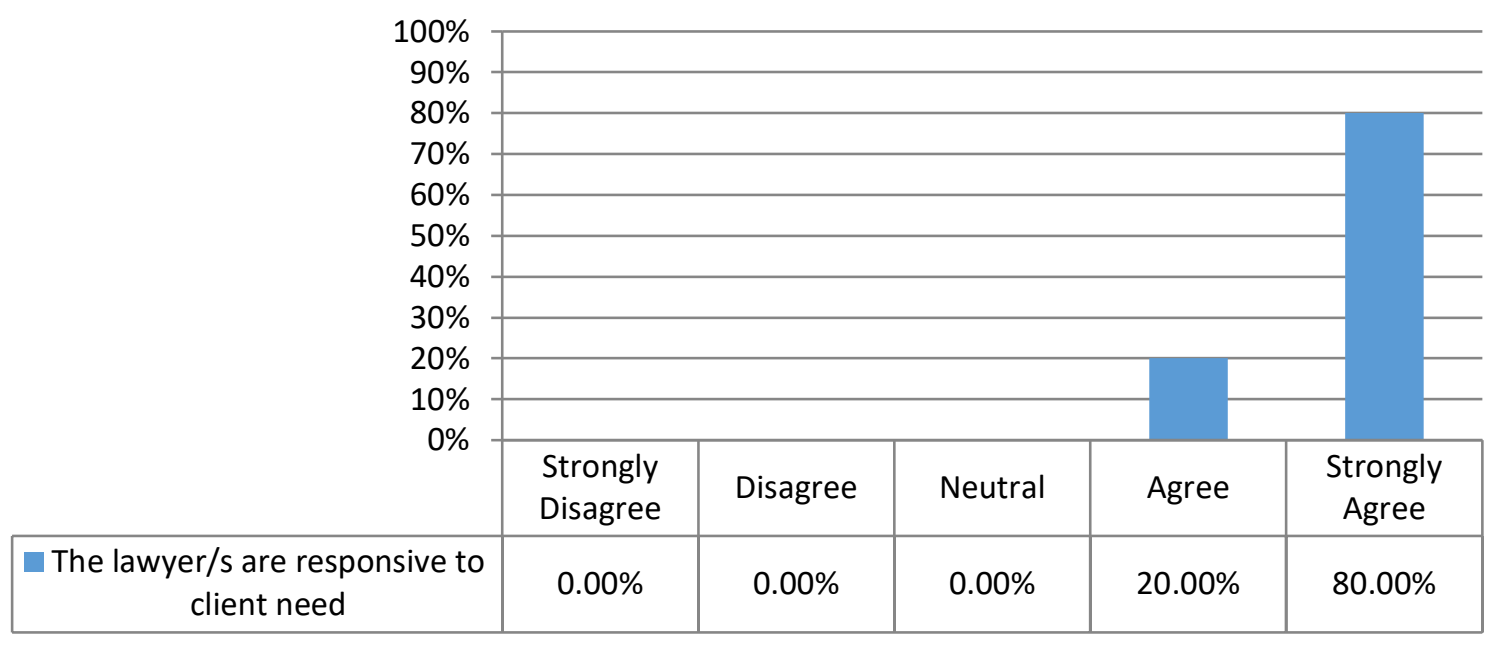

